\title{
Macroeconomic Dynamics and Credit Risk: A Global Perspective
}

\author{
M. Hashem Pesaran, Til Schuermann \\ and Björn-Jakob Treutler
}

June 2003

DAE Working Paper No. 0330

Not to be quoted without permission 


\begin{abstract}
We develop a framework for modeling conditional loss distributions through the introduction of risk factor dynamics. Asset value changes of a credit portfolio are linked to a dynamic global macroeconometric model, allowing macro effects to be isolated from idiosyncratic shocks. Default probabilities are driven primarily by how firms are tied to business cycles, both domestic and foreign, and how business cycles are linked across countries. The model is able to control for firm-specific heterogeneity as well as generate multi-period forecasts of the entire loss distribution, conditional on specific macroeconomic scenarios.
\end{abstract}

Keywords: Risk management, economic interlinkages, loss forecasting, default correlation

JEL Codes: C32, E17, G20 


\title{
Macroeconomic Dynamics and Credit Risk: A Global Perspective*
}

\author{
M. Hashem Pesaran ${ }^{\dagger}$ \\ Til Schuermann ${ }^{\ddagger}$ \\ University of Cambridge Federal Reserve Bank of New York \\ Björn-Jakob Treutler ${ }^{\S}$ \\ Mercer Oliver Wyman and \\ Otto Beisheim Graduate School of Management \\ Scott M. Weiner ${ }^{\S}$ \\ Alliance Capital Management L.P. \\ June 7, 2003
}

\section{Introduction}

Risk management in general and credit risk analysis in particular has been the focus of extensive research in the past several years. Credit risk is the dominant source of risk for banks and the subject of strict regulatory oversight and policy debate (BIS $(2001 \mathrm{a}, \mathrm{b})){ }^{1}$ Most recently, the proposal by the Bank for International Settlements

${ }^{*}$ We would like to thank Roland Demmel, Joshua Rosenberg and Jan-Hendrik Schmidt for their insightful comments, and Mei Kok for her research assistance with estimating the default probabilities. All remaining errors are ours.

${ }^{\dagger}$ Faculty of Economics and Politics, University of Cambridge, Cambridge CB3 9DE. Email: hashem.pesaran@econ.cam.ac.uk

$\ddagger$ Corresponding author. Any views expressed represent those of the author only and not necessarily those of the Federal Reserve Bank of New York or the Federal Reserve System. Email: til.schuermann@ny.frb.org

$\S$ Any views expressed represent those of the authors only and not necessarily those of Mercer Oliver Wyman or Alliance Capital Management respectively. Emails: btreutler@mow.com, scott_weiner@acml.com.

${ }^{1}$ The typical risk taxonomy includes market, credit and operational risk. See, for instance, discussions in Crouhy, Galai and Mark (2001) or Marrison (2002). 
(BIS) to reform the regulation of bank capital for credit risk (known as the New Basel Accord, or BIS 2) has sparked an intense debate in the literature (inter alia, Jones and Mingo (1998), Altman, Bharath and Saunders (2002)). One strand of this debate centers on the effect of business cycles and especially of severe economic downturns on bank risk and value-at-risk capital requirements (Carpenter, Whitesell and Zakrajšek (2001), Carey (2002), Allen and Saunders (2002)). However, this debate has been taking place largely without the benefit of an explicit model of the linkages that exist between the loss distribution of a bank's credit portfolio and the evolution of the macroeonomic factors at national and global levels. Given the increasing interdependencies in the global economy, risk managers of commercial or central banks alike may well be interested in questions like "What would be the impact on the credit loss distribution of a given bank (or banks) in a given region if there were large unfavorable shocks to equity prices, GDP or interest rates in that or other regions?"

Our aim is to develop a conditional modeling framework for credit risk analysis which establishes an explicit linkage between a portfolio of credit assets and the underlying international macroeconomic system. The model is able to distinguish between default (and loss) due to systematic versus idiosyncratic (or firm specific) shocks, providing an explicit channel for and model of default correlation. This enables us to conduct policy analysis on the effect of changes in macroeconomic risk factors on credit risk. Our approach is thus a step towards joint consideration of market and credit risk.

In this paper we start with a simple problem: the development of a conditional loss model using only publicly traded firms. In a simple Merton-type credit portfolio model, credit risk is a function of correlated equity returns of the obligor companies. These equity returns are linked to macroeconomic variables (national as well as global) using an approach structurally similar to the Arbitrage Pricing Theory (APT). Default probabilities are driven primarily by how firms are tied to business cycles, both domestic and foreign, and how business cycles are linked across countries. Importantly, the foreign variables are tailored to match the international trade pattern of the country under consideration. Domestic and foreign business cycle effects are allowed to impact each firm differently. In this way we are able to account for firm-specific heterogeneity in an explicitly interdependent global context. Moreover, we are able to generate multi-period forecasts of the entire loss distribution, conditional on specific macroeconomic scenarios. A flexible understanding of these loss distributions are critical for risk management applications and pricing of complex credit assets such as collaterized debt obligations (CDOs).

Credit risk modeling can be broken down along several dimensions. One split is between asset- or firm-based versus portfolio approaches. Broadly, there are two 
important variables describing asset/firm level credit risk: the probability of default $(P D)$ and the loss given default $(L G D) .{ }^{2}$ The former has generated a rich literature, an early example being Altman (1968). ${ }^{3}$ If the firm is privately held, the modeler has much poorer information than if the firm is public. The private firm case invariably requires a valuation model based on firm financial and non-financial characteristics (e.g. Altman (1968)), while the latter can, in addition to such variables, incorporate information from debt and equity markets (recent examples are Shumway (2001), Kealhofer and Kurbat (2002), Vassalou and Xing (2002)). Several authors have estimated default probabilities through an asset pricing approach by extracting those probabilities from prices of defaultable bonds (Jarrow and Turnbull (1995), Madan and Unal (1998), Duffie and Singleton (1999), Duffee (1999)).

The literature on modeling $L G D$ (sometimes called loss severity) is not nearly as rich as it is for $P D$. Most of the work has been strictly empirical (Altman and Kishore (1996), Gupton, Gates and Carty (2000), Van de Castle, Keisman and Yang (2000)), documenting $L G D$ variation by such factors as industry, instrument seniority and type. The asset pricing literature, recognizing that bond spreads incorporate expected loss (i.e. $E L=P D \cdot L G D$ ), has only recently developed theoretical models which aim to separate recovery $(1-L G D)$ from probability of default (Bakshi, Madan and Zhang (2001), Unal, Madan and Guntay (2003)).

While credit risk models based on asset prices, specifically on credit spreads of defaultable bonds, have a distinct theoretical appeal, recent research strongly suggests that much of the information in bond spreads is unrelated to default risk (Elton, Gruber, Agrawal and Mann (2001), Huang and Huang (2002)). ${ }^{4}$ CollinDufresne, Goldstein and Martin (2001) investigate the changes to the corporate credit spread and conclude that factors such as changes in levels and slopes of treasury interest rates, the business climate, changes in market volatility and the Fama-French type factors, in fact explain only a small fraction of the variations in the corporate credit spread.

Moving from individual assets or firms to a portfolio, most credit portfolio models link the portfolio loss distribution to states of the world which provides the channel for default correlations. However, with only one exception this linkage is to a single, unobserved systematic risk factor. That is the case for adaptations of the options based approach à la Merton (1974) found in credit portfolio models such as Gupton, Finger and Bhatia's (1997) CreditMetrics, KMV's PortfolioManager, as well as in

\footnotetext{
${ }^{2}$ The New Basel Accord explicitly mentions two additional variables: exposure at default and maturity. As these affect credit risk only moderately (and are often taken to be non-stochastic), our discussion will focus on the two dominant variables of $P D$ and $L G D$.

${ }^{3}$ For a survey of different models see Altman and Saunders (1997) and Chava and Jarrow (2001).

${ }^{4}$ The other principal factors are taxes and liquidity.
} 
the actuarial approach employed by CSFB's CreditRisk+ (Credit Suisse First Boston (1997)) where the key risk driver is the variable mean default rate in the economy. Wilson's (1997a,b) model (CreditPortfolioView) is an exception. He allows for the macroeconomic variables to influence a firm's probability of default using a pooled logit specification. However, because the defaults are grouped, typically by industry, and modeled at the (single country) national level, any firm-specific heterogeneity is lost in the estimation.

Business cycle fluctuations can have a major impact on credit portfolio loss distributions. Carey (2002), using re-sampling techniques, shows that mean losses during a recession such as 1990/91 in the U.S. are about the same as losses in the $0.5 \%$ tail during an expansion. Bangia et al. (2002), using a regime switching approach, find that capital held by banks over a one-year horizon needs to be $25-30 \%$ higher in a recession that in an expansion.

Most of the work on $P D$ and $L G D$ referred to above has been done without explicit conditioning on business cycle variables. The exceptions include Carey (1998), Frye (2000) and Altman, Brady, Resti and Sironi (2002). These studies, perhaps not surprisingly, find that losses are indeed worse in recessions. Tapping into information contained in equity returns (as opposed to credit spreads from debt instruments), Vassalou and Xing (2002) show that default risk varies with the business cycle. Allen and Saunders (2002) survey academic and practitioner models of credit risk with a specific focus on the treatment of systematic or cyclical effects. They find that although many models consider the correlation between default $(P D)$ and systematic (e.g. macroeconomic) factors, few extend this dependence to LGD.

The basic idea of our approach is to make the linkage between credit risk and business cycle fluctuations more concrete, providing a tool for policy analysis, risk management and the pricing of credit assets. The first step in developing such a model is to build an economic engine reflective of the environment faced by an internationally active global bank. This is done in Pesaran, Schuermann and Weiner (2003) - hereafter PSW - using recent advances in the analysis of cointegrating systems ${ }^{5}$ where we develop a global vector autoregressive macroeconometric model (GVAR). In contrast to existing models, the use of cointegration is not confined to a single country or region. We first estimate specific vector error-correcting models (VECM) for individual countries (or regions). This VECM structure allows us to impose long-run (cointegrating) restrictions on the variables. ${ }^{6}$ The model uses domestic macroeconomic variables such as GDP, the general price level, the level of

\footnotetext{
${ }^{5}$ In particular, see Pesaran and Shin (2002), and Garratt, Lee, Pesaran and Shin (2003).

${ }^{6}$ To be sure, particular interpretations of these relations in the form of alternative exactly identifying restrictions have no effect on the loss distribution outcomes of the various shock scenarios we consider.
} 
short term interest rates, exchange rate, equity prices (when applicable) and money supply. These are related to corresponding foreign variables constructed exclusively to match the international trade pattern of the country under consideration. Because of the integrated nature of the model, we can analyze how a shock to one specific macroeconomic variable affects other macroeconomic variables, even (and especially) across countries, as well as shocks to risk factors, e.g. oil prices, affecting all regions.

We examine the credit risk of a fictitious corporate loan portfolio and its exposure to this wide range of risk factors in the global economy. We model a firm's probability of default as a function of those risk factors but assume loss given default as an exogenously given random variable. Once we pin down the link between equity returns and macroeconomic variables, we derive the overall single- and multi-period credit loss distribution of a sample portfolio through Monte Carlo simulation.

Sampling takes place along three lines: correlated random draws of macroeconomic factors; draws of firm-specific risk components; and draws of stochastic loss severities. Our baseline distributional assumption is Gaussian, ${ }^{7}$ but we also present results of the fatter tailed Student $t$ distribution with 10 and 5 degrees of freedom. Our approach differs from others such as Wilson's (1997a,b) who directly models the default probability using only single-country macroeconomic factors as regressors. We do so indirectly via the Merton model and use a much richer macroeconometric specification which allows for country/region specific heterogeneities.

The plan for the remainder of the paper is as follows: Section 2 provides an overview of the alternative approaches to credit portfolio modeling. Section 3 sets out the basic framework of our model based on the Merton approach. Section 4 discusses the global macroeconometric model (the GVAR). Section 5 shows how to incorporate the GVAR into the Merton model and develops mathematical expressions for the conditional loss distribution of a given credit portfolio under various shock scenarios, including one-period and multi-period forecasting of the whole loss distribution. Section 6 presents summary estimation results for the GVAR based on 11 countries/regions covering about $80 \%$ of world output. Section 7 considers the loss distribution of a given credit portfolio and empirically investigates its response to different types of shocks (to output, interest rate, money supply and equity prices). Section 8 offers some concluding remarks.

\footnotetext{
${ }^{7}$ Loss severities are drawn from a beta distribution.
} 


\section{Credit Portfolio Models}

\subsection{An Overview}

Our primary goal is to build up the loss distribution of the credit portfolio of a financial institution such as a bank, first unconditionally and then with explicit conditioning on macroeconomic factors. The unconditional distribution is intended to be "cycle-neutral" and provides a benchmark loss distribution which is applicable in the very long run and integrates out the differential effects of business cycle variations (boom, bust, expansion, recession, etc.) on the loss distribution. The conditional loss distribution allows for the effect of business cycle variations and captures such effects at a global level by explicitly taking account of the heterogeneous interconnections and interdependencies that exist between national and international factors. In this setting, the probability of default for firm $j$ in country/region $i$ can be (indirectly) affected by economic activity in some other region, $\ell$.

In any given time period, the probability of default for firm $j$ in region $i$ will be correlated, through the influence of common macro effects (or systematic risk factors) in region $i$, and globally, with the probability of default of other firms in the bank's portfolio. However, not all macro factors will affect all firms in the same way. Most credit portfolio models share this linkage of systematic risk factors to default and loss; they differ in specifically how they are linked.

Generally speaking, there are two broad approaches to credit risk or credit portfolio modeling. ${ }^{8}$ The first couples a simple model of firm performance with a threshold value below which the firm defaults. The default threshold is modeled as a function of the firm's balance sheet and its financial structure. This "structural" model underlies the so-called Merton options approach after Merton (1974), which we will follow in this paper. Practitioner credit portfolio models such as Gupton, Finger and Bhatia's (1997) CreditMetrics as well as KMV's PortfolioManager are adaptations of this approach.

The second modeling approach focusses on the factors that influence firm defaults directly. Two examples are CreditPortfolioView (Wilson (1997a,b)) where the firm-specific probability of default is estimated via a logit specification with macro-variables entering the logit regression directly, and the actuarial approach of CSFB's CreditRisk+ (Credit Suisse First Boston (1997)) where the key risk driver is

\footnotetext{
${ }^{8}$ The different credit portfolio models are also distinct in the way they approach changes to the firms' value. Some models operate on a mark-to-market basis by looking at the change of market value of credit assets based on credit migration and the term structure of credit spreads (CreditMetrics). Others focus on predicting default losses (so-called default mode models such as CSFB's CreditRisk+). Yet there are other approaches that allow for both (e.g. KMV's PortfolioManager, Wilson's CreditPortfolioView).
} 
the mean default rate assumed to be a function of the macroeconomic variables. We provide a brief overview of the Wilson model before developing the Merton optionsbased model. For detailed comparisons, see Koyluoglu and Hickman (1998), Crouhy et al. (2000), Gordy (2000), Saunders and Allen (2002) and Allen and Saunders (2002).

\subsection{A First Generation Credit Risk-Macroeconometric Model}

CreditPortfolioView (CPV) by Wilson (1997a,b) directly models the relationship of transition probabilities or credit grades and the underlying macroeconomic factors, albeit one country at a time. Typically firms are grouped into industry segments and default behavior is modeled at the industry, not at the firm level. ${ }^{9}$ Consequently any firm-specific heterogeneity will be lost in the grouping and could bias the results. Wilson assumes that the probability of default for industry group $g$ in region $i$ at time $t, P D_{\text {git }}$, is determined by a systematic index variable $m_{g i t}$, common to all firms in that industry group:

$$
P D_{g i t}=f_{C P V}\left(m_{g i t}\right)
$$

He further specifies $f(\cdot)$ to be logistic, given by $1 /\left(1+e^{-m_{g i t}}\right)$, though other specifications are possible. The index variable $m_{\text {git }}$ can be viewed as driven by a set of macroeconomic variables $\mathbf{x}_{i t}$ as well as industry specific random shocks $\boldsymbol{v}_{\text {git }}$

$$
m_{\text {git }}=g_{C P V}\left(\mathbf{x}_{i t}, \boldsymbol{v}_{g i t}\right),
$$

such that $\boldsymbol{v}_{g j i t} \backsim N\left(0, \sigma_{g i}^{2}\right)$. The macroeconomic factors, $\mathbf{x}_{i t}$, are modeled by Wilson as univariate $\operatorname{AR}(2)$ processes, although other specifications are possible. Generally we may write

$$
\mathbf{x}_{i t}=h\left(\mathbf{X}_{i, t-1}, \boldsymbol{\varepsilon}_{i t} ; \boldsymbol{\beta}\right),
$$

so that the systematic factor $m_{\text {git }}$ is made up of predetermined macroeconomic variables $\mathbf{X}_{i, t-1}=\left(\mathbf{x}_{i t-1,} \mathbf{x}_{i t-2}, \ldots, \mathbf{x}_{i t-p}\right)$ and a contemporaneous innovation $\boldsymbol{\varepsilon}_{i t}$. For given group and sector specific shocks, $\boldsymbol{v}_{g i t}, \boldsymbol{\varepsilon}_{i t}$, the conditional probability of default can now be written as

$$
P D_{g i t} \mid \mathbf{X}_{i, t-1}=f_{C P V}\left(\mathbf{X}_{i, t-1} ; \boldsymbol{v}_{g i t}, \boldsymbol{\varepsilon}_{i t}\right) .
$$

In practice the effects of the idiosyncratic shocks, $\left(\boldsymbol{v}_{g i t}, \boldsymbol{\varepsilon}_{i t}\right)$, on the probability default also need to be integrated out before true conditional default probability can be obtained.

\footnotetext{
${ }^{9}$ Since defaults are modeled directly with a logistic regression, this grouping is necessary because individual firm defaults are so rare.
} 
Segment specific default probabilities, needed to obtain estimates of the factor loadings $\boldsymbol{\beta}$, are estimated from bank loan loss experience (which is proprietary) or bond histories (which are public). If the portfolio is marked to market using a transition matrix, the conditional probability of default can also be used to adjust the transition matrix. Crouhy et al. (2000), however, criticize the adjustment proposed by Wilson (1997a,b) as being ad hoc.

\section{A Structural Merton Asset-Based Model of De- fault}

In this section we set out the basic framework of our proposed approach. We shall begin with a simple structural model of changes to a firm's credit quality. The basic premise is that the underlying asset value evolves over time (e.g. through a simple diffusion process), and that default is triggered by a drop in firm's asset value below the value of its callable liabilities. Following Merton (1974), the lender is effectively writing a put option on the assets of the borrowing firm. If the value of the firm falls below a certain threshold, the shareholders will put the firm to the debt-holders.

The Merton model is called a "structural" model of credit risk since the model assumptions are imposed upon the balance sheet - the firm's structure. The liability structure in conjunction with the value fluctuations of the firm's assets determine the occurrence of default. In contrast to the actuarial approach, the model has strong underpinnings in the modern theory of corporate finance and option pricing. ${ }^{10}$

Thus there are two aspects which require modeling: (i) the firm's performance or return process, and (ii) the default threshold. Following an approach which is structurally similar to Ross's (1976) Arbitrage Pricing Theory (APT), a firm's change in value (or return) is assumed to be a linear function of changes in the underlying macroeconomic variables (the systematic component) and the firm-specific idiosyncratic shocks. There may be other ways to fruitfully characterize the firm's performance process. However, our broad modeling goal is to develop a framework which allows us to link macroeconomic variables explicitly to firms performance in order to arrive at (macroeconomic) conditional loss distributions. The APT model architecture allows us to achieve this in a parsimonious manner, while at the same time taking proper account of return heterogeneities across firms. ${ }^{11}$

\footnotetext{
${ }^{10}$ For a discussion of the power of Merton default prediction models see Falkenstein and Boral (2001) and Gemmill (2002) who find that the Merton model generally does well in predicting default (Falkenstein and Boral) and credit spreads (Gemmill). Duffee (1999) points out that due to the continuous time diffusion processes underlying the Black Scholes formula, short-term default probabilities may be underestimated.

${ }^{11}$ For an overview of the theoretical and empirical literature on APT, see Campbell, Lo and
} 
We follow a typical adaptation of the Merton model by using asset returns and their volatility instead of total value of assets and their volatility. But since asset returns are difficult to observe directly, we use equity returns as a proxy. ${ }^{12}$

\subsection{Conditional Asset Returns}

Anticipating some of the results from our GVAR model presented in Section 4, we denote the return of firm $j$ in region $i$ over the period $t$ to $t+1$ by $r_{j i, t+1}$ and assume that conditional on the information available at time $t, \Omega_{t}$, it can be decomposed as

$$
r_{j i, t+1}=\mu_{j i t}+\xi_{j i, t+1}
$$

where $\mu_{j i t}$ is the (forecastable) conditional mean, and $\xi_{j i, t+1}$ is the (non-forecastable) innovation component of the return process. Following the standard Merton model we shall assume that

$$
\xi_{j i, t+1} \mid \Omega_{t} \sim N\left(0, \omega_{\xi, j i}^{2}\right) .
$$

The normality assumption could be a good approximation for quarterly returns, but it is relatively easy to adapt the analysis to allow for fat-tailed distributions such as (standard) Student $t$ with low degrees of freedom in the range of, say, $[5,10] .{ }^{13}$ Alternatively, as discussed in Section 5, re-sampling techniques can be used to allow for more general distributional assumptions. The assumption that the conditional variance of returns are time-invariant also seems reasonable for quarterly returns, although it would need to be relaxed for returns measured over shorter periods, such as weeks or days. ${ }^{14}$

The GVAR model provides the link between changes in macroeconomic variables (in region $i$ and globally) in $\mu_{j i t}$, and it does so uniquely for each firm to allow for firm-specific heterogeneity. Specifically, domestic and foreign business cycle effects are allowed to impact each firm differently. The main advantage of using the GVAR as a driver for a credit portfolio model is that it provides the (conditional) correlation structure among macroeconomic variables of the global economy. When generating

MacKinlay (1997). Chen, Roll and Ross (1986) test whether macroeconomic variables specifically matter in asset pricing. Using monthly returns they find that industrial production, changes in the risk premium (spread on $B B B$ corporate and Treasury bonds), twists of the yield curve and inflation are significant in explaining expected stock return. Oil prices were not found to be significant.

${ }^{12}$ Arguably equity returns are even preferred since they allow for non-constant liabilities within the Merton framework.

${ }^{13}$ In fact we do so in Section 7.

${ }^{14}$ Volatility in quarterly models is of third order importance. Our framework could easily be adapted to deal with more complex volatility effects by normalizing returns with dynamic volatilities using, for example, the RiskMetrics method or other GARCH specifications. 
loss distributions, this allows us to account for the state of business cycle and the interdependencies that exist in the global economy in a relatively parsimonious and internally consistent manner.

\subsection{Default Thresholds, $P D$ s and Credit Ratings}

The second aspect of the credit risk model is the default threshold with respect to which the default state can be defined. In the Merton model default occurs if the value of the firm $j$ in region $i$ at time $t$ falls below a given threshold value, $c_{j i}$. We can characterize the separation between a default and a non-default state with an indicator variable $I\left(r_{j i, t+1}<c_{j i}\right)$ such that

$$
\begin{aligned}
& I\left(r_{j i, t+1}<c_{j i}\right)=1 \text { if } r_{j i, t+1}<c_{j i} \Longrightarrow \text { Default, } \\
& I\left(r_{j i, t+1}<c_{j i}\right)=0 \text { if } r_{j i, t+1} \geq c_{j i} \Longrightarrow \text { No Default. }
\end{aligned}
$$

Conceptually it is useful to anchor the default process by fixing the default threshold, for instance at the end of the sample period, thereby allowing the loss distribution to shift in response to macroeconomic factors. The problem is not properly identified if we allow both to be time varying.

Define $P D_{j i t}=\operatorname{Pr}\left(r_{j i, t+1}<c_{j i} \mid \Omega_{t}\right)$ as shorthand notation for the probability of default of company $j$ in region $i$ at time $t$. The corresponding probability of default can then be expressed from (1) and (3) as

$$
P D_{j i t}=\Phi\left(\frac{c_{j i}-\mu_{j i t}}{\omega_{\xi, j i}}\right),
$$

where $\Phi(\cdot)$ is the standard normal distribution function. There are no direct observations on $P D_{j i t}$. Instead what we do have is a credit rating $\mathcal{R}_{j i t}$ for a set of large companies, namely those that were assigned a rating by one of the rating agencies such as Moody's or Standard \& Poor. ${ }^{15}$ Importantly we have the rating histories $\left\{\mathcal{R}_{j i t}\right\}_{t=1}^{T}$ for all companies $j=1,2, \ldots, n c_{i}, i=0,1, \ldots, N$ in the credit portfolio that we shall be considering. We may use these histories, plus histories for all other companies with a rating at the beginning of period $t$, to estimate the default probability for each rating for each time period, $P D_{\mathcal{R}_{t}}$. For example, the estimated probability of default for companies rated ' $\mathcal{B B B}$ ' in period $t$ may be 22 basis points $\left(P D_{\mathcal{B B B}_{t}}=22 \mathrm{bp}\right)$, while in period $t^{\prime}$ it may rise to $37 \mathrm{bp}\left(P D_{\mathcal{B B B}_{t^{\prime}}}=37 \mathrm{bp}\right)$. We are then able to assign that default probability in period $t$ for rating $\mathcal{R}$ to all firms with that rating in that period. ${ }^{16}$

\footnotetext{
${ }^{15} \mathcal{R}$ may take on values such as 'Aaa', 'Aa', 'Baa',..., 'Caa' in Moody's terminology, or 'AAA', 'AA', 'BBB',..., 'CCC' in S\&P's terminology.

${ }^{16}$ See Section 7 for a discussion on estimating $P D_{\mathcal{R}_{t}}$.
} 
Given sufficient data for a particular region or country $i$ (the U.S. comes to mind), one could in principle have $P D$ s varying over $i$. However, since a particular firm $j$ 's default is only observable once, multiple (serial) bankruptcies notwithstanding, it makes less sense to allow $P D$ to vary across $j .{ }^{17}$ Empirically, then, we will abstract from possible variation in default rates across countries $i$, so that probabilities of default vary only across credit ratings and over time. ${ }^{18}$

Thus for a particular credit rating $\mathcal{R}_{j i t}$ for firm $j$ in region $i$ at time $t$, (say ' $\mathcal{B B B}$ '), we assign the corresponding default probability estimate $\operatorname{PD}\left(\mathcal{R}_{j i t}\right)$ which varies over time and across rating types but not over firms individually. Therefore, two different firms with the same credit rating in period $t$ will be assigned the same default probability estimates. Specifically

$$
\operatorname{Pr}\left(r_{j i, t+1}<c_{j i} \mid \Omega_{t}\right)=P D\left(\mathcal{R}_{j i t}\right)
$$

and therefore

$$
c_{j i}=\mu_{j i t}+\omega_{\xi, j i} D T\left(\mathcal{R}_{j i t}\right),
$$

where $D T\left(\mathcal{R}_{j i t}\right)=\Phi^{-1}\left(P D\left(\mathcal{R}_{j i t}\right)\right)$ is the 'default threshold' associated with the estimated default probability $P D\left(\mathcal{R}_{j i t}\right)$, and $\Phi^{-1}(\cdot)$ denotes the inverse cumulative standard normal distribution.

Suppose now that we have time series data over the sample period $t=1,2, \ldots, T$, and we wish to obtain an estimate of the default threshold at $T$ to be used in computation of conditional loss distribution over the period $T$ to $T+1$. Averaging the relations (5) over $t=1$ to $T$ we obtain

$$
c_{j i}=\bar{\mu}_{j i}+\omega_{\xi, j i} \overline{D T}_{\mathcal{R} j i},
$$

where

$$
\bar{\mu}_{j i}=\frac{1}{T} \sum_{t=1}^{T} \mu_{j i t}, \text { and } \overline{D T}_{\mathcal{R} j i}=\frac{1}{T} \sum_{t=1}^{T} D T\left(\mathcal{R}_{j i t}\right) .
$$

Note that taking the average of the thresholds rather than the threshold of the averages will yield different results since the inverse CDF is a nonlinear transformation. A model-free estimate of $\bar{\mu}_{j i}$ is given by $\bar{r}_{j i}$, the average return over the sample period; as noted above estimates of $P D\left(\mathcal{R}_{j i t}\right)$ can be obtained using time series observations of rating histories from credit rating agencies such as Moody's

\footnotetext{
${ }^{17}$ To be sure, one is not strictly prevented from obtaining firm-specific $P D$ estimates at a given point in time. The bankrupcty models of Altman (1968) and Shumway (2001) are such examples, as is the industry model by KMV.

${ }^{18} \mathrm{An}$ important source of heterogeneity is likely the large variation in bankruptcy laws and regulation across countries. However, by using rating agency default data, we use their homogeneous definition of default and are thus not subject to these heterogeneities.
} 
or Standard \& Poor; and a consistent estimate of $\omega_{\xi, j i}$ can be obtained using (42) in Section 5, based on the estimates of the GVAR model and the APT regression for firm $j$ in region $i$. Alternatively, an unconditional (model-free) estimate of the return variance, say $\omega_{j i}^{2}=\operatorname{Var}\left(r_{j i, t+1}\right)$, could be used. The results are unlikley to be much affected by which of the two estimated error-variances is used. But the model-free estimate has the advantage of being simple and arguably is a better reflection of the rating agencies' own approach of not putting too much weight on the business cycle factors in arriving at their credit ratings (see discussion below).

Adopting the model-free estimation approach, $c_{j i}$ can be consistently estimated at time $T$ by

$$
\hat{c}_{j i}=\bar{r}_{j i}+\hat{\omega}_{j i} \overline{D T}_{\mathcal{R} j i}
$$

where

$$
\hat{\omega}_{j i}^{2}=\frac{\sum_{t=1}^{T}\left(r_{j i t}-\bar{r}_{j i}\right)^{2}}{T-1} .
$$

Equation (6), while not time-varying per se, could change in the sense of being updated recursively as new data becomes available, either by using an expanding or a rolling observation window.

Consider now the possibility of firm $j$ in region $i$ defaulting over period $T$ to $T+1$, viewed at time $T$. We would say that conditional on information we have at time $T$ default occurs when $r_{j i, T+1}<\hat{c}_{j i}$, i.e. when

$$
r_{j i, T+1}<\bar{r}_{j i}+\hat{\omega}_{j i} \overline{D T}_{\mathcal{R} j i} .
$$

While we assume that the default threshold remains constant in the future, we do allow $r_{j i, T+1}$ to fluctuate in response to changes in underlying macroeconomic factors. By treating the critical value as constant, we implicitly assume that the leverage ratio remains constant. ${ }^{19}$ Thus we continue to make assumptions about the capital structure of the firm, but ones that are less restrictive and more realistic. ${ }^{20}$ So we may think of (7) as providing a measure of (unconditional) distance from default given the information at time $T$, namely

$$
D f D_{j i, \mathcal{R}}=r_{j i, T+1}-\left(\bar{r}_{j i}+\hat{\omega}_{\xi, j i} \overline{D T}_{\mathcal{R} j i}\right)
$$

\footnotetext{
${ }^{19}$ This approach is reasonable to the extent that firms indeed pursue a target leverage ratio. However, one may argue that it could not be possible to maintain such a target ratio as a firm approaches financial distress. Provided the firm has survived, we assume that the critical value is the same in the next quarter, even if the firm has only narrowly escaped default in the previous quarter.

${ }^{20}$ While the standard Merton model assumes liability growth to be zero, the adapted version can incorporate other growth rates. Still, assuming constant liability growth may be more realistic than allowing for no fluctuation of liability values at all.
} 


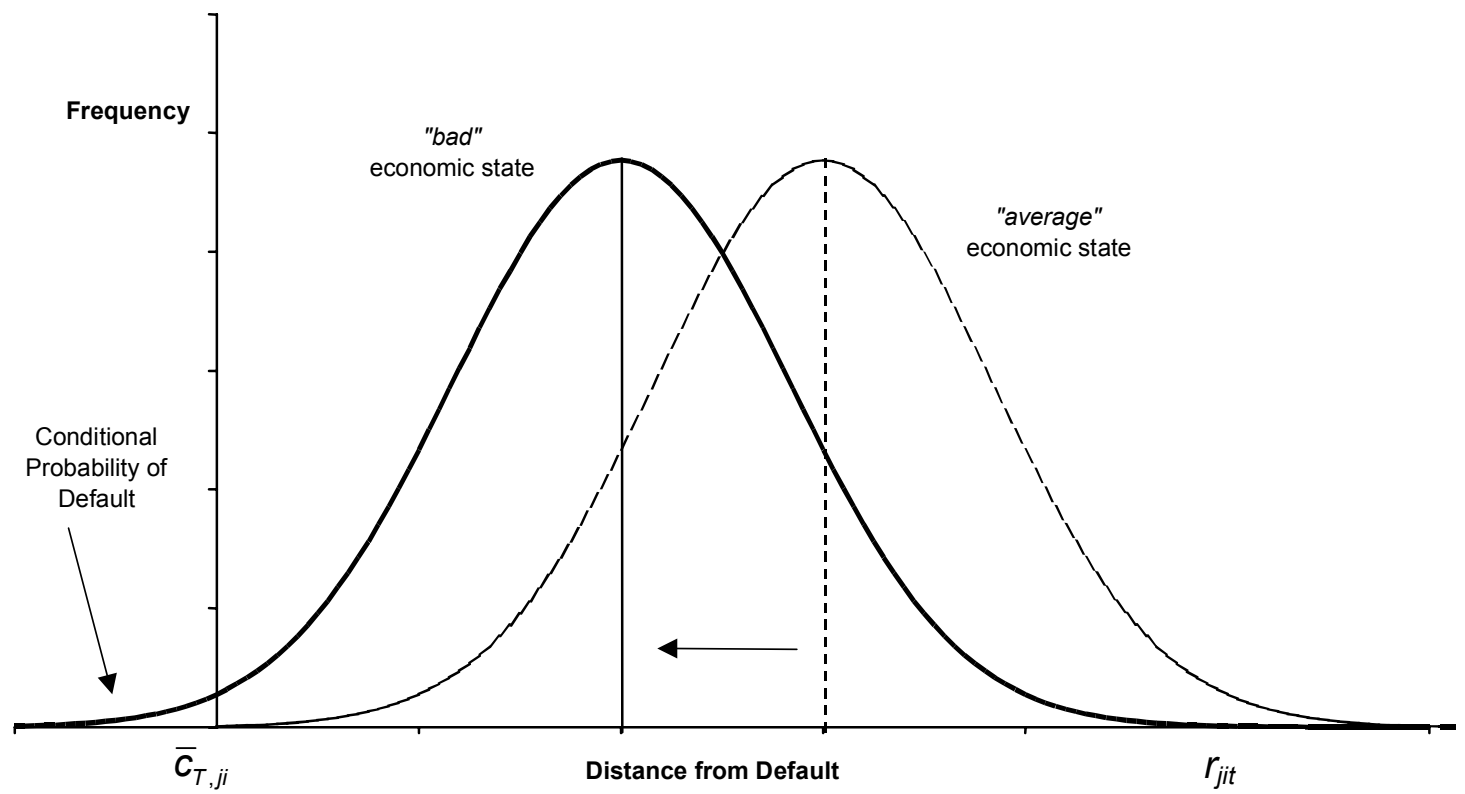

Figure 1: Distance from default conditional on the state of the economy

Figure 1 illustrates the general idea. The right of the two bell-shaped curves represents the return distribution as calculated from the historical average over, say, several decades and thus can be regarded as "unconditional" in that it represents an average state of the economy. Conditional on a certain state of the economy, however, the mean return may shift. The illustrative example in Figure 1 shows the given state of the economy shifting the obligor company closer to default, where the conditional distance from default is given by the solid curve; the tail area to the left of the origin has increased. This area represents the conditional probability of default given a "bad" state of the economy. For the model to be properly identified, either the return, or implicitly the distance from default, distribution can move and the threshold stay fixed, or vice versa, but not both.

In the Merton default prediction model, accounting data (book value of callable liabilities), the market value of equity and the volatility in the market value of equity are used to derive $P D\left(\mathcal{R}_{j i t}\right) .{ }^{21}$ We do the inverse: using an existing measure of expected default probability, we determine the critical value $\hat{c}_{j i}$. This default measure can be obtained from public sources of firm risk ratings provided by rating agencies such as Moody's or Standard \& Poor. ${ }^{22}$ Both of these rating agencies give

\footnotetext{
${ }^{21}$ This approach is taken by KMV to generate what they call EDFs (expected default frequencies) at the firm level. See also footnote 17.

${ }^{22}$ For an overview of credit ratings and the credit rating industry, see Cantor and Packer (1995) and White (2001).
} 
solvency standards for the rated institutions and their publicly issued debt (bonds) in the form of a credit grade, which may then be converted to a probability of default (e.g. $P D\left(\mathcal{A A}_{t}\right)$, the (annual) probability of default for an ' $\mathcal{A} \mathcal{A}$ ' rated firm), using historical data on bond defaults. Hence credit ratings allow us to get a measure of the expected default probability without the need for balance sheet analysis.

Mappings from credit ratings to default probabilities are typically obtained using corporate bond rating histories over many years, often 20 years or more, and thus represent some average across business cycles. The reason for such long samples is simple: default events for investment grade firms are quite rare; for example, the annual $P D$ of an ' $\mathcal{A}$ ' rated firm is approximately one basis point for both Moody's and $\mathrm{S} \& \mathrm{P}$ rated firms.

In the literature, the use and specific interpretation of credit ratings is somewhat ambiguous. One interpretation is that they are "cycle-neutral" (Saunders and Allen (2002), Catarineu-Rabell, Jackson and Tsomocos (2002), Amato and Furfine (2003); Carpenter, Whitesell and Zakrajšek (2001) point to some of the ambiguities), meaning that ratings are assigned only on the basis of firm-specific information and not systematic or macroeconomic information. ${ }^{23}$ The rating agency's own description of their rating methodology broadly supports this view.

(Moody's (1999), p.6,7): ".. [O]ne of Moody's goals is to achieve stable expected [italics in original] default rates across rating categories and time." ... "Moody's believes that giving only a modest weight to cyclical conditions best serves the interests of the bulk of investors."

(S\&P (2001), p.41):"Standard \& Poor's credit ratings are meant to be forward looking; ... Accordingly, the anticipated ups and downs of business cycles - whether industry-specific or related to the general economy - should be factored into the credit rating all along." ... "The ideal is to rate 'through the cycle'".

However, there is ample evidence to suggest that credit ratings and associated default probabilities vary systematically with the business cycle (e.g. Nickell, Perraudin and Varotto (2000), Bangia et al. (2002)). Moody's itself has changed its rating process in this regard (Moody's (1999), p.6): "Moody's has been striving for some time to increase the responsiveness of its ratings to economic developments." Our mapping from default experience to thresholds allows for this time variation.

\footnotetext{
${ }^{23}$ Amato and Furfine (2003) find little evidence of procyclicality in ratings.
} 


\section{An Overview of the GVAR Framework ${ }^{24}$}

This section presents a synopsis of the global vector autoregressive model (GVAR) as a generator of global macroeconomic dynamics and scenarios. It gives an overview of the framework underlying the GVAR without going into the details of estimation techniques. ${ }^{25}$ In contrast to existing modeling approaches, in the GVAR the use of cointegration is not confined to a single country or region. By estimating a cointegrating model for each country/region separately, we are also able to allow for endowment and institutional heterogeneities that exist across the different countries in our modeling strategy. Accordingly, specific vector error-correcting models (VECM) are estimated for individual countries (or regions), by relating domestic macroeconomic variables such as GDP, inflation, equity prices, money supply, exchange rates and interest rates to corresponding foreign variables constructed exclusively to match the international trade pattern of the country/region under consideration. By making use of specific exogeneity assumptions regarding the 'rest of the world' with respect to a given domestic or regional economy, the GVAR makes efficient use of limited amounts of data, and presents a consistently-estimated global model for use in portfolio applications and beyond.

\subsection{Country/Region Specific Models}

The GVAR assumes that there are $N+1$ country/regions in the global economy, indexed by $i=0,1, \ldots, N$, where 0 is the reference country or region (taken to be the U.S.). ${ }^{26}$ Macroeconomic variables of each region are modeled as a function of both their own past and the global economy's current and past state. It is assumed that the regional variables are related to deterministic variables (such as a time trend), foreign variables (which are region-specific weighted averages of the rest of the world) and variables that are taken to be exogenous to this global economy, such as the oil price. We specify the following vector autoregressive form for $k_{i}$ variables: ${ }^{27}$

$$
\begin{aligned}
\mathbf{x}_{i t} & =\mathbf{a}_{i 0}+\mathbf{a}_{i 1} t+\boldsymbol{\Phi}_{i} \mathbf{x}_{i, t-1}+\boldsymbol{\Lambda}_{i 0} \mathbf{x}_{i t}^{*}+\boldsymbol{\Lambda}_{i 1} \mathbf{x}_{i, t-1}^{*}+\boldsymbol{\Psi}_{i 0} \mathbf{d}_{t}+\boldsymbol{\Psi}_{i 1} \mathbf{d}_{t-1}+\varepsilon_{i t}, \\
t & =1,2, \ldots, T ; i=0,1,2, \ldots, N
\end{aligned}
$$

\footnotetext{
${ }^{24}$ This section draws heavily from PSW.

${ }^{25}$ These can be found in PSW.

${ }^{26}$ For simplicity we will refer to regions only. For more on country to region aggregation, see PSW.

${ }^{27}$ Although easily extended to incorporate lags greater than one, the GVAR (1) specification given above is seen as sufficient for the illustrative purposes of this paper. Typical values for $k_{i}$ are 5 or 6 .
} 
where $\mathbf{x}_{i t}$ is the $k_{i} \times 1$ country-specific factors/variables, $\mathbf{a}_{i 1}$ is a $k_{i} \times 1$ vector of linear trend coefficients, $\boldsymbol{\Phi}_{i}$ is a $k_{i} \times k_{i}$ matrix of associated lagged coefficients, $\mathbf{x}_{i t}^{*}$ is the $k_{i}^{*} \times 1$ vector of foreign variables specific to country $i$ (to be defined below) with $\boldsymbol{\Lambda}_{i 0}$ and $\boldsymbol{\Lambda}_{i 1}$ being $k_{i} \times k_{i}^{*}$ matrices of fixed coefficients, $\mathbf{d}_{t}$ is an $s \times 1$ vector of common global variables assumed to be exogenous to the global economy with $\boldsymbol{\Psi}_{i 0}$ and $\boldsymbol{\Psi}_{i 1}$ being $k_{i} \times s$ matrices of fixed coefficients, and $\boldsymbol{\varepsilon}_{i t}$ is a $k_{i} \times 1$ vector of country-specific shocks assumed to be serially uncorrelated with a zero mean and a non-singular covariance matrix, $\boldsymbol{\Sigma}_{i i}=\left(\sigma_{i i, \ell s}\right)$, where $\sigma_{i i, \ell s}=\operatorname{cov}\left(\varepsilon_{i \ell t}, \varepsilon_{i s t}\right)$, or written more compactly

$$
\varepsilon_{i t} \backsim i . i . d .\left(\mathbf{0}, \boldsymbol{\Sigma}_{i i}\right)
$$

Although the model is estimated on a regional basis, we allow for the shocks to be correlated across regions. In particular, we assume that

$$
\begin{aligned}
E\left(\varepsilon_{i t} \varepsilon_{j t^{\prime}}^{\prime}\right) & =\boldsymbol{\Sigma}_{i j} \text { for } t=t^{\prime} \\
& =\mathbf{0} \text { for } t \neq t
\end{aligned}
$$

Interactions take place through three distinct, but interrelated channels:

1. Direct dependence of $\mathbf{x}_{i t}$ on $\mathbf{x}_{i t}^{*}$ and its lagged values.

2. Dependence of the region-specific variables on common global exogenous variables such as oil prices.

3. Non-zero contemporaneous dependence of shocks in region $i$ on the shocks in region $j$, measured via the cross country covariances, $\Sigma_{i j}$.

It is worth noting that the foreign variables $\mathbf{x}_{i t}^{*}$ are tailored to be region-specific. The GVAR assumes that each macroeconomic variable in the vector $\mathbf{x}_{i t}^{*}$ is a weighted average of the corresponding macroeconomic variables of all other regions outside region $i$. Taking output as an example:

$$
y_{i t}^{*}=\sum_{j=0}^{N} w_{i j} y_{j t}, \text { with } \sum_{j=0}^{N} w_{i j}=1 \text { and } w_{i i}=0,
$$

where $y_{i t}^{*}$ is the log of the output of the rest of the world from the perspective of region $i, y_{j t}$ is the $\log$ of the output of region $j$, and $w_{i j}$ is the weight attached to region $j$ 's output in construction of the rest of the world output as seen by region $i$. Weights for the construction of the region-specific global variables could be based on trade shares for variables such as output, prices, exchange rates or money supply 
or on capital flows for equity and interest rates. In what follows $w_{i j}$ denotes the trade share of region $j$ in the total trade volume of region $i .^{28}$

The individual models are estimated allowing for unit roots and cointegration assuming that region-specific foreign variables are weakly exogenous, with the exception of the model for the U.S. economy which is treated as a closed economy model. The U.S. model is linked to the outside world through exchange rates themselves being determined in rest of the region-specific models. While models of the form in equation (9) are relatively standard, PSW show that the careful construction of the global variables as weighted averages of the other regional variables leads to a simultaneous system of regional equations that may be solved to form a global system. They also provide theoretical arguments as well as empirical evidence in support of the weak exogeniety assumption that allows the region-specific models to be estimated consistently.

\subsection{The Global Model and Multi-step Ahead Forecasts}

In view of the contemporaneous dependence of the domestic variables, $\mathbf{x}_{i t}$, on the foreign variables, $\mathbf{x}_{i t}^{*}$, the region-specific VAR models (9) still need to be solved simultaneously for all the domestic variables, $\mathbf{x}_{i t}, i=0,1, \ldots, N$. The global solution to the model yields a $k \times 1$ vector $\mathbf{x}_{t}$, which contains the macroeconomic variables of all regions, such that $\mathbf{x}_{t}$ is a function of time, the lagged values of all macroeconomic variables $\mathbf{x}_{t-1}$ and the exogenous variables common to all regions (and their lags):

$$
\mathbf{x}_{t}=\mathbf{b}_{0}+\mathbf{b}_{1} t+\digamma \mathbf{x}_{t-1}+\Upsilon_{0} \mathbf{d}_{t}+\Upsilon_{1} \mathbf{d}_{t-1}+\mathbf{u}_{t}
$$

$\mathbf{x}_{t}=\left(\mathbf{x}_{0 t}^{\prime}, \mathbf{x}_{1 t}^{\prime}, \ldots, \mathbf{x}_{N t}^{\prime}\right)^{\prime}$ is the global $k \times 1$ vector, where $k=\sum_{i=0}^{N} k_{i}$ is the total number of the endogenous variables in the global model, $\mathbf{b}_{0}$ and $\mathbf{b}_{1}$ are $k \times 1$ vectors of coefficients, ${ }^{29} \digamma$ is a $k \times k$ matrix of coefficients, $\mathbf{d}_{t}$ is an $s \times 1$ vector of common global variables assumed to be exogenous to the global economy (here to be the oil price) with corresponding $k \times s$ matrices of coefficients, $\boldsymbol{\Upsilon}_{0}$ and $\boldsymbol{\Upsilon}_{1} \cdot{ }^{30}$ Finally, $\mathbf{u}_{t}$ is a $k \times 1$ vectors of (reduced form) shocks that are linear functions of the region-specific shocks $\left(\varepsilon_{i t}\right)$. In particular, we have $\mathbf{u}_{t}=\mathbf{G}^{-1} \varepsilon_{t}$, where $\varepsilon_{t}=\left(\varepsilon_{0 t}^{\prime}, \varepsilon_{1 t}^{\prime}, \ldots, \varepsilon_{N t}^{\prime}\right)^{\prime}$, and

\footnotetext{
${ }^{28} \mathrm{See}$ PSW for more details on how weights are constructed. The weights for the exchange rate, which is expressed in terms of the currency of the reference country, differ in their calculation and do not necessarily sum to one.

${ }^{29} \mathrm{In}$ the presence of unit root and cointegration it is desirable to ensure that the trend coefficients, $\mathbf{b}_{1}$, are restricted so that the trend characteristics of $\mathbf{x}_{t}$ are not affected by the number of unit roots in $\boldsymbol{\digamma}$. This is achieved by setting $\mathbf{b}_{1}=(\mathbf{I}-\digamma) \boldsymbol{\gamma}_{1}$, where $\boldsymbol{\gamma}_{1}$ is a vector of unrestricted coefficients. For further details and discussions see Section 4 in PSW.

${ }^{30}$ The exact relationships between the parameters of the GVAR model in (11), and those of the underlying region-specific models (9) are given in PSW.
} 
the $k \times k$ matrix $\mathbf{G}$ is defined in Section 3 of PSW. We also have

$$
\operatorname{Var}\left(\mathbf{u}_{t}\right)=\mathbf{G}^{-1} \mathbf{\Sigma}_{\varepsilon} \mathbf{G}^{\prime-1}
$$

where $\boldsymbol{\Sigma}_{\varepsilon}=\operatorname{Var}\left(\varepsilon_{t}\right)$.

In what follows we assume that the GVAR model is estimated over the period $t=1,2, \ldots, T$, and the objective of the exercise is to generate forecasts, both unconditionally as well as conditional on a particular shock scenario, over the period $t=T+1, \ldots, T+n$, with $n$ being the forecast horizon. Accordingly, all forecasts and loss distributions at different forecast horizons, $n=1,2, \ldots$, will be conditioned on the state of the economy as characterized by the GVAR model and all the available information at time $T$, namely $\Omega_{T}=\left(\mathbf{x}_{T}, \mathbf{d}_{T}, \mathbf{x}_{T-1}, \mathbf{d}_{T-1}, \ldots\right)$.

For multi-step ahead forecasting and impulse response (or shock scenario) analysis the above solution to the GVAR model needs to be augmented with a model for the common global variables $\mathbf{d}_{t}$. To this end we adopt the following autoregressive specification

$$
\mathbf{d}_{t}=\boldsymbol{\mu}_{d}+\boldsymbol{\Phi}_{d} \mathbf{d}_{t-1}+\varepsilon_{d t}, \text { for } t=T+1, T+2, \ldots, T+n,
$$

where $\varepsilon_{d t} \backsim$ i.i.d. $\left(\mathbf{0}, \boldsymbol{\Sigma}_{d}\right)$, which are assumed to be distributed independently of the macroeconomic shocks, $\varepsilon_{t}, t=T+1, T+2, \ldots, T+n$. We shall assume that all the eigen values of $\boldsymbol{\Phi}_{d}$ lie on or inside the unit circle and $\Delta \mathbf{d}_{t}$ is stationary with a constant mean.

For multi-step analysis it is convenient to stack up (11) and (13), and solve out the contemporaneous effect of $\mathbf{d}_{t}$ on $\mathbf{x}_{t}$ to yield

$$
\mathbf{y}_{t}=\boldsymbol{\mu}+\boldsymbol{\delta} t+\boldsymbol{\Phi}_{t-1}+\mathfrak{D} \boldsymbol{v}_{t}
$$

where

$$
\begin{gathered}
\mathbf{y}_{t}=\left(\begin{array}{c}
\mathbf{x}_{t} \\
\mathbf{d}_{t}
\end{array}\right), \boldsymbol{\mu}=\left(\begin{array}{c}
\mathbf{b}_{0}+\mathbf{\Upsilon}_{0} \boldsymbol{\mu}_{d} \\
\boldsymbol{\mu}_{d}
\end{array}\right), \boldsymbol{\delta}=\left(\begin{array}{c}
\mathbf{b}_{1} \\
\mathbf{0}
\end{array}\right), \boldsymbol{v}_{t}=\left(\begin{array}{c}
\varepsilon_{t} \\
\varepsilon_{d t}
\end{array}\right), \\
\mathbf{\Phi}=\left(\begin{array}{cc}
\digamma & \Upsilon_{1}+\Upsilon_{0} \boldsymbol{\Phi}_{d} \\
\mathbf{0} & \mathbf{\Phi}_{d}
\end{array}\right), \text { and } \mathfrak{D}=\left(\begin{array}{cc}
\mathbf{G}^{-1} & \mathbf{\Upsilon}_{0} \\
\mathbf{0} & \mathbf{I}_{s}
\end{array}\right) .
\end{gathered}
$$

The $(k+s) \times 1$ vector, $\boldsymbol{v}_{t}$, augments the region-specific shocks of interest, $\boldsymbol{\varepsilon}_{t}$, with the common global shocks, $\varepsilon_{d t}$. In view of the independence of these shocks we have

$$
\operatorname{Var}\left(\boldsymbol{v}_{t}\right)=\boldsymbol{\Sigma}_{\boldsymbol{v}}=\left(\begin{array}{cc}
\boldsymbol{\Sigma}_{\varepsilon} & \mathbf{0} \\
\mathbf{0} & \boldsymbol{\Sigma}_{d}
\end{array}\right)
$$


Solving the above difference equation forward from $\mathbf{y}_{T}$, we now obtain

$$
\begin{aligned}
\mathbf{y}_{T+n}= & \boldsymbol{\Phi}^{n} \mathbf{y}_{T}+\sum_{\tau=0}^{n-1} \boldsymbol{\Phi}^{\tau}[\boldsymbol{\mu}+(T+n-\tau) \boldsymbol{\delta}] \\
& +\sum_{\tau=0}^{n-1} \boldsymbol{\Phi}^{\tau} \mathfrak{D} \boldsymbol{v}_{T+n-\tau}
\end{aligned}
$$

This solution has three distinct components: The first component, $\boldsymbol{\Phi}^{n} \mathbf{y}_{T}$, measures the effect of initial values, $\mathbf{y}_{T}$, on the future state of the system. The second component captures the deterministic trends embodied in the underlying VAR model. Finally, the last term in (17) represents the stochastic (unpredictable) component of $\mathbf{y}_{T+n}$.

As we shall see below, for the purpose of simulating the loss distribution of a given portfolio, the conditional probability distribution of $\Delta \mathbf{y}_{T+n}$ is needed. ${ }^{31}$ Using (17) and after some algebra we obtain

$$
\Delta \mathbf{y}_{T+n}=\left(\boldsymbol{\Phi}^{n}-\boldsymbol{\Phi}^{n-1}\right) \mathbf{y}_{T}+\mathfrak{g}(T, n)+\mathcal{U}_{T+n},
$$

where

$$
\mathfrak{g}(T, n)=\boldsymbol{\Phi}^{n-1}[\boldsymbol{\mu}+(T+1) \boldsymbol{\delta}]+\sum_{\tau=1}^{n-1} \boldsymbol{\Phi}^{\tau-1} \boldsymbol{\delta}
$$

and

$$
\mathcal{U}_{T+n}=\mathfrak{D} \boldsymbol{v}_{T+n}+\sum_{\tau=1}^{n-1}\left(\boldsymbol{\Phi}^{\tau}-\boldsymbol{\Phi}^{\tau-1}\right) \mathfrak{D} \boldsymbol{v}_{T+n-\tau}
$$

Hence

$$
\begin{gathered}
E\left(\Delta \mathbf{y}_{T+n} \mid \Omega_{T}\right)=\left(\boldsymbol{\Phi}^{n}-\boldsymbol{\Phi}^{n-1}\right) \mathbf{y}_{T}+\mathfrak{g}(T, n) \\
\operatorname{Var}\left(\Delta \mathbf{y}_{T+n} \mid \Omega_{T}\right)=\mathfrak{D} \boldsymbol{\Sigma}_{v} \mathfrak{D}^{\prime}+\sum_{\tau=1}^{n-1}\left(\boldsymbol{\Phi}^{\tau}-\boldsymbol{\Phi}^{\tau-1}\right)\left(\mathfrak{D} \boldsymbol{\Sigma}_{v} \mathfrak{D}^{\prime}\right)\left(\boldsymbol{\Phi}^{\tau}-\boldsymbol{\Phi}^{\tau-1}\right)^{\prime} .
\end{gathered}
$$

If it is further assumed that the region-specific shocks, $\varepsilon_{t}$, and the common global shocks, $\boldsymbol{\varepsilon}_{d t}$, are normally distributed, we then have ${ }^{32}$

$$
\Delta \mathbf{y}_{T+n} \mid \Omega_{T} \backsim N\left\{\left(\Phi^{n}-\Phi^{n-1}\right) \mathbf{y}_{T}+\mathfrak{g}(T, n), \mathbf{\Psi}_{n}\right\},
$$

where

$$
\boldsymbol{\Psi}_{n}=\mathfrak{B}+\sum_{\tau=1}^{n-1}\left(\boldsymbol{\Phi}^{\tau}-\boldsymbol{\Phi}^{\tau-1}\right) \mathfrak{B}\left(\boldsymbol{\Phi}^{\tau}-\boldsymbol{\Phi}^{\tau-1}\right)^{\prime},
$$

\footnotetext{
${ }^{31}$ That is because returns are modeled as being driven by changes in systematic factors in Section 5.

${ }^{32}$ It is also possible to work with non-Gaussian shocks. An important example are t-distributed shocks that we shall consider in our empirical applications in Section 7.4.
} 
and

$$
\mathfrak{B}=\mathfrak{D} \Sigma_{v} \mathfrak{D}^{\prime}=\left(\begin{array}{cc}
\mathbf{G}^{-1} \boldsymbol{\Sigma} \mathbf{G}^{\prime-1}+\Upsilon_{0} \Sigma_{d} \mathbf{\Upsilon}_{0}^{\prime} & \Upsilon_{0} \Sigma_{d} \\
\Sigma_{d} \Upsilon_{0}^{\prime} & \Sigma_{d}
\end{array}\right)
$$

Finally, in the present application where the underlying GVAR model admits unit roots and cointegration, the limit distribution of $\Delta \mathbf{y}_{T+n} \mid \Omega_{T}$ exists and is finite if $\boldsymbol{\delta}=(\mathbf{I}-\boldsymbol{\Phi}) \boldsymbol{\gamma}$, otherwise $\mathfrak{g}(T, n)$ increases without bound as $n \rightarrow \infty$. Under $\boldsymbol{\delta}=(\mathbf{I}-\boldsymbol{\Phi}) \boldsymbol{\gamma}$, using (19) we have

$$
\mathfrak{g}(T, n)=\boldsymbol{\Phi}^{n-1} \boldsymbol{\mu}+(T+1)\left(\boldsymbol{\Phi}^{n-1}-\boldsymbol{\Phi}^{n}\right) \boldsymbol{\gamma}+\left(\mathbf{I}-\boldsymbol{\Phi}^{n-1}\right) \boldsymbol{\gamma}
$$

and it is easily seen that

$$
\lim _{n \rightarrow \infty}[\mathfrak{g}(T, n)]=\mathbf{\Phi}^{*} \boldsymbol{\mu}+\left(\mathbf{I}-\mathbf{\Phi}^{*}\right) \boldsymbol{\gamma}
$$

where $\boldsymbol{\Phi}^{*}=\lim _{n \rightarrow \infty}\left(\boldsymbol{\Phi}^{n}\right)$ is finite under our assumptions. More specifically, if $\boldsymbol{\delta}=(\mathbf{I}-\boldsymbol{\Phi}) \boldsymbol{\gamma}$ we have

$$
\lim _{n \rightarrow \infty} \Delta \mathbf{y}_{T+n} \mid \Omega_{T} \backsim N\left\{\boldsymbol{\Phi}^{*} \boldsymbol{\mu}+\left(\mathbf{I}-\boldsymbol{\Phi}^{*}\right) \boldsymbol{\gamma}, \mathbf{\Psi}^{*}\right\}
$$

where $^{33}$

$$
\boldsymbol{\Psi}^{*}=\mathfrak{B}+\sum_{\tau=1}^{\infty}\left(\boldsymbol{\Phi}^{\tau}-\boldsymbol{\Phi}^{\tau-1}\right) \mathfrak{B}\left(\boldsymbol{\Phi}^{\tau}-\boldsymbol{\Phi}^{\tau-1}\right)^{\prime} .
$$

Therefore, as argued in Section 4 of PSW, it is important that the GVAR model is estimated subject to the restrictions, $\mathbf{b}_{1}=(\mathbf{I}-\digamma) \gamma_{1}$, which in conjunction with the model for the common global variables, (13), ensure that $\boldsymbol{\delta}=(\mathbf{I}-\boldsymbol{\Phi}) \boldsymbol{\gamma}$.

In summary, the GVAR's sequential regional estimation and global aggregation methodology allows for the practitioner to solve for the conditional distribution of the macroeconomic factors globally, whereas single-stage estimation of the global system in equation (11) would be prohibitive due to the very large number of coefficients and generally thin data sets. As a result, the model allows us to examine the effects of a shock in one region on the macroeconomic factors that describe the system globally, as our discussion of impulse response functions below shows.

\subsection{Shock Scenario Analysis through GIRFs}

For policy analysis, one would like to be able to examine how an isolated contemporaneous shock to one macroeconomic variable affects all other macroeconomic variables in the global economy. For example, it might be of interest to determine

\footnotetext{
${ }^{33}$ Notice that all the elements of $\left(\boldsymbol{\Phi}^{\tau}-\boldsymbol{\Phi}^{\tau-1}\right)$ decay exponentially with $\tau$ even under unit roots and hence $\boldsymbol{\Psi}^{*}$ exists and is finite.
} 
the effects of a contemporaneous 10\% drop in the Japanese equity prices on other macroeconomic variables, and the effects that these have on the credit risk of a given portfolio. Impulse response functions provide us with the tools to carry out this type of analysis. In so doing, it is of course important that the correlations that exists across the different shocks, both within and across regions, are properly taken into accounted. However, in a model which consists only of regional VAR's (as in equation (9)) which are not integrated as in the GVAR, it is impossible to uncover these effects because the interdependencies within regions are lost. On the other hand, single-stage estimation of the global model (11) is extremely difficult, and even if it were possible (and consistent), it would be impossible to construct a regional shock (a shock to $\varepsilon_{i t}$ ) within the context of such a global model. Only with the GVAR can both of these challenges be adequately addressed.

In the traditional VAR literature this is accomplished by means of the orthogonalized impulse responses (OIR) à la Sims (1980), where impulse responses are computed with respect to a set of orthogonalized shocks, say $\boldsymbol{\xi}_{t}$, instead of the original shocks, $\varepsilon_{t}$. The link between the two sets of shocks are given by

$$
\boldsymbol{\xi}_{t}=\mathbf{P}^{-1} \varepsilon_{t},
$$

where $\mathbf{P}$ is a $k \times k$ lower triangular Cholesky factor of the variance covariance matrix, $\operatorname{Var}\left(\varepsilon_{t}\right)=\Sigma_{\varepsilon}$, namely

$$
\mathbf{P P}^{\prime}=\boldsymbol{\Sigma}_{\varepsilon}
$$

Therefore, by construction $E\left(\boldsymbol{\xi}_{t} \boldsymbol{\xi}_{t}^{\prime}\right)=\mathbf{I}_{k}$. However, the drawback of using OIR is that the outcome is dependent on the order of the variables. ${ }^{34}$ Koop, Pesaran and Potter (1996) and Pesaran and Shin (1998) have developed an approach which is invariant to the order of the variables, known as the generalized impulse response function (GIRF). The GIRF can be applied to region-specific shocks as well as to the common global shocks. For example, if factor $\ell$ in country $i$ is (purposefully) shocked by one standard error (i.e. $\sqrt{\sigma_{i i, \ell}}$ ) in the period from $T$ to $T+1$, the GIRF of $\mathbf{y}_{T+n}$ is given by

$$
\boldsymbol{\psi}_{i \ell}(\mathbf{y}, n)=E\left(\mathbf{y}_{T+n} \mid \Omega_{T}, \varepsilon_{i, T+1, \ell}=\sqrt{\sigma_{i i, \ell \ell}}\right)-E\left(\mathbf{y}_{T+n} \mid \Omega_{T}\right) .
$$

The first term captures the expected effect of the shock, while the second term represents the baseline scenario in the absence of the shock. In the case of the GVAR model, using (17) we have

$$
\boldsymbol{\psi}_{i \ell}(\mathbf{y}, n)=\boldsymbol{\Phi}^{n-1} \mathfrak{D} E\left(\boldsymbol{v}_{T+1} \mid \Omega_{T}, \varepsilon_{i, T+1, \ell}=\sqrt{\sigma_{i i, \ell \ell}}\right),
$$

\footnotetext{
${ }^{34}$ This is due to the non-uniqueness of the Cholesky decomposition. While OIR are suitable for low-dimensional models where variables can be arranged in causal order, they are not suitable for large dimensional GVAR models.
} 
which yields

$$
\boldsymbol{\psi}_{i \ell}(\mathbf{y}, n)=\frac{1}{\sqrt{\sigma_{i i, \ell \ell}}} \boldsymbol{\Phi}^{n-1} \mathfrak{D} \boldsymbol{\Sigma}_{\boldsymbol{v}} \mathfrak{s}_{i \ell}, n=1,2, \ldots,
$$

where $\mathfrak{s}_{i \ell}$ is a $(k+s) \times 1$ selection vector with its element corresponding to the $\ell^{\text {th }}$ variable in country $i$ being unity and zeros elsewhere. A similar expression can also be derived for the effect of shocking one of the common global variables by an appropriate choice of the selection vector, $\mathfrak{s}$, and by replacing $\sqrt{\sigma_{i i, \ell \ell}}$ with the one standard error of the common global variable being shocked. ${ }^{35}$

The GIRF of the changes in the $n$-period ahead forecast, $\Delta \mathbf{y}_{T+n}$, can also be derived directly using (18) and is given by

$$
\begin{aligned}
\boldsymbol{\psi}_{i \ell}(\Delta \mathbf{y}, n) & =\frac{1}{\sqrt{\sigma_{i i, \ell \ell}}} \mathfrak{D} \boldsymbol{\Sigma}_{\boldsymbol{v}} \mathfrak{s}_{i \ell} \text { for } n=1, \\
& =\frac{1}{\sqrt{\sigma_{i i, \ell \ell}}}\left(\boldsymbol{\Phi}^{n-1}-\boldsymbol{\Phi}^{n-2}\right) \mathfrak{D} \boldsymbol{\Sigma}_{\boldsymbol{v}} \mathfrak{s}_{i \ell}, \text { for } n=2,3, . .
\end{aligned}
$$

Clearly, on impact (for $n=1), \boldsymbol{\psi}_{i \ell}(\mathbf{y}, n)=\boldsymbol{\psi}_{i \ell}(\Delta \mathbf{y}, n)$, but the two impulse response functions deviate at higher order horizons.

Finally, to analyze the impact of shock scenarios on the loss distribution, we also need to consider the effect of region-specific and common global shocks on the whole probability distribution function of $\Delta \mathbf{y}_{T+n}$ conditional on $\Omega_{T}$. For this purpose we assume that the magnitude and the nature of the shock is not such as to alter the probability distribution function of $\boldsymbol{v}_{T+1}$, and distinguish between the cases where the change in $\varepsilon_{i, T+1, \ell}$ is pre-announced or anticipated, as compared to the case where the change is unanticipated. The former could be relevant in the case of policy announcements such as specific tax changes or general changes to the monetary policy. But for risk analysis unanticipated forms of shocks seem more relevant. Assuming that the errors, $\boldsymbol{v}_{T+1}$, are distributed as multivariate normal (even after the system is hit by the shock), the probability distribution in the presence of an unanticipated unit shock to $\ell^{\text {th }}$ factor in country $i$ is given by

$\Delta \mathbf{y}_{T+n} \mid \Omega_{T}, \varepsilon_{i, T+1, \ell}=\sqrt{\sigma_{i i, \ell \ell}} \backsim N\left\{\left(\boldsymbol{\Phi}^{n}-\boldsymbol{\Phi}^{n-1}\right) \mathbf{y}_{T}+\mathfrak{g}(T, n)+\boldsymbol{\psi}_{i \ell}(\Delta \mathbf{y}, n), \boldsymbol{\Psi}_{n}\right\}$,

where $\boldsymbol{\psi}_{i \ell}(\Delta \mathbf{y}, n)$, and $\boldsymbol{\Psi}_{n}$ are defined by (26) and (24). Here we are assuming that the shock, if unanticipated, does not change the conditional covariance matrix of $\boldsymbol{v}_{T+1}{ }^{36}$

\footnotetext{
${ }^{35}$ The GIRF are identical to the orthogonalized impulse response function only when $\boldsymbol{\Sigma}_{\boldsymbol{v}}$ is diagonal and/or when the focus of the analysis is on the impulse response function of shocking the first element of $\boldsymbol{v}_{t}$. See Pesaran and Shin (1998).

${ }^{36} \mathrm{In}$ principle it is possible to allow for simultaneous mean and variance change, for example, by adopting mean-in-GARCH type models where conditional variance is assumed to be depend on the conditional mean of the errors.
} 
When the shock (or more accurately the policy intervention) is anticipated its variance as well as its covariances with the other components of $\boldsymbol{v}_{T+1}$ will be zero on impact and we have

$$
\Delta \mathbf{y}_{T+n} \mid \Omega_{T}, \varepsilon_{i, T+1, \ell}=\sqrt{\sigma_{i i, \ell \ell}} \backsim N\left\{\left(\boldsymbol{\Phi}^{n}-\boldsymbol{\Phi}^{n-1}\right) \mathbf{y}_{T}+\mathfrak{g}(T, n)+\boldsymbol{\psi}_{i \ell}(\Delta \mathbf{y}, n), \boldsymbol{\Psi}_{n, i \ell}\right\},
$$

where

$$
\begin{gathered}
\boldsymbol{\Psi}_{n, i \ell}=\mathfrak{B}_{i \ell}, \quad \text { for } n=1, \\
\boldsymbol{\Psi}_{n, i \ell}=\mathfrak{B}_{i \ell}+\sum_{\tau=1}^{n-1}\left(\boldsymbol{\Phi}^{\tau}-\boldsymbol{\Phi}^{\tau-1}\right) \mathfrak{B}\left(\boldsymbol{\Phi}^{\tau}-\boldsymbol{\Phi}^{\tau-1}\right)^{\prime}, \text { for } n=2,3, \ldots \\
\mathfrak{B}_{i \ell}=\mathfrak{D}\left[\boldsymbol{\Sigma}_{v}-\boldsymbol{\Sigma}_{v} \mathfrak{s}_{i \ell}\left(\mathfrak{s}_{i \ell}^{\prime} \boldsymbol{\Sigma}_{v} \mathfrak{s}_{i \ell}\right)^{-1} \mathfrak{s}_{i \ell}^{\prime} \boldsymbol{\Sigma}_{v}\right] \mathfrak{D}^{\prime} .
\end{gathered}
$$

\section{Conditional Credit Risk Modeling}

The conditional loss distribution of a given credit portfolio can now be derived by linking up the return processes of individual firms, initially presented in equation (1), explicitly to the macro and global variables in the GVAR model.

\subsection{Return Regressions: A More General Formulation}

Firm returns are usually modeled as a function of macro variables that are specific to the firm's domicile country plus global variables such as changes in oil prices. But such a specification leaves out one of the key features of the GVAR model, namely the foreign-specific variables which could be particularly important in the case of large international corporations. Here we extend the firm return model by incorporating all GVAR factors to take full advantage of the GVAR dynamics. Accordingly, a firm's change in value (or return) is assumed to be a function of changes in the underlying macroeconomic factors (the systematic component), say $k_{i}$ region-specific domestic and $k_{i}^{*}$ foreign macroeconomic variables, the exogenous global variables $\mathbf{d}_{t}$ (in our application oil prices) and the firm-specific idiosyncratic shocks $\eta_{j i t}$ :

$r_{j i, t+1}=\alpha_{j i}+\sum_{\ell=1}^{k_{i}} \beta_{j i, \ell} \Delta x_{i, t+1, \ell}+\sum_{\ell=1}^{k_{i}^{*}} \beta_{j i, \ell}^{*} \Delta x_{i, t+1, \ell}^{*}+\sum_{\ell=1}^{s} \gamma_{j i, \ell} \Delta d_{t+1, \ell}+\eta_{j i, t+1}, t=1,2, \ldots, T$,

where $r_{j i, t+1}$ is the equity return from $t$ to $t+1$ for firm $j\left(j=1, \ldots, n c_{i}\right)$ in region $i$. $\alpha_{j i}$ is a regression constant for company $j$ in region $i, k_{i}$ and $k_{i}^{*}$ are the number 
of domestic and foreign macroeconomic factors (drivers), respectively, in region $i$, $\beta_{j i, \ell}$ and $\beta_{j i, \ell}^{*}$ are the factor loadings corresponding to, respectively, the change in the $\ell^{\text {th }}$ domestic and foreign macroeconomic variable for company $j$ in region $i$, $\Delta x_{i, t+1, \ell}$ and $\Delta x_{i, t+1, \ell}^{*}$ are, respectively, the log difference of the $\ell^{t h}$ domestic and foreign macroeconomic factor in region $i, d_{t+1, \ell}$ is the $\ell^{\text {th }}$ global factor, and $\gamma_{j i, \ell}$ is its associated coefficient. This can be written more compactly as

$$
r_{j i, t+1}=\alpha_{j i}+\boldsymbol{\beta}_{j i}^{\prime} \Delta \mathbf{x}_{i, t+1}+\boldsymbol{\beta}_{j i}^{* \prime} \Delta \mathbf{x}_{i, t+1}^{*}+\gamma_{j i}^{\prime} \Delta \mathbf{d}_{t+1}+\eta_{j i, t+1},
$$

where $\mathbf{x}_{i, t+1}, \mathbf{x}_{i, t+1}^{*}$, and $\mathbf{d}_{t+1}$ are the $k_{i} \times 1, k_{i}^{*} \times 1$, and $s \times 1$ vectors of macroeconomic and global factors. The exact link between the macro factors in these APT regressions and the variables in the GVAR model is through the composite vector $\mathbf{z}_{i, t+1}=\left(\mathbf{x}_{i, t+1}^{\prime}, \mathbf{x}_{i, t+1}^{\prime *}\right)^{\prime}$. As shown in PSW, this regional composite vector can be obtained from the global variables:

$$
\mathbf{z}_{i, t+1}=\left(\begin{array}{c}
\mathbf{x}_{i, t+1} \\
\mathbf{x}_{i, t+1}^{*}
\end{array}\right)=\mathbf{W}_{i} \mathbf{x}_{t+1},
$$

where the weight matrix $\mathbf{W}_{i}$ serves as the 'link' between the global variable vector $\mathbf{x}_{t+1}$ and the domestic $\left(\mathbf{x}_{i, t+1}\right)$ and foreign $\left(\mathbf{x}_{i, t+1}^{*}\right)$ variables for region $i$. The nonzero elements of $\mathbf{W}_{i}$ are given by trade weights of country $i$ relative to all other countries in the GVAR model. Hence we have

$$
r_{j i, t+1}=\alpha_{j i}+\mathbf{B}_{j i}^{\prime} \mathbf{W}_{i} \Delta \mathbf{x}_{t+1}+\gamma_{j i}^{\prime} \Delta \mathbf{d}_{t+1}+\eta_{j i, t+1},
$$

where $\mathbf{B}_{j i}=\left(\boldsymbol{\beta}_{j i}^{\prime}, \boldsymbol{\beta}_{j i}^{* \prime}\right)^{\prime}$. The GVAR model provides forecasts of all the global variables, $\mathbf{x}_{t+1}$, that directly or indirectly affect the returns, $r_{j i, t+1}$. If the model captures all systematic risk, the idiosyncratic risk components of any two companies in the model would be uncorrelated, namely the idiosyncratic risks, $\eta_{j i, t+1}$, ought to be cross-sectionally uncorrelated. The values of the global exogenous variables, $\mathbf{d}_{t+1}$, could either by fixed to represent particular scenarios of interest, such as high or low oil prices, or could be forecast using a sub-model such as the VAR specification given by (13). Under this specification, due to the contemporaneous dependence of $\Delta \mathbf{x}_{t+1}$ on $\Delta \mathbf{d}_{t+1}$, we re-write (34) as

$$
r_{j i, t+1}=\alpha_{j i}+\Gamma_{j i}^{\prime} \Delta \mathbf{y}_{t+1}+\eta_{j i, t+1},
$$

where the factor loadings $\Gamma_{j i}^{\prime}=\left(\mathbf{B}_{j i}^{\prime} \mathbf{W}_{i}, \gamma_{j i}^{\prime}\right)$, and as before $\Delta \mathbf{y}_{t+1}=\left(\Delta \mathbf{x}_{t+1}^{\prime}, \Delta \mathbf{d}_{t+1}^{\prime}\right)^{\prime}$.

\subsection{Expected Loss Due to Default}

Given the value change process for firm $j$, defined by (33), and the default threshold, $\hat{c}_{j i}$, obtainable from an initial credit rating (see Section 3.2), we now consider the 
conditions under which the firm goes bankrupt and is thus no longer able to repay its debt obligations. Specifically, we need to define the expected loss to firm $j$ at time $T$ given information available to the lender (e.g. a bank) at time $T$, which we assume is given by $\Omega_{T}$. Following (3), default occurs when the firm's value (return) falls below some threshold $\hat{c}_{j i}$ (e.g. when the value of a firm's assets falls below the value of its callable liabilities). Expected loss at time $T$ (but occurring at $T+1$ ), $E_{T}\left(L_{j i, T+1}\right)=E\left(L_{j i, T+1} \mid \Omega_{T}\right)$, is given by

$$
\begin{aligned}
E_{T}\left(L_{j i, T+1}\right)= & \operatorname{Pr}\left(r_{j i, T+1}<\hat{c}_{j i} \mid \Omega_{T}\right) E_{T}\left(\mathcal{X}_{j i, T+1}\right) E_{T}\left(\mathcal{S}_{j i, T+1}\right) \\
& +\left[1-\operatorname{Pr}\left(r_{i j, T+1}<\hat{c}_{j i} \mid \Omega_{T}\right)\right] \times \tilde{L}
\end{aligned}
$$

where $\mathcal{X}_{j i, T+1}$ is the maximum loss exposure assuming no recoveries for company $j$ in region $i$ (typically the face value of the loan) and is known at time $T, \mathcal{S}_{j i, T+1}$ is the percentage of exposure which cannot be recovered in the event of default (sometimes called loss given default or severity), ${ }^{37}$ and $\tilde{L}$ is some future loss in the event of non-default at $T+1$ (which we set to zero for simplicity). Typically $\mathcal{S}_{j i, T+1}$ is not known at time of default and will be treated as a random variable over the range $[0,1]$. In the empirical application we make the typical assumption that $\mathcal{S}_{j i, T+1}$ are draws from a beta distribution with given mean and variance calibrated to (pooled) historical data on default severity. ${ }^{38}$

Substituting (34) into (36) and setting $\tilde{L}$ to zero we now obtain: ${ }^{39}$

$$
E_{T}\left(L_{j i, T+1}\right)=\pi_{j i, T+1 \mid T} E_{T}\left(\mathcal{X}_{j i, T+1}\right) E_{T}\left(\mathcal{S}_{j i, T+1}\right)
$$

where

$$
\pi_{j i, T+1 \mid T}=\operatorname{Pr}\left(\alpha_{j i}+\Gamma_{j i}^{\prime} \Delta \mathbf{y}_{T+1}+\eta_{j i, T+1}<\hat{c}_{j i} \mid \Omega_{T}\right),
$$

is the conditional default probability over the period $T$ to $T+1$, formed at time $T$. Our modeling framework allows us to derive an explicit expression for $\pi_{j i, T+1 \mid T}$. Using (18) and after some simplifications we have

$$
\pi_{j i, T+1 \mid T}=\operatorname{Pr}\left(\xi_{j i, T+1}<\hat{c}_{j i}-\mu_{j i, T} \mid \Omega_{T}\right)
$$

where

$$
\xi_{j i, T+1}=\eta_{j i, T+1}+\Gamma_{j i}^{\prime} \mathfrak{D} \boldsymbol{v}_{T+1}
$$

\footnotetext{
${ }^{37}$ One would expect loss severity to be higher in recessions than expansions (see Frye (2000) and Altman et al. (2002)). Bankruptcies are pro-cyclical, flooding the market with distressed assets which drive down their price (or increasing severity). However, for simplicity we follow the standard assumption that exposure and severity are independently distributed.

${ }^{38}$ The beta distribution is usually chosen since it is bounded, typically on the unit interval, with two shape parameters which can be expressed in terms of mean and standard deviation of losses.

${ }^{39} \mathrm{It}$ is common practice in the industry to set $\widetilde{L}$ to zero.
} 
and

$$
\mu_{j i, T+1 \mid T}=\alpha_{j i}+\Gamma_{j i}^{\prime}[\boldsymbol{\mu}+(T+1) \boldsymbol{\delta}]-\Gamma_{j i}^{\prime}\left(\mathbf{I}_{k+s}-\mathbf{\Phi}\right) \mathbf{y}_{T} .
$$

These results decompose the return for firm $j$ in region $i$ into its explained (expected) and unexplained (unexpected) components, with $\mu_{j i, T+1 \mid T}$ being the expected value of return formed at time $T$, and $\xi_{j i, T+1}$ the unexpected component. To clarify, the explained or forecastable portion of firm return, $\mu_{j i, T+1 \mid T}$, is comprised of firm-specific fixed effects, $\alpha_{j i}$ (i.e. the "alphas" in an APT context), the drift components of the macro factors and the global exogenous variables, $(T+1) \Gamma_{j i}^{\prime} \boldsymbol{\delta}$, and factor loadings, $-\Gamma_{j i}^{\prime}\left(\mathbf{I}_{k+s}-\mathbf{\Phi}\right)$, which collect the effects of the region-specific factors and the global exogenous variables on the firm's expected return.

The unexpected component, defined by (39), is influenced by three different types of shocks: a firm's own shock, $\eta_{j i, T+1}$, macroeconomic shocks, $\varepsilon_{T+1}$, and the global exogenous shock, $\varepsilon_{d, T+1}$ (in our model the oil price shock). ${ }^{40}$ Note that although the firm in question operates in country/region $i$, its probability of default could be affected by macroeconomic shocks worldwide. Under the assumption that all these shocks are jointly normally distributed and the parameter estimates are given, we have the following expression for the probability of default over $T$ to $T+1$ formed at $T^{41}$

$$
\pi_{j i, T+1 \mid T}=\Phi\left[\frac{\hat{c}_{j i}-\mu_{j i, T+1 \mid T}}{\sqrt{\operatorname{Var}\left(\xi_{j i, T+1} \mid \Omega_{T}\right)}}\right],
$$

where

$$
\operatorname{Var}\left(\xi_{j i, T+1} \mid \Omega_{T}\right) \equiv \omega_{\xi, j i}^{2}=\omega_{\eta, j i}^{2}+\Gamma_{j i}^{\prime} \mathfrak{B} \Gamma_{j i} .
$$

and $\mathfrak{B}=\mathfrak{D} \Sigma_{\boldsymbol{v}} \mathfrak{D}^{\prime}$ is given by (25). The first term in $\omega_{\xi, j i}^{2}$ is the variance of firm's idiosyncractic shock, $\eta_{j i, T+1}$. Also, since the region-specific shocks and the common global shocks are uncorrelated, the second term in $\omega_{\xi, j i}^{2}$ can be further decomposed into two components as

$$
\Gamma_{j i}^{\prime} \mathfrak{B} \Gamma_{j i}=\boldsymbol{\theta}_{j i}^{\prime} \boldsymbol{\Sigma}_{\varepsilon} \boldsymbol{\theta}_{j i}+\boldsymbol{\theta}_{j i, d}^{\prime} \boldsymbol{\Sigma}_{d} \boldsymbol{\theta}_{j i, d}
$$

where

$$
\boldsymbol{\theta}_{j i}^{\prime}=\mathbf{B}_{j i}^{\prime} \mathbf{W}_{i} \mathbf{G}^{-\mathbf{1}}, \boldsymbol{\theta}_{j i, d}^{\prime}=\gamma_{j i}^{\prime}+\mathbf{B}_{j i}^{\prime} \mathbf{W}_{i} \mathbf{\Upsilon}_{0} .
$$

Both of the restrictions (given parameter values and joint normality) can be relaxed. Parameter uncertainty can be taken into account by integrating out the true parameters using posterior or predictive likelihoods of the unknown parameters,

\footnotetext{
${ }^{40}$ Recall that $\boldsymbol{v}_{T+1}=\left(\varepsilon_{T+1}^{\prime}, \boldsymbol{\varepsilon}_{d, T+1}^{\prime}\right)^{\prime}$.

${ }^{41}$ Joint normality is sufficient but not necessary for $\xi_{j i, t+1}$ to be approximately normally distributed. This is due to the fact that $\xi_{j i, t+1}$ is a linear function of a large number of weakly correlated shocks (63 in our particular application).
} 
as in Garratt et al. (2002). In the presence of non-normal shocks one could either simulate the loss distributions assuming fat-tailed distributions such as Student $t$ with a sufficiently low degree of freedom as adopted in our empirical work below. Alternatively, one can employ non-parametric stochastic simulation techniques by re-sampling from estimated residuals of the GVAR model to estimate $\pi_{j i, T+1 \mid T}$.

The expected loss due to default of a loan (credit) portfolio can now be computed by aggregating the expected losses across the different loans. Denoting the loss of a loan portfolio over the period $T$ to $T+1$ by $L_{T+1}$ we have

$$
E_{T}\left(L_{T+1}\right)=\sum_{i=0}^{N} \sum_{j=1}^{n c_{i}} \pi_{j i, T+1 \mid T} E_{T}\left(\mathcal{X}_{j i, T+1}\right) E_{T}\left(\mathcal{S}_{j i, T+1}\right)
$$

where $n c_{i}$ is the number of obligors (which could be zero) in the bank's loan portfolio resident in country/region $i$.

\subsection{Simulation of the Loss Distribution}

The expected loss as well as the entire loss distribution can be computed once the GVAR model parameters in (11), the return process parameters in (34) and the thresholds in (6) have been estimated for a sample of observations $t=1,2, \ldots, T$. We do this by stochastic simulation using draws from the joint distribution of the shocks, $\epsilon_{T+1}=\left(\boldsymbol{\varepsilon}_{T+1}^{\prime}, \boldsymbol{\varepsilon}_{d, T+1}^{\prime}, \boldsymbol{\eta}_{T+1}^{\prime}\right)^{\prime}$, where $\boldsymbol{\eta}_{T+1}$ is the $\left(\sum_{i=0}^{N} n c_{i}\right) \times 1$ vector of firm-specific shocks. As noted earlier these draws could either be carried out parametrically from normal or t-distributed random variables, or if sufficient data points are available, can be implemented non-parametrically using re-sampling techniques. Under the parametric specification the variance covariance matrix of $\epsilon_{t+1}$ is given by

$$
\operatorname{Var}\left(\epsilon_{T+1}\right)=\left(\begin{array}{ccc}
\boldsymbol{\Sigma}_{\varepsilon} & \mathbf{0} & \mathbf{0} \\
\mathbf{0} & \boldsymbol{\Sigma}_{d} & \mathbf{0} \\
\mathbf{0} & \mathbf{0} & \boldsymbol{\Sigma}_{\eta}
\end{array}\right)
$$

where $\boldsymbol{\Sigma}_{\eta}$ is a diagonal matrix with elements $\omega_{\eta, j i}^{2}, j=1,2, \ldots, n c_{i}, i=0,1, \ldots, N$.

Denote the $r^{t h}$ draw of this vector by $\epsilon_{T+1}^{(r)}$, and compute the firm-specific return, $r_{i T, t+1}^{(r)}$, noting that

$$
r_{i j, T+1}^{(r)}=\mu_{j i, T+1 \mid T}+\xi_{j i, T+1}^{(r)},
$$

where $\mu_{j i, T+1 \mid T}$ is given by $(40)$ and

$$
\xi_{j i, T+1}^{(r)}=\eta_{j i, T+1}^{(r)}+\boldsymbol{\theta}_{j i}^{\prime} \varepsilon_{T+1}^{(r)}+\boldsymbol{\theta}_{j i, d}^{\prime} \varepsilon_{d, T+1}^{(r)} .
$$


Then simulate the loss in period $T+1$ using (known) loan face values, say $F V_{j i, T}$, as exposures, and draws from a beta distribution for severities (as described above):

$$
L_{T+1}^{(r)}=\sum_{i=0}^{N} \sum_{j=1}^{n c_{i}} I\left(r_{i j, T+1}^{(r)}<\hat{c}_{j i}\right) F V_{j i, T} \mathcal{S}_{j i, T+1}^{(r)} .
$$

The simulated expected loss due to default is given by (using $R$ replications)

$$
\bar{L}_{R, T+1}=\frac{1}{R} \sum_{r=1}^{R} L_{T+1}^{(r)} .
$$

When $\epsilon_{T+1}^{(r)}$ are drawn from a multivariate normal distribution with a covariance matrix given by (45), then

$$
\bar{L}_{R, T+1} \stackrel{p}{\rightarrow} E_{T}\left(L_{T+1}\right), \text { as } R \rightarrow \infty
$$

The simulated loss distribution is given by ordered values of $L_{T+1}^{(r)}$, for $r=1,2, \ldots, R$. For a desired percentile, for example the $99 \%$, and a given number of replications, say $R=10,000$, credit value at risk is given as the $100^{\text {th }}$ highest loss.

\subsection{Default and Expected Loss Given Economic Shocks}

In credit risk analysis we may also be interested in evaluating quantitatively the relative importance of changes in different macroeconomic factors on the loss distribution. In the argot of risk management this is sometimes called scenario analysis. To this end the loss distribution conditional on a given shock can be compared to a baseline distribution without such a shock. As with all counterfactual experiments it is important that the effects of the shock on other macroeconomic factors are clearly specified. One possibility would be to assume that the other factors are displaced according to their historical covariances with the variable being shocked. This is in line with the GIRF analysis discussed in Section 4.3. In this set-up, if factor $\ell$ in country $i$ is shocked by one standard error (i.e. $\sqrt{\sigma_{i i, \ell}}$ ) in the period from $T$ to $T+1$, on impact the vector of the macroeconomic factors would be displaced by

$$
\boldsymbol{\psi}_{i \ell}(\Delta \mathbf{y}, 1)=\frac{1}{\sqrt{\sigma_{i i, \ell \ell}}} \mathfrak{D} \boldsymbol{\Sigma}_{\boldsymbol{v}} \mathfrak{s}_{i \ell}
$$

given by (27) for $n=1$. Such a shock has no effect on the global exogenous variables nor on the firm-specific shocks. In the absence of any macroeconomic shocks, namely when $\boldsymbol{\varepsilon}_{T+1}=\mathbf{0}$, firm-specific returns are given by

$$
r_{i j, T+1}^{0}=\mu_{j i, T+1 \mid T}+\eta_{j i, T+1}+\boldsymbol{\theta}_{j i, d}^{\prime} \boldsymbol{\varepsilon}_{d, T+1},
$$


so that the only sources of innovation are firm-specific $\left(\eta_{j i, T+1}\right)$ and specific to the global exogenous variable $\left(\varepsilon_{d, T+1}\right)$. With a one standard error shock to the $\ell^{\text {th }}$ variable in country $i, x_{i, T+1, \ell}$, we have an additional component (see (45) and (46)):

$$
r_{i j, T+1}^{\ell}=\mu_{j i, T+1 \mid T}+\Gamma_{j i}^{\prime} \boldsymbol{\psi}_{i \ell}(\Delta \mathbf{y}, 1)+\eta_{j i, T+1}+\boldsymbol{\theta}_{j i, d}^{\prime} \varepsilon_{d, T+1}
$$

The loss distributions associated with these two scenarios can now be simulated using these returns in (48).

The above counterfactual, while of some interest, will underestimate the expected loss under both shock scenarios since it abstracts from volatility of the macroeconomic factors. To allow for volatility of macroeconomic factors in the analysis consider the case where the various shocks are jointly normally distributed, and note that

$$
r_{i j, T+1}=\mu_{j i, T+1 \mid T}+\Gamma_{j i}^{\prime} \mathfrak{D} \boldsymbol{v}_{T+1}+\eta_{j i, T+1},
$$

where $\mu_{j i, T+1 \mid T}$ is defined by (40). Following a similar line of argument as in Section 4.3 , if the shock is assumed to be anticipated we have

$$
r_{i j, T+1} \mid \Omega_{T}, \varepsilon_{i T+1, \ell}=\sqrt{\sigma_{i i, \ell \ell}} \backsim N\left\{\mu_{j i, T+1 \mid T}+\Gamma_{j i}^{\prime} \boldsymbol{\psi}_{i \ell}(\Delta \mathbf{y}, 1), \omega_{\xi, j i, i \ell}^{2}\right\},
$$

where $\varepsilon_{i, T+1, \ell}=\mathfrak{s}_{i \ell}^{\prime} \boldsymbol{v}_{T+1}, \boldsymbol{\psi}_{i \ell}(\Delta \mathbf{y}, 1)$ is defined by (50) and ${ }^{42}$

$$
\omega_{\xi, j i, i \ell}^{2}=\omega_{\eta, j i}^{2}+\Gamma_{j i}^{\prime} \mathfrak{B}_{i \ell} \Gamma_{j i}
$$

where $\mathfrak{B}_{i \ell}$ is defined by (31). But if the shock is unanticipated (which we consider to be more relevant for credit risk analysis) we have

$$
r_{i j, T+1} \mid \Omega_{T}, \quad \varepsilon_{i T+1, \ell}=\sqrt{\sigma_{i i, \ell \ell}} \backsim N\left\{\mu_{j i, T+1 \mid T}+\Gamma_{j i}^{\prime} \boldsymbol{\psi}_{i \ell}(\Delta \mathbf{y}, 1), \omega_{\xi, j i}^{2}\right\},
$$

where $\omega_{\xi, j i}^{2}$ is given by $(42)$.

Therefore, to allow for volatility of the shocks (macroeconomic as well as idiosyncratic shocks), the simulation of the loss distribution needs to be carried out using the draws

$$
r_{i j, T+1}^{i l,(r)}=\mu_{j i, T+1 \mid T}+\Gamma_{j i}^{\prime} \boldsymbol{\psi}_{i \ell}(\Delta \mathbf{y}, 1)+\omega_{\xi, j i} \mathcal{Z}^{(r)}
$$

where $\mathcal{Z}^{(r)} \sim \operatorname{IIN}(0,1)$.

In the case of our empirical application where the log of oil prices is the only global variable in the model, the effect of a unit unanticipated shock to oil prices, $P_{t}^{o}$, can be simulated by generating the returns as

\footnotetext{
${ }^{42}$ Note that $\mathfrak{s}_{\ell}^{\prime} \boldsymbol{\Sigma} \mathfrak{s}_{\ell}=\sigma_{i i, \ell \ell}$.
}

$$
r_{i j, T+1}^{o,(r)}=\mu_{j i, T+1 \mid T}+\Gamma_{j i}^{\prime} \boldsymbol{\psi}_{o}(\Delta \mathbf{y}, 1)+\omega_{\xi, j i,} \mathcal{Z}^{(r)}
$$


where

$$
\boldsymbol{\psi}_{o}(\Delta \mathbf{y}, 1)=\frac{1}{\sigma_{o}} \mathfrak{D} \boldsymbol{\Sigma}_{\boldsymbol{v} \mathfrak{s}_{o}}=\sigma_{o}\left(\begin{array}{c}
\Upsilon_{0} \\
1
\end{array}\right)
$$

$\sigma_{o}^{2}$ is the variance of oil price shock, $\varepsilon_{o t}, \mathfrak{s}_{o}$ is a $(k+1) \times 1$ vector of zeros except for its last element which is set equal to unity, such that $\mathfrak{s}_{o}^{\prime} \boldsymbol{v}_{t}=\varepsilon_{o t}$. It is also worth noting that

$$
\Gamma_{j i}^{\prime} \boldsymbol{\psi}_{o}(\Delta \mathbf{y}, 1)=\sigma_{o}\left(\mathbf{B}_{j i}^{\prime} \mathbf{W}_{i} \boldsymbol{\Upsilon}_{0}+\boldsymbol{\gamma}_{j i}^{\prime}\right)=\sigma_{o} \theta_{j i, o}
$$

simplifying the oil shock-conditional first period return to

$$
r_{i j, T+1}^{o,(r)}=\mu_{j i, T+1 \mid T}+\sigma_{o} \theta_{j i, o}+\omega_{\xi, j i} \mathcal{Z}^{(r)}
$$

This expression clearly shows that, relative to the baseline, the mean is increased by $\sigma_{o} \theta_{j i, o}{ }^{43}$

The baseline loss distributions can also be simulated directly using the draws

$$
r_{i j, T+1}^{(r)}=\mu_{j i, T+1 \mid T}+\omega_{\xi, j i} \mathcal{Z}^{(r)},
$$

where the baseline return variance $\omega_{\xi, j i}^{2}$ is defined by (42). Default occurs if the $r^{t h}$ simulated return falls below the threshold $\hat{c}_{j i}$ defined by $(6)$ :

$$
\begin{aligned}
\text { Baseline } r_{i j, T+1}^{(r)}<\hat{c}_{j i} \Longrightarrow \text { Default, } \\
\text { Macro-shock-Conditional } r_{i j, T+1}^{i l,(r)}<\hat{c}_{j i} \Longrightarrow \text { Default, } \\
\text { Oil-shock-Conditional } r_{i j, T+1}^{o,(r)}<\hat{c}_{j i} \Longrightarrow \text { Default. }
\end{aligned}
$$

Using these results in (48), the loss distribution can be simulated for any desired level of accuracy by selecting $R$, the number of replications, to be sufficiently large.

Finally, it is might also be of interest to compare the base line default probability, $\pi_{j i, T+1 \mid T}$, given by (41) with the default probability that results under the (unanticipated) shock to $x_{i, T+1, \ell}$, which we denote by $\pi_{j i, T+1 \mid T}^{i \ell}$. We have

$$
\pi_{j i, T+1 \mid T}=\Phi\left(\frac{\hat{c}_{j i}-\mu_{j i, T+1 \mid T}}{\omega_{\xi, j i}}\right)
$$

and

$$
\pi_{j i, T+1 \mid T}^{i \ell}=\Phi\left(\frac{\hat{c}_{j i}-\mu_{j i, T+1 \mid T}-\Gamma_{j i}^{\prime} \boldsymbol{\psi}_{i \ell}(\Delta \mathbf{y}, 1)}{\omega_{\xi, j i}}\right) .
$$

The above results readily extend to the case where the shocks follow multivariate $\mathrm{t}$ distributions with the same degrees of freedom. In this more general case the linear

\footnotetext{
${ }^{43}$ For an anticipated oil price shock the variance term $\omega_{\xi, j i}^{2}$ in (55) needs to be replaced by $\omega_{\xi, j i, o}^{2}=\omega_{\eta, j i}^{2}+\boldsymbol{\theta}_{j i}^{\prime} \boldsymbol{\Sigma}_{\varepsilon} \boldsymbol{\theta}_{j i}$.
} 
combinations of t-distributed shocks would still be t-distributed and the simulated returns in the case of a unit shock to $x_{i, T+1, \ell}$ will be given by

$$
r_{i j, T+1}^{l,(r)}=\mu_{j i, T+1 \mid T}+\Gamma_{j i}^{\prime} \boldsymbol{\psi}_{i \ell}(\Delta \mathbf{y}, 1)+\omega_{\xi, j i}\left(\sqrt{\frac{v-2}{v}}\right) \mathcal{T}_{v}^{(r)}
$$

where $\mathcal{T}_{v}^{(r)}$ are draws from the Student $t$ with $v$ degrees of freedom. ${ }^{44}$ Similarly, for the simulation of the baseline loss distribution we need to use the draws

$$
r_{i j, T+1}^{(r)}=\mu_{j i, T+1 \mid T}+\omega_{\xi, j i}\left(\sqrt{\frac{v-2}{v}}\right) \mathcal{T}_{v}^{(r)} .
$$

\subsection{Simulation of Multi-Step Ahead Loss Distributions}

Simulation of loss distributions over more than one period ahead poses new difficulties. We are now presented with the problem of simulating from the joint probability distribution function of future returns $\left(r_{j i, T+1}, r_{j i, T+2}, \ldots, r_{j i, T+n}\right)$, conditional on $\Omega_{T}$, where $n$ is the forecast horizon. Using (18) in (35) we have

$$
r_{i j, T+\kappa}=\mu_{j i, T+\kappa \mid T}+\xi_{j i, T+\kappa}, \text { for } \kappa=1,2, \ldots, n
$$

where

$$
\begin{aligned}
\mu_{j i, T+\kappa \mid T} & =\alpha_{j i}+\Gamma_{j i}^{\prime}\left[\left(\boldsymbol{\Phi}^{\kappa}-\boldsymbol{\Phi}^{\kappa-1}\right) \mathbf{y}_{T}+\mathfrak{g}(T, \kappa)\right] \\
\xi_{j i, T+\kappa} & =\Gamma_{j i}^{\prime} \mathcal{U}_{T+\kappa}+\eta_{j i, T+\kappa}
\end{aligned}
$$

and

$$
\mathcal{U}_{T+\kappa}=\mathfrak{D} \boldsymbol{v}_{T+\kappa}+\sum_{\tau=1}^{\kappa-1}\left(\boldsymbol{\Phi}^{\tau}-\boldsymbol{\Phi}^{\tau-1}\right) \mathfrak{D} \boldsymbol{v}_{T+\kappa-\tau}
$$

is the composite systematic (i.e. non-idiosyncratic) innovation over future periods $T+\kappa=1,2, \ldots, n$. It is clear that at time $T$, the conditional mean returns, $\mu_{j i, T+\kappa \mid T}$ $, \kappa=1,2, \ldots, n$, are known insofar as they are forecast. It is also easily seen that the unpredictable components of the returns over the different horizons have the following recursive structure:

$$
\begin{aligned}
\xi_{j i, T+1}= & \Gamma_{j i}^{\prime} \mathcal{H}_{0} \mathfrak{D} \boldsymbol{v}_{T+1}+\eta_{j i, T+1} \\
\xi_{j i, T+2}= & \Gamma_{j i}^{\prime} \mathcal{H}_{1} \mathfrak{D} \boldsymbol{v}_{T+1}+\Gamma_{j i}^{\prime} \mathcal{H}_{0} \mathfrak{D} \boldsymbol{v}_{T+2}+\eta_{j i, T+2} \\
& \vdots \\
\xi_{j i, T+n}= & \Gamma_{j i}^{\prime} \mathcal{H}_{n-1} \mathfrak{D} \boldsymbol{v}_{T+1}+\Gamma_{j i}^{\prime} \mathcal{H}_{n-2} \mathfrak{D} \boldsymbol{v}_{T+2}+\ldots .+\Gamma_{j i}^{\prime} \mathcal{H}_{0} \mathfrak{D} \boldsymbol{v}_{T+n}+\eta_{j i, T+n}
\end{aligned}
$$

${ }^{44}$ Note that $\operatorname{Var}\left(\mathcal{T}_{v}^{(r)}\right)=v /(v-2)$. 
where

$$
\mathcal{H}_{\kappa}=\boldsymbol{\Phi}^{\kappa}-\boldsymbol{\Phi}^{\kappa-1}, \kappa=1,2, \ldots, n \text { and } \mathcal{H}_{0}=\mathbf{I}_{k+s} .
$$

Recall that the matrix $\boldsymbol{\Phi}$ collects all the GVAR coefficients other than constants and trends and thus characterizes the effect of initial values $\mathbf{y}_{T}$ on the future state of the macroeconomic system (see (17)). Therefore, the conditional distribution of the returns across the different forecast horizons are correlated, and in the simulation of the loss distribution one needs to draw from the joint distribution of $\mathbf{r}_{j i}=\left(r_{j i, T+1}, r_{j i, T+2}, \ldots, r_{j i, T+n}\right)^{\prime}$. For this purpose we note that $\xi_{j i, T+\kappa}, \kappa=1,2, . ., n$, have zero means and a variance covariance matrix $\operatorname{Var}\left(\mathbf{r}_{j i}\right)$ whose $(\mathfrak{w}, \mathfrak{n})$ element is given by

$$
\begin{aligned}
& \Gamma_{j i}^{\prime}\left(\sum_{\tau=1}^{\mathfrak{m}} \mathcal{H}_{\mathfrak{w}-\tau} \mathfrak{B} \mathcal{H}_{\mathfrak{w}-\tau}^{\prime}\right) \Gamma_{j i}+\omega_{\eta, j i}^{2}, \text { if } \mathfrak{w}=\mathfrak{n}, \\
& \Gamma_{j i}^{\prime}\left(\sum_{\tau=1}^{\operatorname{Min}(\mathfrak{m}, \mathfrak{n})} \mathcal{H}_{\mathfrak{m}-\tau} \mathfrak{B} \mathcal{H}_{\mathfrak{n}-\tau}^{\prime}\right) \Gamma_{j i}, \quad \text { if } \mathfrak{w} \neq \mathfrak{n},
\end{aligned}
$$

where $\mathfrak{B}=\mathfrak{D} \Sigma_{v} \mathfrak{D}^{\prime}$.

Alternatively, the returns can be simulated using the relations

$$
r_{i j, T+\kappa}^{(r)}=\mu_{j i, T+\kappa \mid T}+\xi_{j i, T+\kappa}^{(r)}, \text { for } \kappa=1,2, \ldots, n,
$$

where

$$
\xi_{j i, T+\kappa}^{(r)}=\sum_{\tau=0}^{\kappa-1}\left(\Gamma_{j i}^{\prime} \mathcal{H}_{\tau} \mathfrak{B} \mathcal{H}_{\tau}^{\prime} \Gamma_{j i}\right)^{1 / 2} Z_{\tau}^{(r)}+\omega_{\eta, j i} Z_{\eta \kappa}^{(r)},
$$

where $Z_{0}^{(r)}, Z_{1}^{(r)}, \ldots, Z_{n-1}^{(r)} ; Z_{\eta 1}^{(r)}, Z_{\eta 2}^{(r)}, \ldots, Z_{\eta n}^{(r)}$ are draws from $\operatorname{IID} N(0,1)$.

\subsubsection{Baseline Multi-period Loss Distribution}

The loss distribution due to default by firm $j$ in region $i$ over the period $T$ to $T+n$ can now be written as

$$
\begin{aligned}
L_{j i}(T+1, T+n)= & L_{j i, T+1}+\lambda I\left(r_{j i, T+1} \geq \hat{c}_{j i}\right) L_{j i, T+2} \\
& +\ldots+\lambda^{n-1}\left[\prod_{\tau=1}^{n-1} I\left(r_{j i, T+\tau} \geq \hat{c}_{j i}\right)\right] L_{j i, T+n}
\end{aligned}
$$

where $\lambda$ is a discount factor $(0 \leq \lambda<1$, could be set as $\lambda=1 /(1+\rho)$ with $\rho$ being an average real rate of interest) and

$$
L_{j i, T+\kappa}=I\left(r_{j i, T+\kappa}<\hat{c}_{j i}\right) \mathcal{X}_{j i, T+\kappa} \mathcal{S}_{j i, T+\kappa}, \text { for } \kappa=1,2, \ldots, n
$$


The multi-period loss expression (63) can be thought of as a survival function which progressively computes loss in period $T+\tau+1$ only if the firm has survived the previous period $T+\tau$. Using this architecture the multi-period baseline loss distribution can be simulated using the draws $r_{j i, T+\tau}^{(r)}$, for $\tau=1,2, . ., n$ and $r=$ $1,2, \ldots, R$ (see $(61))$, the empirical distribution of $L_{j i}(T+1, T+n)$ can be constructed from $L_{j i}^{(r)}(T+1, T+n)$ where

$$
L_{j i}^{(r)}(T+1, T+n)=L_{j i, T+1}^{(r)}+\sum_{t=2}^{n} \lambda^{t-1}\left[\prod_{\tau=1}^{t-1} I\left(r_{j i, T+\tau}^{(r)} \geq \hat{c}_{j i}\right)\right] L_{j i, T+t}^{(r)}
$$

and

$$
L_{j i, T+\kappa}^{(r)}=I\left(r_{j i, T+\kappa}^{(r)}<\hat{c}_{j i}\right) \mathcal{X}_{j i, T+\kappa}^{(r)} \mathcal{S}_{j i, T+\kappa}^{(r)}, \text { for } \kappa=1,2, \ldots, n .
$$

Aggregating across firms, we finally obtain the time $T$ conditional, $n$ step-ahead simulated loss distribution of the credit portfolio:

$$
L^{(r)}(T+1, T+n)=\sum_{i=0}^{N} \sum_{j=1}^{n c_{i}} L_{j i}^{(r)}(T+1, T+n), r=1,2, \ldots, R .
$$

\subsubsection{Multi-period Loss Distribution Given Economic Shocks}

Consider now the effect of a one standard error shock to factor $\ell$ in country $i$ on the multi-period loss distribution. Using the results in Section 4.3 on impulse responses we have

$$
r_{i j, T+\kappa}^{i \ell,(r)}=\mu_{j i, T+\kappa \mid T}+\Gamma_{j i}^{\prime} \psi_{i \ell}(\Delta \mathbf{y}, \kappa)+\xi_{j i, T+\kappa}^{i \ell,(r)}, \text { for } \kappa=1,2, \ldots, n,
$$

where $\boldsymbol{\psi}_{i \ell}(\Delta \mathbf{y}, \kappa)$ is defined by $(27)$ and

$$
\xi_{j i, T+\kappa}^{i \ell,(r)}=\left(\Gamma_{j i}^{\prime} \mathfrak{B}_{j i}\right)^{1 / 2} Z_{0}^{(r)}+\sum_{\tau=1}^{\kappa-1}\left(\Gamma_{j i}^{\prime} \mathcal{H}_{\tau} \mathfrak{B} \mathcal{H}_{\tau}^{\prime} \Gamma_{j i}\right)^{1 / 2} Z_{\tau}^{(r)}+\omega_{\eta, j i} Z_{\eta \kappa}^{(r)},
$$

where as before $\mathfrak{B}=\mathfrak{D} \boldsymbol{\Sigma}_{v} \mathfrak{D}^{\prime}$. Since $\Delta \mathbf{y}$ contains both the endogenous macroeconomic variables $\Delta \mathbf{x}$ as well as the exogenous global variable $\Delta \mathbf{d}$, oil prices in our applications, we no longer need to derive a separate expression for oil price shocks. Note also that the second term in (65) will be zero when $\kappa=1$.

Clearly, the Student $t$ random draws, $\left(\sqrt{\frac{v-2}{v}}\right) \mathcal{T}_{v}^{(r)}$, can also be used instead of the Normal draws, $Z^{(r)}$, in the simulation of the loss distributions, as in (59) and (60). 


\section{Estimation of GVAR}

\subsection{Region and Country Settings}

We estimate a global quarterly model over the period 1979Q1-1999Q1 comprising a total of 25 countries which are grouped into eleven regions (shown in bold in Table 1). The advantage of the GVAR is that it allows for a true multi-country setting; however it can become computationally demanding very quickly. For that reason we model the seven key economies of the U.S., Japan, China, Germany, U.K., France and Italy as regions of their own while grouping the other 19 countries into four regions. ${ }^{45}$

Table 1

Countries/Regions in the GVAR Model

\begin{tabular}{|c|c|c|}
\hline U.S.A. & Germany & Japan \\
\hline Western Europe & South East Asia & Latin America \\
\hline -Spain & ·Korea & ·Argentina \\
\hline -Belgium & -Thailand & ·Brazil \\
\hline - Netherlands & -Indonesia & Chile \\
\hline \multirow[t]{3}{*}{-Switzerland } & ·Malaysia & $\cdot$ Peru \\
\hline & -Philippines & $\cdot$ Mexico \\
\hline & ·Singapore & \\
\hline Middle East & China & France \\
\hline ·Kuwait & U.K. & Italy \\
\hline \multicolumn{3}{|l|}{-Saudi Arabia } \\
\hline ·Turkey & & \\
\hline
\end{tabular}

The output from these countries comprise around $80 \%$ of world GDP (in 1999). They were chosen largely because the major banks in G-7 countries have much of their exposure in this set of countries. Noticeably absent are Scandinavian countries, Africa and Australia-New Zealand. Future extensions of the model will look to incorporate countries from these regions. Time series data on regions such as Latin America or South East Asia were constructed from each country in the region weighted by the GDP share. For this we used purchasing power parity (PPP)-weighted GDP figures, which is thought to be more reliable than using weights based on U.S. dollar GDPs. ${ }^{46}$ For credit risk modeling purposes we distinguish between the regions with developed capital markets, namely U.S., Germany, Japan, Western European countries, South East Asia and Latin America, and the rest, namely China and Middle East, which

\footnotetext{
${ }^{45}$ See PSW, Section 8, for details on cross-country aggregation into regions.

${ }^{46}$ PPP figures are from June 1996, Penn World Tables.
} 
over our sample period may not have had fully developed capital markets. Finally, as noted earlier, the U.S. dollar will be used as the numeraire exchange rate and its value in terms of the other currencies will be determined outside the U.S. model.

\subsection{Macroeconomic Variables and Data Sources}

The vector $\mathbf{x}_{i t}$ is defined as the $k_{i} \times 1$ country-specific factors/variables. A typical set of endogenous variables ${ }^{47}$ for country $i(i \neq 0)$, is:

$$
\left.\begin{array}{rl}
y_{i t} & =\ln \left(G D P_{i t} / C P I_{i t}\right), \\
p_{i t} & =\ln \left(C P I_{i t}\right), \\
q_{i t} & =\ln \left(E Q_{i t} / C P I_{i t}\right), \\
m_{i t} & =\ln \left(M_{i t} / C P I_{i t}\right), \\
e_{i t} & =\ln \left(E_{i t}\right), \\
\rho_{i t} & =0.25 * \ln \left(1+R_{i t} / 100\right),
\end{array}\right\}
$$

where $^{48}$

$$
\begin{aligned}
& G D P_{i t}= \begin{array}{c}
\text { Nominal Gross Domestic Product of country } i \text { during period } t, \\
\text { in domestic currency }
\end{array} \\
& C P I_{i t}= \text { Consumer Price Index in country } i \text { at time } t \text {, equal to } 1.0 \\
& \quad \text { in a base year (say 1996) }
\end{aligned}
$$

The GVAR uses quarterly data covering 21 years from 1979Q1 to 1999Q1. Main data sources are the International Financial Statistics (IFS), Datastream and Data Resources Incorporated (DRI). Note that in the case of the base economy (i.e. the U.S. in the current model), $e_{0 t}=0$. Therefore $k_{0}=5$. In addition to that, the full set of macroeconomic factors is not available for all regions (especially due to the dearth of data in emerging markets). Table 2 represents available data for the eleven regions.

\footnotetext{
${ }^{47}$ Other variables are certainly possible. For credit risk applications, one might also want to include more financial market information, e.g. credit spreads, and perhaps aggregate default or bankruptcy rates. However, we wanted to restrict our macroeconomic variable set to be small and easily measured across a wide set of countries. Arguably these six variables reasonably span the relevant economic space in our "world" of 26 countries.

${ }^{48}$ Note that the last transformation specified in (66) converts the annual rate of interest, $R_{i t}$, to quarterly interest rate, $\rho_{i t}$, using a logarithmic scale.
} 
Table 2

Domestic Variables and Global Variables by Region

\begin{tabular}{|c|c|c|c|c|c|c|c|c|c|c|c|c|c|c|}
\hline \multirow[b]{2}{*}{ Region } & \multicolumn{6}{|c|}{ Domestic Variables } & \multirow[b]{2}{*}{$k_{i}$} & \multicolumn{6}{|c|}{ Foreign Variables } & \multirow[b]{2}{*}{$k_{i}^{*}$} \\
\hline & $y_{i t}$ & $p_{i t}$ & $q_{i t}$ & $m_{i t}$ & $e_{i t}$ & $r_{i t}$ & & $y_{i t}^{*}$ & $p_{i t}^{*}$ & $q_{i t}^{*}$ & $m_{i t}^{*}$ & $e_{i t}^{*}$ & $r_{i t}^{*}$ & \\
\hline U.S.A & $\checkmark$ & $\checkmark$ & $\checkmark$ & $\checkmark$ & - & $\checkmark$ & 5 & - & - & - & - & $\checkmark$ & - & 1 \\
\hline U.K. & $\checkmark$ & $\checkmark$ & $\checkmark$ & $\checkmark$ & $\checkmark$ & $\checkmark$ & 6 & $\checkmark$ & $\checkmark$ & $\checkmark$ & $\checkmark$ & - & $\checkmark$ & 5 \\
\hline Germany & $\checkmark$ & $\checkmark$ & $\checkmark$ & $\checkmark$ & $\checkmark$ & $\checkmark$ & 6 & $\checkmark$ & $\checkmark$ & $\checkmark$ & $\checkmark$ & - & $\checkmark$ & 5 \\
\hline France & $\checkmark$ & $\checkmark$ & $\checkmark$ & $\checkmark$ & $\checkmark$ & $\checkmark$ & 6 & $\checkmark$ & $\checkmark$ & $\checkmark$ & $\checkmark$ & - & $\checkmark$ & 5 \\
\hline Italy & $\checkmark$ & $\checkmark$ & $\checkmark$ & $\checkmark$ & $\checkmark$ & $\checkmark$ & 6 & $\checkmark$ & $\checkmark$ & $\checkmark$ & $\checkmark$ & - & $\checkmark$ & 5 \\
\hline W. Europe & $\checkmark$ & $\checkmark$ & $\checkmark$ & $\checkmark$ & $\checkmark$ & $\checkmark$ & 6 & $\checkmark$ & $\checkmark$ & $\checkmark$ & $\checkmark$ & - & $\checkmark$ & 5 \\
\hline Mid East & $\checkmark$ & $\checkmark$ & - & $\checkmark$ & $\checkmark$ & $\checkmark$ & 5 & $\checkmark$ & $\checkmark$ & $\checkmark$ & $\checkmark$ & - & $\checkmark$ & 5 \\
\hline China & $\checkmark$ & $\checkmark$ & - & $\checkmark$ & $\checkmark$ & $\checkmark$ & 5 & $\checkmark$ & $\checkmark$ & $\checkmark$ & $\checkmark$ & - & $\checkmark$ & 5 \\
\hline S.E. Asia & $\checkmark$ & $\checkmark$ & $\checkmark$ & $\checkmark$ & $\checkmark$ & $\checkmark$ & 6 & $\checkmark$ & $\checkmark$ & $\checkmark$ & $\checkmark$ & - & $\checkmark$ & 5 \\
\hline Japan & $\checkmark$ & $\checkmark$ & $\checkmark$ & $\checkmark$ & $\checkmark$ & $\checkmark$ & 6 & $\checkmark$ & $\checkmark$ & $\checkmark$ & $\checkmark$ & - & $\checkmark$ & 5 \\
\hline \multirow[t]{2}{*}{ L. America } & $\checkmark$ & $\checkmark$ & $\checkmark$ & $\checkmark$ & $\checkmark$ & $\checkmark$ & 6 & $\checkmark$ & $\checkmark$ & $\checkmark$ & $\checkmark$ & - & $\checkmark$ & 5 \\
\hline & & & & & & & 63 & & & & & & & 51 \\
\hline
\end{tabular}

In total, there are 63 region-specific domestic macroeconomic variables or factors and therefore 63 equations to estimate, albeit not simultaneously. The problem of endogeneity is mitigated in this version of the GVAR by allowing for only one global variable for the U.S. - the exchange rate. Feedback mechanisms are thus confined to the channel of the exchange rate. For all other regions, the exchange rate $e_{i t}^{*}$ is omitted as a global variable. ${ }^{49}$ Details of the estimated model, unit root tests, residual serial correlation test and tests of weak exogeneity of foreign-specific variables (namely $\mathbf{x}_{i t}^{*}$ ) can be found in PSW. We also checked that all the 64 elements of $\mathfrak{g}(T, n)$ defined by (19) do in fact converge to finite limits as $n \rightarrow \infty$. Recall from our discussion at the end of Section 4.1 that the existence of the limit of $\mathfrak{g}(T, n)$ as $n \rightarrow \infty$ is a necessary condition for the existence of $E\left(\Delta \mathbf{y}_{T+n} \mid \Omega_{T}\right)$ which is one of the key components of the multi-step ahead loss distributions.

\footnotetext{
${ }^{49}$ Bearing in mind that the exchange rate is defined in terms of U.S. dollars, the currency of the base economy, a depreciation of the currencies in the rest of the world is per definition equal to an appreciation of the U.S. dollar. Given this "mirror" relationship, it should suffice to incorporate the exchange rate mechanism as mentioned above.
} 


\section{$7 \quad$ Credit Loss Results}

\subsection{Estimating $P D$ s and Default Thresholds}

Using methods described in Lando and Skødeberg (2002) and Schuermann and Jafry (2003), we obtain quarterly $P D$ estimates from time homogeneous transition intensities using ratings histories for firms rated by Moody's from January 1, 1979 to March 31, 1999, i.e. 1979Q1 to 1999Q1. The transition intensity approach uses techniques from survival analysis which make efficient use of ratings histories to obtain transition probabilities. This becomes especially important for the estimation of the transition from rating $\mathcal{R}$ to default, denoted here as $P D_{\mathcal{R}_{t}}$. No default event may have occurred within a particular quarter; that does not, however, necessarily mean that $P D_{\mathcal{R}_{t}}=0$. The transition intensity approach may still yield a positive probability of default for highly rated obligors even though no default was observed during the sampling period. It suffices that an obligor migrated from, say, Aaa to $A a$ to $A$, and then defaulted, to contribute probability mass to $P D_{A a a_{t}}$. Still, there may be instances when there is no movement at all during a particular quarter. In that case the estimated default probability would indeed be identically equal to zero.

For each quarter and each rating-specifc $P D, P D_{\mathcal{R}_{t}}$, we compute the inverse CDF to obtain a time series of rating specific thresholds. ${ }^{50}$ Since Moody's only rates a subset of large firms (in 1979 they rated 1190 firms of which about $98 \%$ were U.S. domiciled; by early 1999 this had risen to 3710, about $80 \%$ U.S.), it is reasonable to assign a non-zero (albeit very small) probability of default, even if the empirical estimate is zero. After all, we may want to infer default behavior for a much broader universe of firms than is covered by the rating agencies. Hence we impose a lower bound on the quarterly $P D$ and their implied thresholds at a $P D$ value of $1 / 100,000$ per annum, corresponding to $1 / 250,000$ or 0.025 basis points per quarter.

Table 3 presents quarterly $P D$ estimates obtained using the transition intensity approach with Moody's rating histories from 1979Q1 - 1999Q1. Specifically, the table presents the $P D$ implied by the average of quarterly inverse CDFs which we use to compute the default threshold $\hat{c}_{j i}$. The averages are weighted by the number of obligors rated at the beginning of each quarter. Default probabilities exhibit the expected sharp increase as we descend the credit spectrum.

\footnotetext{
${ }^{50}$ While (5) and (6) are written in terms of a standard normal distribution, other distributions such as (standard) student-t can be substituted.
} 


\section{Table 3}

Quarterly $P D$ Estimates from

Moody's Rating Histories

\begin{tabular}{lc} 
(1979Q1 - 1999Q1) \\
\hline Rating & $\begin{array}{c}\text { PDverse CDF } \\
\text { (in Basis Points) }\end{array}$ \\
\hline Aaa & 0.0250 \\
Aa & 0.0276 \\
A & 0.0309 \\
Baa & 0.0748 \\
Ba & 2.0486 \\
B & 52.505 \\
Caa & 131.599 \\
\hline
\end{tabular}

Following the discussion in Section 3.2, average critical values $\overline{D T}_{\mathcal{R} j i}$ (recall that $\overline{D T}_{\mathcal{R} j i}=\frac{1}{T} \sum_{t=1}^{T} D T\left(\mathcal{R}_{j i t}\right)$ where $\left.D T\left(\mathcal{R}_{j i t}\right)=\Phi^{-1}\left(P D\left(\mathcal{R}_{j i t}\right)\right)\right)$ are used to compute default thresholds $\hat{c}_{j i}$ in (6).

\subsection{The Sample Portfolio}

We analyze the effects of economic shocks on a fictitious large-corporate loan portfolio which is summarized in Table 4. It contains a total of 119 companies, resident over ten of the eleven regions. In order for a firm to enter our sample, several criteria had to be met. We restricted ourselves to major, publicly traded firms which had a credit rating from either Moody's or S\&P. Thus, for example, Chinese companies are not included for lack of a credit rating. The firms should be represented within the major equity index for that country. We favored firms for which equity return data was available for the entire sample period, i.e. going back to 1979. Typically this would exclude large firms such as telephone operators which in many instances have only been privatized recently, even though they might now represent a significant share in their country's dominant equity index. The data source is Datastream, and we took their Total Return Index variable which is a cum dividend return measure.

The column to the right in Table 4 indicates the inception of the equity series available for APT-type regression analysis. We wanted to mimic (broadly) the portfolio of a large, internationally active bank. Arbitrarily picking Germany as the bank's domicile country, the portfolio is relatively more exposed to German 
firms than would be the case if exposure were allocated purely on a GDP share (in our "world" of 25 countries). For the remaining regions, exposure was more in line with GDP share. Within a region, loan exposure is randomly assigned. The expected severity for loans to U.S. companies is the lowest at $20 \%$, based upon studies by Citibank, Fitch Investor Service and Moody's Investor Service. ${ }^{51}$ All other severities are based on assumptions, reflecting the idea that severities are higher in less developed countries. Table 4 gives the portfolio composition, regional weights, individual exposures and expected $\left(\mu_{\beta}\right)$ and unexpected $\left(\sigma_{\beta}\right)$ severities. $^{52}$

\footnotetext{
${ }^{51}$ As cited in Saunders and Allen (2002).

${ }^{52}$ Mean severity is assumed to be slightly lower in Germany (as compared to France or U.K., for example), since Germany is assumed to be the bank's domicile country and hence the bank may have some local advantages in the recovery of distress assets. Unexpected severity refers to standard deviation of severity distribution assumed here to be Beta distributed.
} 
Table 4

The Composition of the Sample Portfolio for Regions

\begin{tabular}{|c|c|c|c|c|c|c|}
\hline \multirow[b]{2}{*}{ Region } & \multirow[b]{2}{*}{ \# Obligors } & \multirow{2}{*}{$\begin{array}{c}\text { Equity Series }{ }^{1} \\
\text { Quarterly }\end{array}$} & \multirow{2}{*}{$\begin{array}{c}\text { Credit Rating }^{2} \\
\text { Range }\end{array}$} & \multirow{2}{*}{$\begin{array}{l}\text { Portfolio } \\
\text { Per cent }\end{array}$} & \multicolumn{2}{|c|}{ Severity $^{3}$} \\
\hline & & & & & Mean & S.D. \\
\hline & & & & & $\left(\mu_{\beta}\right)$ & $\left(\sigma_{\beta}\right)$ \\
\hline U.S. & 14 & 79Q1 - 99Q1 & AAA to BBB- & 20 & $20 \%$ & $10 \%$ \\
\hline U.K. & 9 & 79Q1 - 99Q1 & $\mathrm{AA}$ to $\mathrm{BBB}+$ & 6 & $35 \%$ & $15 \%$ \\
\hline Germany & 18 & 79Q1 - 99Q1 & AAA to BBB- & 21 & $30 \%$ & $15 \%$ \\
\hline France & 8 & 79Q1 - 99Q1 & $\mathrm{AA}$ to $\mathrm{BBB}$ & 8 & $35 \%$ & $15 \%$ \\
\hline Italy & 6 & 79Q1 - 99Q1 & A to BBB- & 8 & $35 \%$ & $15 \%$ \\
\hline W. Europe & 12 & 79Q1 - 99Q1 & $\mathrm{AAA}$ to $\mathrm{BBB}+$ & 8 & $35 \%$ & $15 \%$ \\
\hline Middle East & 4 & 90Q3 - 99Q1 & B- & 2 & $60 \%$ & $20 \%$ \\
\hline S.E. Asia & 23 & 89Q3 - 99Q1 & A to $\mathrm{B}$ & 10 & $50 \%$ & $20 \%$ \\
\hline Japan & 13 & 79Q1 - 99Q1 & AAA to $\mathrm{B}+$ & 10 & $35 \%$ & $15 \%$ \\
\hline L. America & 12 & 89Q3 - 99Q1 & A to B- & 5 & $65 \%$ & $20 \%$ \\
\hline Total & 119 & - & - & 100 & - & - \\
\hline
\end{tabular}

1. Equity prices of companies in emerging markets are not available over the full sample period used for the estimation horizon of the GVAR. We have a complete series for all firms only for the U.S., U.K., Germany and Japan. For France, Italy and W. Europe, although some of the series go back through 1979Q1, data was available for all firms from 1987Q4 (France), 1987Q4 (Italy), 1989Q3

(W. Europe). We used that sample range for the APT regressions for those regions. For L. America we have a complete sample range for all firms from 1990Q2.

2. The sample contains a mix of Moody's and S\&P ratings, although $\mathrm{S} \& \mathrm{P}$ rating nomenclature is used for convenience.

3. Severity is drawn from a beta distribution with mean $\mu_{\beta}$ and standard deviation $\sigma_{\beta}$.

\subsection{APT Regressions}

\subsubsection{Factor Selection Process}

With the GVAR framework serving as the global economic engine, we make use of the APT model to capture systematic risk for use in the firm default model. Equation (32) above lays out the general form of the APT regressions, but a closer look at this specification reveals two important issues. First, given the diverse nature of the operations of the firms in our portfolio, one is tempted to included all the domestic, foreign and global factors (i.e. oil price changes) in the APT regressions. This general approach may be particularly important in the case where a multinational is resident in one country, but the bulk of its operations takes place in the global 
arena. However, because there is likely to be a high degree of correlation between some of the domestic and foreign variables (e.g. real equity prices and interest rates), it is by no means obvious how to proceed with the model selection process.

Secondly, because not all regressors, be they foreign or domestic, are likely to be statistically significant, it may be efficient to restrict those insignificant coefficients to zero for subsequent loss simulation purposes. To this end two possible approaches can be followed. A standard procedure would be to apply regressor selection methods to each of the firm-specific APT regressions separately. Since we have 119 firms in our portfolio with as many as $13^{53}$ estimated coefficients each, the application of such a procedure besides being very time-consuming can be subject to a considerable degree of specification searches with undesirable consequences. Alternatively, we could view the 119 APT regressions as forming a panel with heterogeneous slope coefficients. ${ }^{54}$ Such panels have been studied recently by Pesaran and Smith (1995) and Pesaran, Smith and Im (1996), where it is shown that instead of considering firm-specific estimates one could base the analysis on the means of the estimated coefficients, referred to as the mean group estimators (MGE). This approach assumes that the variations of factor loadings, $\beta_{j i, \ell}$ and $\beta_{j i, \ell}^{*}$ in (32) across firms in different regions are approximately randomly distributed around the fixed means, $\beta_{\ell}$ and $\beta_{\ell}^{*}$. This is the standard random coefficient model used extensively in the panel literature. The choice of the factors in the APT regressions can now be based on the statistical significance of the (population) mean coefficients, $\beta_{\ell}$ and $\beta_{\ell}^{*}$, by using the MGE to select the slimmed-down regressor set. The appropriate test statistics for this purpose are given by

$$
t_{\ell}=\frac{\hat{\beta}_{\ell}}{\sqrt{\widehat{\operatorname{Var}}\left(\hat{\beta}_{\ell}\right)}} \text { and } t_{\ell}^{*}=\frac{\hat{\beta}_{\ell}^{*}}{\sqrt{\widehat{\operatorname{Var}}\left(\hat{\beta}_{\ell}^{*}\right)}},
$$

where, for $n c_{i}$ companies in region $i, i=0, \ldots, N$,

$$
\begin{aligned}
\hat{\beta}_{\ell} & =\frac{\sum_{i=0}^{N} \sum_{j=1}^{n c_{i}} \hat{\beta}_{j i, \ell}}{\sum_{i=0}^{N} n c_{i}}, \\
\widehat{\operatorname{Var}}\left(\hat{\beta}_{\ell}\right) & =\frac{\sum_{i=0}^{N} \sum_{j=1}^{n c_{i}}\left(\hat{\beta}_{j i, \ell}-\hat{\beta}_{\ell}\right)^{2}}{\left(\sum_{i=0}^{N} n c_{i}\right)\left(\sum_{i=0}^{N} n c_{i}-1\right)},
\end{aligned}
$$

and similarly for $\hat{\beta}_{\ell}^{*}$ and $\widehat{\operatorname{Var}}\left(\hat{\beta}_{\ell}^{*}\right) \cdot{ }^{55}$

\footnotetext{
${ }^{53}$ One constant, 6 domestic, 5 foreign macroeconomic variables plus oil prices.

${ }^{54}$ While we demonstrate the model with a portfolio of 119 firms, our approach could easily be applied to a much larger portfolio.

${ }^{55} \mathrm{~A}$ similar exercise can of course be carried out at the country/region level. However, in the
} 
With these issues in mind, we are now able to take a systematic approach towards estimating the APT regressions for each firm. For all firms, we start by estimating an APT regression that includes all variables which correspond to the choice of variables in the GVAR model itself for the firm's domicile region. These regressor sets are summarized in Table 2 where we can see that the U.S. firm equations are somewhat different from those in the other regions in that the only foreign regressor included is foreign real exchange rate $\left(\Delta e^{*}\right)$, but the domestic exchange rate variable is excluded as the U.S. dollar is the numeraire currency. For the non-U.S. regressions, we apply the MGE procedure to remove insignificant variables. Because of the limited number of U.S. firms, we rely on t-statistics and the signs of individual coefficients to choose the best subset of regressors. Finally, recognizing the likely collinearity of $\Delta q$ and $\Delta q^{*}$ (the domestic and foreign equity series), we run two versions of each model, one with domestic equity and one with foreign. We choose the model with the higher adjusted R-squared, $\bar{R}^{2}{ }^{56,57}$

\subsubsection{APT Regression Results}

A summary result of the initial APT regressions are provided in Table 5 in Appendix 10 where the proportion of firms with significant APT regressions (using an F-test at the $5 \%$ level) and significant t-ratios for individual factors are given across different countries/regions. This table is not meant to convey statistical significance or lack thereof but should rather be considered as broadly descriptive of the APT regression results. For instance, the precision of the ratios (averages) depends on the number of firms in each of the cells; reporting those would make the table visually awkward.

Around $90 \%$ of those regressions were significant (using the F-test) at the $5 \%$ level. ${ }^{58}$ The F-test values in the first row of Table 5 suggest that changes in the macroeconomic factors have a significant influence on equity returns. The t-statistics for the coefficients of individual macroeconomic factors clearly single out two im-

present application we did not think the number of firms at the region level are sufficient for the MG test to be meaningful.

${ }^{56}$ Since the two non-nested APT regressions have the same number of coefficients the same result would follow if other model selection criteria are used.

${ }^{57}$ Of course, there are other approaches to choosing an APT specification for each firm. We considered (and, in fact, carried out) alternative approaches, including one which began with only domestic variables (plus oil) in the APT regressions, slimming down via MGE, and then potential substitution of foreign for domestic variables if the significance or sign of the domestic variable was called into question. In the end, we felt that taking an approach that was more consistent with the framework of the GVAR model (i.e. beginning with all of the GVAR models and then paring the model down) was more appropriate.

${ }^{58}$ In PSW by comparison, where only the domestic variables (plus oil price) entered the APT regressions, around $80 \%$ of those regressions attained this significance level. 
portant ones: the domestic and foreign real equity returns. ${ }^{59}$ For regions where no full equity series could be incorporated in the GVAR, i.e. the Middle East, we cannot identify one dominant macroeconomic factor. In South East Asia, both domestic and foreign output matter, as does the exchange rate. Oil price changes are significant in about a quarter of the regressions.

Across the ten regions, variation in the macroeconomic factors explains between $25 \%$ and $50 \%$ of the total variations in firm returns, as measured by $\bar{R}^{2}$. If we have captured overall systematic risk reasonably well, the diversification benefits in an all-German portfolio (average $\bar{R}^{2}=0.29$ ) should thus be greater than for an allSouth East Asian portfolio (average $\bar{R}^{2}=0.47$ )), which seems to be more driven by systematic risk. Consequently, similarly sized macroeconomic shocks should affect loans to South East Asian obligors to a higher extent than loans to German obligors.

We now employ the MGE test in order to determine the significance of the factors using our panel of estimates, the results of which are presented in Table 6 .

Table 6

Mean Group Estimates of Factor Loadings in APT Regressions

\begin{tabular}{l|cccc}
\hline \multirow{2}{*}{ Factors } & MGE & S.E. of MGE & t-ratios & $\begin{array}{c}\text { Number of } \\
\text { Coefficients }\end{array}$ \\
& $\hat{\beta}_{\ell}\left(\hat{\beta}_{\ell}^{*}\right)$ & $\sqrt{\widehat{\operatorname{Var}}\left(\hat{\beta}_{\ell}\right)}$ & $t_{\ell}\left(t_{\ell}^{*}\right)$ & $\sum_{i=0}^{N} n c_{i}$ \\
\hline constant & 0.03 & 0.01 & 3.10 & 119 \\
$\Delta y$ & 0.39 & 0.61 & 0.64 & 119 \\
$\Delta^{2} p$ & -1.22 & 0.39 & -3.16 & 119 \\
$\Delta q$ & 0.62 & 0.07 & 9.30 & 115 \\
$\Delta e$ & 0.08 & 0.10 & 0.81 & 105 \\
$\Delta r$ & -1.43 & 0.97 & -1.47 & 119 \\
$\Delta m$ & -0.01 & 0.26 & -0.02 & 119 \\
$\Delta y^{*}$ & -2.01 & 1.15 & -1.75 & 105 \\
$\Delta^{2} p^{*}$ & -2.26 & 1.14 & -1.98 & 105 \\
$\Delta q^{*}$ & 0.48 & 0.11 & 4.28 & 105 \\
$\Delta e^{*}$ & 0.10 & 0.15 & 0.62 & 14 \\
$\Delta r^{*}$ & 5.29 & 3.21 & 1.65 & 105 \\
$\Delta m^{*}$ & -0.42 & 0.58 & -0.72 & 105 \\
$\Delta p^{o}$ & 0.15 & 0.07 & 2.13 & 119 \\
\hline
\end{tabular}

Based on the MG test results the statistically most significant factors are, perhaps not surprisingly, changes in domestic and foreign real equity prices $(\Delta q$ and

\footnotetext{
${ }^{59}$ Thus, it seems plausible to reduce the multi-factor APT-type approach to a single factor CAPM-type approach for regions where an equity series is available.
} 
$\Delta q^{*}$. The MGE of equity prices have the expected signs and their magnitudes seem plausible. For example, the estimated coefficients of changes in domestic and foreign equity prices add up to 1.10, suggesting that the composition of the loan portfolio closely matches that of a global market portfolio. Domestic inflation (and to a lesser extent foreign inflation) and oil prices were also statistically significant. Both domestic and foreign inflation have negative effects on returns, as to be expected. The overall effect of the oil price changes is, however, positive. This seems a reasonable outcome for energy and petrochemical companies and for some of the banks, although one would not expect this result to be universal. In fact we do observe considerable variations in the individual estimates of the coefficients of oil prices changes across different firms in our portfolio. Amongt the remaining factors, interest rates and foreign output are also marginally significant. The latter is difficult to explain, particularly considering that domestic output is not statistically significant and foreign output has a wrong sign. In view of this we decided to exclude both of the output variables from our subsequent analysis. Of the two interest rate variables we included the domestic rate which had the correct sign.

Our concerns regarding multicollinearity were confirmed by the regression results. Initially, we included both foreign and domestic equity variables but found implausible (negative) estimates for some of the APT regressions, which we believe partly reflects the high correlation of $\Delta q$ and $\Delta q^{*}$ in some regions. Working with APT regressions with perversely signed estimated coefficients is particularly problematic for the analysis of shock scenarios where the coefficient of equity prices plays a critical role in the transmission of shocks to the loss distribution. We ran two sets of APT regressions (including inflation, interest rate and the oil price variables); one with $\Delta q$ and another with $\Delta q^{*}$, and selected the regression with higher $\bar{R}^{2}$. The summary of the final set of APT regressions and the associated MG estimates are given in Table 7 . In this specification inflation, equity price changes and oil price changes remain the key driving factors in the APT regressions. It is also worth noting that the mean group estimate of the equity price variable is not significantly different from unity, which suggests the credit risk portfolio we have selected is close to the (global) market portfolio which has a "beta" of unity. 
Table 7

Mean Group Estimates of Factor Loadings

The Preferred Model

\begin{tabular}{l|cccc}
\hline \multirow{2}{*}{ Factors } & MGE & S.E. of MGE & t-ratios & $\begin{array}{c}\text { Number of } \\
\text { Coefficients }\end{array}$ \\
& $\hat{\beta}_{\ell}\left(\hat{\beta}_{\ell}^{*}\right)$ & $\sqrt{\widehat{\operatorname{Var}}\left(\hat{\beta}_{\ell}\right)}$ & $t_{\ell}\left(t_{\ell}^{*}\right)$ & $\sum_{i=0}^{N} n c_{i}$ \\
\hline constant & 0.02 & 0.003 & 6.14 & 119 \\
$\Delta^{2} p$ & -1.20 & 0.37 & -3.21 & 119 \\
$\Delta q / \Delta q^{*}$ & 1.08 & 0.05 & 22.36 & 119 \\
$\Delta e$ & 0.07 & 0.15 & 0.46 & 14 \\
$\Delta r^{*}$ & -1.37 & 0.98 & -1.40 & 105 \\
$\Delta p^{o}$ & 0.32 & 0.07 & 4.27 & 119 \\
\hline
\end{tabular}

\subsection{Simulated Conditional Loss Distributions}

With the estimated GVAR model serving as the economic scenario generator and the fitted APT regressions as the linkage between firms and the economy, we simulated loss distributions for three different horizons: one, four and eight-quarters ahead. ${ }^{60}$ A one year horizon is typical for credit risk management and thus of particular interest. For each horizon we examined the impact of several shock scenarios. ${ }^{61}$

- $\mathrm{a}-2.33 \sigma$ shock to real U.S. equity, corresponding to a quarterly drop of $14.28 \%$

- $\mathrm{a}+2.33 \sigma$ shock to real German output, corresponding to a quarterly rise of $2.17 \%$

- a $-2.33 \sigma$ shock to real S.E. Asian equity, corresponding to a quarterly drop of $24.77 \%$

- $\mathrm{a}+2.33 \sigma$ shock to Japanese real money supply, corresponding to a quarterly rise of $2.87 \%$

- $\mathrm{a}+2.33 \sigma$ shock to the price of crude oil, corresponding to a quarterly rise of $16.01 \%{ }^{62}$

\footnotetext{
${ }^{60}$ The important issue of credit risk model evaluation is beyond the scope of this paper; we plan to address it in subsequent work. See also Lopez and Saidenberg (2000).

${ }^{61} 2.33 \sigma$ corresponds, in the Gaussian case, to the $99 \%$ Value-at-Risk (VaR), a typical benchmark in risk management.

${ }^{62}$ The price at the end of $1999 \mathrm{Q} 1$ was $\$ 12.31$ a barrel (Brent Crude). A $+2.33 \sigma$ shock would raise the price to $\$ 14.45$.
} 
In addition we experimented with symmetric positive shocks to U.S. and S.E. Asian equity prices, and a symmetric negative shock to the price of crude oil. These are of particular interest here since their impacts on losses will not be (negatively) symmetric due to the nonlinearity of the credit risk model. We also include a stress scenario for the U.S. equity market as reported in PSW, namely an adverse shock of $8.02 \sigma$. Such a large shock corresponds to a quarterly drop of $49 \%$ which is the largest quarterly drop in the S\&P 500 index since 1928 (which occurred in the three months to May, 1932). It also corresponds to the recent decline from their peak in 2000 to a recent low (in early October, 2002). Finally we include an intermediate negative equity shock of $-5 \sigma$.

We carried out 50,000 simulations for each shock scenario using Gaussian and Student $t$ distributed (compound) innovations with 5 and 10 degrees of freedom, the former reflecting fat-tails commonly found in equity and foreign exchange rate markets, the latter being an intermediate case of fat-tailed innovations. ${ }^{63}$ All losses are discounted with a real interest rate of $2 \%$ per annum. For the forecasts and shock scenarios, we computed expected loss results, both theoretical (using (44)) and simulated (49). The two sets of estimates turn out to be very close indeed so we only report the simulated ones. The simulated expected loss results for all three simulation horizons are summarized in Table 8a, where each column represents a particular scenario. The scenarios are ordered roughly in descending order (left to right) of loss impact.

Taking first the shocks of size $2.33 \sigma$, the most significant impact on expected loss $(E L)$ comes from the the adverse shock to U.S. real equity prices. For the Gaussian case, at one quarter ahead, losses are nearly three times the baseline values (Gaussian: $3.5 \mathrm{bp}$ vs. $1.2 \mathrm{bp}$ ), but the relative magnitude declines as the forecast horizon extends; about $70 \%$ higher at four quarters (6.8bp vs. $4.0 \mathrm{bp}$ ) and just $36 \%$ higher at eight quarters (11.0bp vs. $8.1 \mathrm{bp})$. If compound innovations are taken to be Student $t$ distributed, the relative severity of the U.S. real equity price scenario compared to the baseline is less: about twice for one quarter ahead (5.2bp vs. $2.2 \mathrm{bp}$ for $t[10], 8.3 \mathrm{bp}$ vs. $4.4 \mathrm{bp}$ for $t[5]), 30-40 \%$ for four quarters ahead (13.6bp vs. $9.7 \mathrm{bp}$ for $t[10]$ and $21.6 \mathrm{bp}$ vs. $16.7 \mathrm{bp}$ for $t[5]$ ), and just $16-28 \%$ for eight quarters ahead (19.9bp vs. $15.5 \mathrm{bp}$ for $t[10]$ and $39.1 \mathrm{bp}$ vs. $33.7 \mathrm{bp}$ for $t[5])$. Not surprisingly, the expected losses increase as we go from Gaussian shocks to the $t$ distributed shocks with much fatter tails, with losses being largest in the case of $t$ distributed shocks with 5 degrees of freedom. As we shall see this pattern gets repeated as we consider other aspects of the loss distribution.

\footnotetext{
${ }^{63}$ To ensure convergence, we also performed simulations up to 200,000 runs; the results were indistinguishable from our base runs based on 50,000 replications.
} 
From a risk perspective, it is not so much expected as unexpected loss $(U L)$ which matters. This is captured in the volatility or the standard deviation of losses summarized in Table 8b, and there a similar story emerges. Taking again the $2.33 \sigma$ shock to U.S. real equity prices, the ratio of $U L_{U S E Q}$ to $U L_{b a s e l i n e}$ declines as the distribution of compound innovations becomes more fat-tailed, irrespective of whether one, four or eight quarters ahead is considered. Risk differences mitigate as the horizon extends. That ratio is 1.79 (12.0bp to 6.7bp), 1.27 and 1.14 for Gaussian, one, four and eight quarters respectively. For $t[10]$ it is 1.60 (14.9bp to $9.3 \mathrm{bp}), 1.21$ and 1.13 for one, four and eight quarters respectively, and for the most fat-tailed $t[5]$ it is a more modest $1.39(19.1 \mathrm{bp}$ vs. $13.7 \mathrm{bp}), 1.14$ and 1.08 for one, four and eight quarters respectively.

But as to be expected, the absolute levels of expected and unexpected losses are greater the fatter are the tail of the distribution assumed for the innovations. This overall pattern is consistent across shock scenarios. For a given horizon, as we move from Gaussian to $t[10]$ and then $t[5]$, losses increase as expected. As the horizon extends, an initially severe shock generates very similar $E L$ and $U L$ levels by the time two years have passed. These results clearly show the importance of allowing for fat-tailed shocks for loss distributions particularly over relatively short horizons. As horizons are extended the tail properties tend to be less important; a result which requires further analysis.

Symmetric shocks do not result in symmetric outcomes, namely positive and negative shocks of the same absolute size do not have the same absolute effects on loss distributions. We have two scenarios with (negatively) symmetric shocks: U.S. and S.E. Asian real equity prices. This asymmetry is apparent by looking at either $E L$ or $U L$, Gaussian or $t$-distributed. For example, for the S.E. Asian case, Gaussian innovations, in the first quarter the $E L$ of the adverse shock is about $90 \%$ bigger than the baseline while the positive shock generates losses that are only about $20 \%$ smaller (Table 8a). In the U.S. case, the asymmetry is less at the mean $(E L)$, where losses increase (decrease) by a factor of about 2.9 (2.3) for an adverse (positive) shock, than in the volatility of losses ( $U L$; see Table $8 \mathrm{~b}$ ), where an adverse shock increases $U L$ by about $79 \%$ while a positive shock of the same magnitude reduces loss volatility only by about $50 \%$.

The asymmetry is especially pronounced if one considers the tails of the loss distributions. These are shown in Figures 2 (one quarter), 3 (four quarters) and 4 (eight quarters) which chart the $99 \%$ tail of the simulated loss distributions. For instance, looking at the four quarter horizon (Figure 3), the S.E. Asian and U.S. negative equity shock-induced loss distributions lie further above the baseline than their positive counterparts lie below that baseline. The shapes of the tails are also different both across scenarios and across forecast horizons. The tail is especially 
kinked after just the first quarter when the impact is the largest for the far tail (Figure 2). Those tails smooth out considerably as the forecast horizons extends, as can be seen in Figures 3 and 4.

The benign shock to U.S. real equity prices reduces losses. In fact, in the first quarter, the $99 \% \mathrm{VaR}$ is $21.5 \mathrm{bp}$ compared to a baseline loss of $41.5 \mathrm{bp}$. This changes as the horizon is extended. By four quarters out (Figure 3), losses under this benign scenario at the $99 \%$ level are $51.3 \mathrm{bp}$ compared with $55.5 \mathrm{bp}$ for the baseline scenario. After two years the difference is yet smaller (Figure 4): 66.8bp vs. $73.4 \mathrm{bp}$.

A positive shock to German real output does not have a substantial impact on the loss distribution, despite the relative concentration of credit exposures to Germany in this portfolio ( $21 \%$ of total face value). In fact, a positive shock to S.E. Asian real equity prices has a more beneficial effect than a positive shock to German real output at any horizon (Figures 2-4). This is likely driven by the important role equity prices play in our APT models relative to output which do not enter the preferred model at all (see Table 7). Thus shocks to GDP will translate to losses indirectly through the other factors as governed by the generalized impulse response functions. A similar outcome is also observed with Japanese money supply shock.

Figure $5 \mathrm{a}$ and $5 \mathrm{~b}$ illustrate the impact of symmetric shocks to the oil price on credit loss. At a magnitude of $2.33 \sigma$, we use both a positive (price increase) and a negative oil price shock (price decrease). Interestingly, both shocks are found to have adverse impacts on credit loss - more so for the negative oil shock. This is true for expected and unexpected loss (Tables 8a\&b), as well as the whole loss distribution. While one would not generally expect this result, it is in line with our mean group estimates of the return regression equation, which are found to be positive at 0.32 (see Table 7). For the majority of firms in our sample, an upward shock to the oil price has benign effects. Yet, there are also firms which move close to default in the presence of an upward shock to the oil price (as one would expect for many industries). As we have already seen, symmetric shocks do not result in symmetric changes to the loss distribution. The increase in credit loss from an adverse shock is disproportionately larger than loss mitigation from a benign shock of the same magnitude. While oil price shocks may have opposite effects on individual firm default risk, the adverse effect tends to outweigh the benign one. Thus, it is plausible within the portfolio context of our model that positive and negative shocks to the same variable may both result in adverse effects on credit loss.

Figure 5a displays the loss distribution for a much longer portion of the tail than the other charts: $90 \%$ and beyond instead of $99 \%$ and beyond. One can clearly see just how steep, in this display manner, the loss curve becomes in the far tail. Past a certain point, about the 99\%-ile, losses increase dramatically. It is no accident that credit risk managers focus on this region. 
Figures 6 and 7 display the effect of using fat-tailed innovations, as compared with our Gaussian basecase. In an attempt to summarize the effect over time across different shocks, in Figure 6 we look at just the marginal mean loss, EL, for each of one to eight quarters. The top part of the chart, shaded in pink, captures the $t[5]$ loss region, and the bottom part, shaded in light yellow, captures the losses resulting from Gaussian innovations. The expected loss from the basline $t[10]$ case is also included as a visual reference point; as expected, it falls between the Gaussian and $t[5]$.

As the innovations become more fat tailed, losses increase, exactly as expected. Marginal losses due to shocks converge quickly to the marginal baseline shocks as the horizon extends beyond three quarters. Baseline losses roughly double as one moves from Gaussian to $t[10]$ and double again from $t[10]$ to $t[5]$.

What happens as the shocks become more and more extreme? This question is addressed in Figure 7 for different U.S. real equity shock scenarios: $-5.00 \sigma$ and $-8.02 \sigma$, the latter matching the largest quarterly drop in the S\&P 500 index since 1928. In this chart we display again the $99 \%$ tail of the simulated loss distributions for the typical risk management horizon of four quarters. We also display the baseline loss distribution for comparison. To be sure, a shock as extreme as $-8.02 \sigma$ is, of course, outside the bounds of the estimated model. It would be unreasonable to believe that such a large shock would not result in changes of the underlying parameters. However, it is still instructive to examine the apparent trade-offs between size of shock and fatness of tails of the innovations, two ways one might stress a credit risk model.

The loss curves are most spread apart for the baseline case, least for the extreme shock case $(-8.02 \sigma)$ where loss curves are quite close together. Interestingly the tail losses due to a $-5 \sigma$ shock under Gaussian assumptions are only a little larger than the tail losses under the no-shock baseline scenario assuming innovations are $t[5]$ distributed. Moreover the chart shows that when assuming a Gaussian process, it seems perhaps unreasonable to consider a shock of such a magnitude $(-5 \sigma$ or $-8.02 \sigma$ ) as its likelihood would have been zero (or very nearly so!) if the Gaussian assumption were in fact true. ${ }^{64}$

\section{Concluding Remarks}

In this paper we developed a coherent and consistent framework for modeling conditional loss distributions through the introduction of risk factor dynamics. We explicitly link the asset value changes of a credit (loan) portfolio to a dynamic global

\footnotetext{
${ }^{64}$ Indeed this may be a good example of how the logic of a modeling strategy imposes restrictions on the type of shocks that one could consider as a plausible counter-factual.
} 
macroeconometric model which allows us to isolate macro effects from idiosyncratic shocks as they relate to default (and hence loss). Default probabilities are driven primarily by how firms are tied to business cycles, both domestic and foreign, and how business cycles are linked across countries. In our model, domestic and foreign business cycle effects are allowed to have differential impacts on different firms. Not only are we able to control for firm-specific heterogeneity, but we also are able to generate multi-period forecasts of the entire loss distribution, conditional on specific macroeconomic shock scenarios. Our conditional modeling framework is thus a step towards joint consideration of market and credit risk.

The first step in developing such a model is to build an economic engine reflective of the environment faced by an internationally active global bank. Our macroeconometric model, developed in Pesaran, Schuermann and Weiner (2003), builds on recent advances in the analysis of cointegrating systems and allows for interaction among different economies through three separate but interrelated channels:

1. Direct dependence of the relevant macro-factors on their region-specific foreign counterparts and their lagged values;

2. Dependence of the region-specific variables on common global exogenous variables such as oil prices and possibly other variables controlling for major global political events;

3. Non-zero contemporaneous dependence of shocks in region $i$ on the shocks in region $j$, measured via the cross-region covariances.

Thus, for instance, we are able to account for inter-linkages (if any) between interest rate changes in the U.S. and output in Germany.

For the credit portfolio component of our model we use a simple Merton-type framework, modeling credit risk as a function of correlated equity returns of the obligor companies. Equity returns are linked to correlated macroeconomic variables using an approach structurally similar to the Arbitrage Pricing Theory (APT). In this way we are able to account for firm-specific heterogeneity in an explicitly interdependent global context; domestic and foreign business cycle effects are allowed to impact each firm differently. We then use the estimated global model as the economic engine for generating a multi-period conditional loss distribution of a credit portfolio using stochastic simulation. Sampling takes place along three lines: correlated random draws of macroeconomic factors; draws of firm-specific risk components; and draws of stochastic loan loss severities. Finally we analyze the impact of a shock to a set of specific macroeconomic variables on the loss distribution, allowing us to analyze the effect of a particular macroeconomic shock in one region on credit portfolios concentrated in other regions, as well as shocks to risk factors, e.g. oil prices, affecting all regions.

Our credit risk modeling approach has three other features of particular relevance 
for risk managers: exploration of scale and symmetry of shocks on credit risk; effect of non-normality; and ranking of shock impacts on credit risk. First, our framework allows for the analysis of symmetry and scale for a variety of macroeconomic shocks. Indeed we show that shocks not only have an asymmetric but also non-proportional impact on credit risk due to the nonlinearity of the credit risk model. Because the Merton model is an option-theoretic model, these traits echo characteristics of the options markets: large movements in the underlying prices have disproportional effects on the value of the option portfolio.

Second, we allow for simulated innovations to be drawn from non-normal distributions such as the Student $t$ with varying degrees of freedom to reflect the fat-tailed nature of some financial variables. We show that the absolute levels of expected and unexpected losses are greater the fatter are the tail of the innovation distribution. These effects are mitigated as we increase the horizon of analysis.

Third, the model allows us to rank the effects of different shocks on a global portfolio. Not surprisingly, shocks to real equity prices seem to have the most significant effect on implied credit losses, followed here by shocks to the price of crude oil. Having arbitrarily picked Germany as the portfolio's domicile country, we naturally were interested in the impact of, say, a positive shock to German real output. We find that such a shock does not have a substantial impact on the loss distribution, despite the relative concentration of credit exposures to German economy in this portfolio ( $21 \%$ of total face value). In fact, a positive shock to S.E. Asian real equity prices has a more beneficial effect than a proportionate positive shock to German real output. Thus from the perspective of a German risk manager, the viewpoint we are trying to mimic, given this portfolio, positive shocks to German output are less cause for excitement than positive shocks to S.E. Asian equity prices. Information of this kind is quite valuable for portfolio and/or risk managers, who typically perform scenario analyses on a quarterly (or perhaps even more frequent) basis. It would then allow the manager to consider alternative strategies such as reallocation or derivative solutions to managing the largest risks associated with a portfolio.

In being able to analyze the impact of shocks to markets and macroeconomic variables, the effectiveness of macro-hedging strategies of credit risk may be considered. Most of the underlying risk factors can now be hedged with financial contracts and instruments, even the macroeconomic ones. ${ }^{65}$ In addition, our framework can be employed in other applications ranging from the pricing of credit instruments such as collateralized debt obligations (CDOs) and credit derivatives, to firm-wide risk and capital management applications for financial institutions. These are clearly

\footnotetext{
${ }^{65}$ For example, one U.S. investment bank currently offers options on economic statistics, so-called economic derivatives.
} 
fruitful areas for future research.

\section{References}

\section{References}

[1] Allen, L. and A. Saunders (2002), "A Survey of Cyclical Effects in Credit Risk Measurement Models", mimeo, Stern School of Business, NYU; available at $<$ http://pages.stern.nyu.edu/ asaunder/procyclicality_allensaunders.pdf $>$.

[2] Altman, E.I. (1968), "Financial Ratios, Discriminant Analysis and the Prediction of Corporate Bankruptcy", Journal of Finance 20, 589-609.

[3] Altman, E.I. and V. Kishore (1996), "Almost Everything You Wanted To Know About Recoveries On Defaulted Bonds", Financial Analysts Journal, Nov/Dec 1996, 57-64. Reprinted in High Yield Bonds: Market Structure Portfolio Management and Credit Models, T. Barnhill and W. Maxwell, Editors, New York: McGraw-Hill, 1999.

[4] Altman, E.I. and A. Saunders (1997), "Credit Risk Measurement: Developments over the last 20 years", Journal of Banking \& Finance 21 (11-12), 17211742 .

[5] Altman, E.I., S. Bharath and A. Saunders, (2002), "Credit Ratings and the BIS Capital Adequacy Reform Agenda", Journal of Banking $\&$ Finance 26 (5), 909-921.

[6] Altman, E.I., B. Brady, A. Resti and A. Sironi (2002), "The Link between Default and Recovery Rates: Implications for Credit Risk Models and Procyclicality", Stern School of Business, NYU, Working Paper.

[7] Amato, J.D. and C.H. Furfine (2003), "Are Credit Ratings Procyclical?", available at <http://papers.ssrn.com/sol3/papers.cfm?abstract_id=384080>.

[8] Bakshi, G., D. Madan and F. Zhang (2001), "Recovery in Default Risk Modeling: Theoretical Foundations and Empirical Applications", Federal Reserve Board, Finance and Economics Discussion Series \#2001-37.

[9] Bangia, A., F.X. Diebold, A. Kronimus, C. Schagen and T. Schuermann (2002), "Ratings Migration and the Business Cycle, With Applications to Credit Portfolio Stress Testing", Journal of Banking \& Finance, 26 (2-3), 235-264. 
[10] BIS, (2001a), "The New Basel Capital Accord," Basel Committee on Banking Supervision, January; available at <http://www.bis.org/publ/bcbsca03.pdf $>$.

[11] BIS, (2001b), "Risk Management Practices and Regulatory Capital", The Joint Forum, November; available at <http://www.bis.org/publ/joint03.pdf $>$.

[12] Campbell, J.Y., A.W. Lo and A.C. MacKinlay (1997), The Econometrics of Financial Markets, Princeton, NJ: Princeton University Press.

[13] Cantor, R. and F. Packer (1995), "The Credit Rating Industry", Journal of Fixed Income, December, 10-34.

[14] Carey, M. (2002), "A Guide to Choosing Absolute Bank Capital Requirements", Journal of Banking \& Finance, 26 (5), 929-951.

[15] Carey, M. (1998), "Credit Risk in Private Debt Portfolios", Journal of Finance 53 (4), 1363-1387.

[16] Carpenter, S.B., W. Whitesell and E. Zakrajšek (2001), "Capital Requirements, Business Loans and Business Cycles: An Empirical Analysis of the Standardized Approach in the New Basel Accord", Federal Reserve Board, Finance and Economics Discussion Series \# 2001-48.

[17] Catarineu-Rabell, E., P. Jackson and D.P. Tsomocos (2002), "Procycliality and the New Basel Accord: Banks' Choice of Loan Rating Systems", presented at a conference "The Impact of Economic Slowdowns on Financial Institutions and Their Regulators" at the Federal Reserve Bank of Boston, April; available at $<$ http://www.bos.frb.org/bankinfo/conevent/slowdown/rabelletal.pdf $>$.

[18] Chava, A. and R.A. Jarrow (2001), "Bankruptcy Prediction with Industry Effects, Market versus Accounting Variables, and Reduced Form Credit Risk Models", mimeo, Johnson Graduate School of Management, Cornell University.

[19] Chen, N.-F., R. Roll and S.A. Ross (1986), "Economic Forces and the Stock Market," Journal of Business 59 (3), 383-403.

[20] Collin-Dufresne, P., R.S. Goldstein and J.S. Martin (2001), "The Determinants of Credit Spread Changes", Journal of Finance 56 (6), 2177 - 2207.

[21] Credit Suisse First Boston (1997), "CreditRisk+ - A Credit Risk Management Framework", New York.

[22] Crouhy, M., D. Galai, and R. Mark (2000), "A Comparative Analysis of Current Credit Risk Models", Journal of Banking \& Finance 24 (1-2), 59-117. 
[23] Crouhy, M., D. Galai, and R. Mark (2001), Risk Management, New York: McGraw Hill.

[24] Duffee, G. (1999), "Estimating the Price of Default Risk." Review of Financial Studies, 12 (1), 197-226.

[25] Duffie, D. and K.J. Singleton (1999), "Modeling Term Structures of Defaultable Bonds", Review of Financial Studies 12 (4), 687-720.

[26] Elton, E.J., M.J. Gruber, D. Agrawal and C. Mann (2001), "Explaining the Rate Spread on Corporate Bonds", Journal of Finance 56 (1), 247-277.

[27] Falkenstein, E. and A. Boral (2001), "Some empirical results on the Merton Model", Risk Professional, April.

[28] Frye, J. (2000), "Depressing Recoveries", Federal Reserve Bank of Chicago working paper, an abridged version appeared in Risk, November.

[29] Garratt, A., K. Lee, M.H. Pesaran, and Y. Shin (2003), "A Long Run Structural Macroeconometric Model of the UK", Economic Journal, (forthcoming April 2003).

[30] Garratt, A., K. Lee, M.H. Pesaran and Y. Shin (2002), "Forecast Uncertainties in Macroeconometric Modelling: An Application to the UK Economy," University of Cambridge DAE Working Paper No. 0004, available at $<$ http://www.econ.cam.ac.uk/faculty/pesaran>.

[31] Gemmill, G. (2002), "Testing Merton's Model for Credit Spreads on Zero-Coupon Bonds", Faculty of Finance, City University Business School; available at $<$ http://www.staff.city.ac.uk/g.gemmill/working_papers/credit_spread.pdf $>$.

[32] Gordy, M.B. (2000), "A Comparative Anatomy of Credit Risk Models", Journal of Banking \& Finance, 24 (1-2), 119-149.

[33] Gupton, G., D. Gates and L. Carty (2000), "Bank Loan Loss Given Default" Moody's Special Comment, November.

[34] Gupton, G.M., C.C. Finger and M. Bhatia (1997), CreditMetrics ${ }^{\text {TM }}$ - Technical Document, this version: April 2, 1997 (J.P. Morgan, New York).

[35] Huang, J.Z. and M. Huang (2002), "How Much of the CorporateTreasury Yield Spread is Due to Credit Risk?", available at

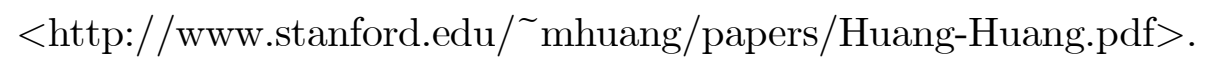


[36] Jarrow, R.A. and S.M. Turnbull (1995), "Pricing Derivatives on Financial Securities Subject to Credit Risk", Journal of Finance 50, 53-86.

[37] Jones, D. and Mingo, J. (1998), "Industry Practices in Credit Risk Modeling and Internal Capital Allocations: Implications for a Models-Based Regulatory Capital Standard." Federal Reserve Bank of New York Economic Policy Review October, 53-60.

[38] Kealhofer, S. and M. Kurbat (2002), "Predictive Merton Models", Risk February, 67-71.

[39] Koop, G., Pesaran, M.H. and Potter, S. M. (1996), "Impulse Response Analysis in Nonlinear Multivariate Models", Journal of Econometrics 74, 119-147.

[40] Koyluoglu, H.U., and A. Hickman (1998), "A Generalized Framework for Credit Risk Portfolio Models", available at $<$ http://www.defaultrisk.com/pp_model_17.htm $>$. An abridged version was published under the title of "Reconcilable Differences" in Risk, October.

[41] Lando, D. and T. Skødeberg (2002), "Analyzing Ratings Transitions and Rating Drift with Continuous Observations", Journal of Banking $\&$ Finance 26 (2-3), 423-444.

[42] Lopez, J.A. and M. Saidenberg (2000), "Evaluating Credit Risk Models", Journal of Banking \& Finance 24 (1/2), 151-167.

[43] Madan, D.B. and H. Unal (1998),"Pricing the Risks of Default," Review of Derivatives Research (2), 121-160.

[44] Marrison, C. (2002), The Fundamentals of Risk Management, New York: McGraw Hill.

[45] Merton, Robert C. (1974), "On the Pricing of Corporate Debt: The Risk Structure of Interest Rates", Journal of Finance 29, 449-470.

[46] Moody's Investors Services (1999), Rating Methodology: The Evolving Meanings of Moody's Bond Ratings.

[47] Nickell, P., W. Perraudin and S. Varotto (2000), "Stability of Rating Transitions", Journal of Banking \&5 Finance 24 (1-2), 203-227.

[48] Pesaran, M.H., T. Schuermann and S. Weiner (2003) "Modeling Regional Interdependencies using a Global Error-Correcting Macroeconometric Model", forthcoming, Journal of Business and Economic Statistics. 
[49] Pesaran, M.H., Y. Shin (2002), "Long Run Structural Modelling", Econometric Reviews 21, 49-87.

[50] Pesaran, M.H. and Y. Shin (1998), "Generalised Impulse Response Analysis in Linear Multivariate Models", Economics Letters 58, 17-29.

[51] Pesaran, M.H., R.P. Smith and K.S. Im (1996), "Dynamic Linear Models for Heterogenous Panels", in L. Mátyás and P. Sevestre (eds.), The Econometrics of Panel Data, Dordrecht, The Netherlands: Kluwer Academic Publishers.

[52] Pesaran, M.H., R.P. Smith (1995), "Long-Run Relationships from Dynamic Heterogeneous Panels", Journal of Econometrics 68, pp.79-113.

[53] Ross, S.A. (1976), "The Arbitrage Pricing Theory of Capital Asset Pricing," Journal of Economic Theory 13, 341-360.

[54] Saunders, Anthony and Linda Allen (2002), Credit Risk Measurement- New Approaches to Value at Risk and Other Paradigms, $2^{\text {nd }}$ Ed., New York: John Wiley \& Sons.

[55] Schuermann, T. and Y. Jafry (2003), "Measurement and Estimation of Credit Migration Matrices", Wharton Financial Institutions Center Working Paper \#03-08; available at <http://fic.wharton.upenn.edu/fic/papers/03/p0308.html>.

[56] Shumway, T. (2001), "Forecasting Bankruptcy more Accurately: A Simple Hazard Model", Journal of Business 74, 101-124.

[57] Standard \& Poors (2001), Rating Methodology: Evaluating the Issuer.

[58] Sims, C. (1980), "Macroeconomics and Reality", Econometrica 48, 1-48.

[59] Unal, H., D. Madan and L. Guntay (2003), "Pricing the risk of recovery in default with absolute priority rule violation", Journal of Banking \& Finance 27 (6), 1001-1025.

[60] Vassalou, M. and Y. Xing (2002), "Default Risk in Equity Returns", mimeo, Graduate School of Business, Columbia University; available at <http://www.gsb.columbia.edu/faculty/mvassalou/default4.pdf>.

[61] Van de Castle, Karen, David Keisman and Ruth Yang (2000), "Suddenly Structure Mattered: Insights into Recoveries of Defaulted Debt." Standard \& Poors, May. 
[62] Wilson, T. (1997a), "Portfolio Credit Risk, Part I", Risk 10 (9), 111-117.

[63] Wilson, T. (1997b), "Portfolio Credit Risk, Part II", Risk 10 (10), 56-61.

[64] White, L. (2002), "The Credit Rating Industry: An Industrial Organization Analysis," ch. 2 in R.M. Levich, C. Reinhart, and G. Majnoni, eds. Ratings, Rating Agencies and the Global Financial System, Dordrecht, The Netherlands: Kluwer Academic Publishers. 


\section{APT Regression Results}

Table 5

Results from Firm APT-type regressions: $\%$ of firms significant at $5 \%$ level $^{66}$

\begin{tabular}{l|cccccccccc}
\hline & & & & & & W. & Mid & S. E. & Latin \\
& U.S.A. & U.K. & Germany & France & Italy & Europe & East & Asia & Japan & America \\
\hline F-test & $93 \%$ & $100 \%$ & $94 \%$ & $88 \%$ & $83 \%$ & $100 \%$ & $75 \%$ & $91 \%$ & $91 \%$ & $58 \%$ \\
const. $^{67}$ & $21 \%$ & $44 \%$ & $6 \%$ & $0 \%$ & $17 \%$ & $17 \%$ & $0 \%$ & $17 \%$ & $15 \%$ & $8 \%$ \\
$\Delta y$ & $14 \%$ & $11 \%$ & $0 \%$ & $0 \%$ & $0 \%$ & $8 \%$ & $25 \%$ & $39 \%$ & $8 \%$ & $0 \%$ \\
$\Delta^{2} p$ & $21 \%$ & $11 \%$ & $0 \%$ & $13 \%$ & $0 \%$ & $0 \%$ & $25 \%$ & $17 \%$ & $0 \%$ & $42 \%$ \\
$\Delta q$ & $93 \%$ & $44 \%$ & $11 \%$ & $25 \%$ & $67 \%$ & $92 \%$ & - & $70 \%$ & $85 \%$ & $67 \%$ \\
$\Delta^{2} e$ & - & $11 \%$ & $0 \%$ & $0 \%$ & $0 \%$ & $0 \%$ & $0 \%$ & $39 \%$ & $38 \%$ & $8 \%$ \\
$\Delta r$ & $0 \%$ & $0 \%$ & $0 \%$ & $0 \%$ & $17 \%$ & $8 \%$ & $50 \%$ & $9 \%$ & $0 \%$ & $25 \%$ \\
$\Delta m$ & $14 \%$ & $0 \%$ & $0 \%$ & $0 \%$ & $0 \%$ & $25 \%$ & $25 \%$ & $13 \%$ & $0 \%$ & $8 \%$ \\
\hline$\Delta y^{*}$ & - & $0 \%$ & $0 \%$ & $0 \%$ & $17 \%$ & $25 \%$ & $0 \%$ & $52 \%$ & $8 \%$ & $8 \%$ \\
$\Delta^{2} p^{*}$ & - & $11 \%$ & $0 \%$ & $13 \%$ & $0 \%$ & $8 \%$ & $0 \%$ & $4 \%$ & $0 \%$ & $17 \%$ \\
$\Delta q^{*}$ & - & $56 \%$ & $100 \%$ & $75 \%$ & $0 \%$ & $58 \%$ & $25 \%$ & $13 \%$ & $15 \%$ & $17 \%$ \\
$\Delta^{2} e^{*}$ & $7 \%$ & - & - & - & - & - & - & - & - & - \\
$\Delta r^{*}$ & - & $22 \%$ & $0 \%$ & $13 \%$ & $17 \%$ & $17 \%$ & $25 \%$ & $4 \%$ & $0 \%$ & $8 \%$ \\
$\Delta m^{*}$ & - & $0 \%$ & $0 \%$ & $0 \%$ & $0 \%$ & $0 \%$ & $0 \%$ & $13 \%$ & $0 \%$ & $0 \%$ \\
\hline$\Delta p^{\circ}$ & $21 \%$ & $22 \%$ & $33 \%$ & $25 \%$ & $33 \%$ & $25 \%$ & $0 \%$ & $22 \%$ & $0 \%$ & $8 \%$ \\
\hline avg. $R^{2}$ & 0.30 & 0.34 & 0.38 & 0.49 & 0.56 & 0.64 & 0.52 & 0.61 & 0.40 & 0.48 \\
\hline avg. $\bar{R}^{2}$ & 0.25 & 0.25 & 0.29 & 0.34 & 0.43 & 0.51 & 0.33 & 0.47 & 0.31 & 0.27 \\
\hline
\end{tabular}

${ }^{66}$ We use the maximum sample length available to all firms in one region.

${ }^{67}$ The remaining are t-tests. 
Table 8a

Mean (Expected Loss) of Simulated Losses for 1, 4 and 8 Quarters Ahead (in Basis Points of Exposure) ${ }^{1}$

\begin{tabular}{|c|c|c|c|c|c|c|c|c|c|c|c|c|c|}
\hline & $\begin{array}{c}-8.02 \sigma \\
\text { U.S. } \\
\text { Equity }\end{array}$ & $\begin{array}{c}-5.00 \sigma \\
\text { U.S. } \\
\text { Equity }\end{array}$ & $\begin{array}{c}-2.33 \sigma \\
\text { U.S. } \\
\text { Equity }\end{array}$ & $\begin{array}{c}-2.33 \sigma \\
\text { Oil }\end{array}$ & $\begin{array}{c}-2.33 \sigma \\
\text { SEA } \\
\text { Equity }\end{array}$ & $\begin{array}{c}+2.33 \sigma \\
\text { Japanese } \\
\text { Money }\end{array}$ & $\begin{array}{c}+2.33 \sigma \\
\text { U.S. } \\
\text { Interest }\end{array}$ & $\begin{array}{l}\text { Base- } \\
\text { line }\end{array}$ & $\begin{array}{c}+2.33 \sigma \\
\text { German } \\
\text { Output }\end{array}$ & $\begin{array}{c}-2.33 \sigma \\
\text { U.S. } \\
\text { Interest }\end{array}$ & $\begin{array}{c}+2.33 \sigma \\
\text { Oil }\end{array}$ & $\begin{array}{c}+2.33 \sigma \\
\text { SEA } \\
\text { Equity }\end{array}$ & $\begin{array}{c}+2.33 \sigma \\
\text { U.S. } \\
\text { Equity }\end{array}$ \\
\hline 1Q Gaussian & 133.2 & 21.8 & 3.5 & 3.5 & 2.3 & 1.5 & 1.5 & 1.2 & 1.2 & 1.1 & 1.3 & 1.0 & 0.5 \\
\hline $\mathrm{t}[10]$ & 134.7 & 24.4 & 5.2 & 4.5 & 3.6 & 2.5 & 2.3 & 2.2 & 2.2 & 2.0 & 2.3 & 1.8 & 1.1 \\
\hline $\mathrm{t}[5]$ & 135.8 & 27.3 & 8.3 & 6.8 & 6.0 & 4.6 & 4.5 & 4.4 & 4.4 & 4.3 & 4.5 & 3.9 & 2.7 \\
\hline 4Q Gaussian & 138.1 & 26.0 & 6.8 & 6.4 & 5.5 & 4.5 & 4.3 & 4.0 & 3.9 & 4.0 & 4.1 & 3.5 & 2.9 \\
\hline $\mathrm{t}[10]$ & 143.4 & 34.0 & 13.6 & 11.9 & 11.8 & 10.2 & 9.7 & 9.7 & 9.4 & 9.6 & 9.9 & 8.6 & 7.8 \\
\hline $\mathrm{t}[5]$ & 152.4 & 42.4 & 21.6 & 19.1 & 19.1 & 17.3 & 16.5 & 16.7 & 16.1 & 16.8 & 16.9 & 15.4 & 14.1 \\
\hline 8Q Gaussian & 143.2 & 30.7 & 11.0 & 10.0 & 9.7 & 8.5 & 8.2 & 8.1 & 7.7 & 7.8 & 8.2 & 7.1 & 6.6 \\
\hline $\mathrm{t}[10]$ & 152.9 & 40.6 & 19.9 & 17.6 & 18.1 & 16.2 & 15.7 & 15.5 & 15.1 & 15.4 & 16.2 & 14.2 & 13.4 \\
\hline $\mathrm{t}[5]$ & 171.6 & 60.8 & 39.1 & 35.6 & 36.9 & 34.3 & 33.7 & 33.7 & 32.9 & 33.7 & 34.7 & 31.6 & 30.4 \\
\hline
\end{tabular}

\footnotetext{
${ }^{1}$ All losses are discounted by a real interest rate of $2 \%$ per annum.
} 
Table 8b

Standard Deviation (Unexpected Loss) of Simulated Losses for 1, 4 and 8 Quarters Ahead (in Basis Points of Exposure) ${ }^{2}$

\begin{tabular}{|c|c|c|c|c|c|c|c|c|c|c|c|c|c|}
\hline & $\begin{array}{c}-8.02 \sigma \\
\text { U.S. } \\
\text { Equity }\end{array}$ & $\begin{array}{c}-5.00 \sigma \\
\text { U.S. } \\
\text { Equity }\end{array}$ & $\begin{array}{c}-2.33 \sigma \\
\text { U.S. } \\
\text { Equity }\end{array}$ & $\begin{array}{c}-2.33 \sigma \\
\text { Oil }\end{array}$ & $\begin{array}{c}-2.33 \sigma \\
\text { SEA } \\
\text { Equity }\end{array}$ & $\begin{array}{c}+2.33 \sigma \\
\text { Japanese } \\
\text { Money }\end{array}$ & $\begin{array}{c}+2.33 \sigma \\
\text { U.S. } \\
\text { Interest }\end{array}$ & $\begin{array}{l}\text { Base- } \\
\text { line }\end{array}$ & $\begin{array}{c}+2.33 \sigma \\
\text { German } \\
\text { Output }\end{array}$ & $\begin{array}{c}-2.33 \sigma \\
\text { U.S. } \\
\text { Interest }\end{array}$ & $\begin{array}{c}+2.33 \sigma \\
\text { Oil }\end{array}$ & $\begin{array}{c}+2.33 \sigma \\
\text { SEA } \\
\text { Equity }\end{array}$ & $\begin{array}{c}+2.33 \sigma \\
\text { U.S. } \\
\text { Equity }\end{array}$ \\
\hline 1Q Gaussian & 63.1 & 30.1 & 12.0 & 11.8 & 9.4 & 7.6 & 7.5 & 6.7 & 6.9 & 6.7 & 7.0 & 6.3 & 4.2 \\
\hline$t[10]$ & 63.0 & 32.0 & 14.9 & 13.4 & 11.9 & 10.0 & 9.6 & 9.3 & 9.2 & 9.3 & 9.4 & 8.4 & 6.6 \\
\hline $\mathrm{t}[5]$ & 64.0 & 34.4 & 19.1 & 16.8 & 15.9 & 13.9 & 13.7 & 13.7 & 13.6 & 13.7 & 13.9 & 13.1 & 10.6 \\
\hline 4Q Gaussian & 87.0 & 52.1 & 31.1 & 29.7 & 28.4 & 25.9 & 25.1 & 24.4 & 24.0 & 24.6 & 24.7 & 22.7 & 20.6 \\
\hline $\mathrm{t}[10]$ & 95.4 & 62.2 & 42.4 & 38.8 & 39.0 & 360.0 & 34.5 & 35.0 & 33.9 & 35.2 & 35.6 & 32.8 & 30.2 \\
\hline $\mathrm{t}[5]$ & 110.1 & 78.7 & 60.2 & 56.2 & 56.5 & 53.9 & 52.4 & 52.8 & 51.9 & 53.4 & 53.4 & 50.9 & 48.3 \\
\hline 8Q Gaussian & 114.6 & 78.4 & 55.7 & 52.8 & 53.2 & 50.2 & 49.0 & 48.9 & 47.6 & 48.3 & 49.2 & 45.8 & 43.8 \\
\hline $\mathrm{t}[10]$ & 133.8 & 98.7 & 78.1 & 72.9 & 75.1 & 71.0 & 69.3 & 69.4 & 68.1 & 69.4 & 7.2 & 66.1 & 63.7 \\
\hline $\mathrm{t}[5]$ & 166.6 & 1334.0 & 114.2 & 108.5 & 111.0 & 106.9 & 105.5 & 106.1 & 104.3 & 106.3 & 108.2 & 102.6 & 100.3 \\
\hline
\end{tabular}

\footnotetext{
${ }^{2}$ All losses are discounted by a real interest rate of $2 \%$ per annum.
} 
Figure 2

Shock Impacts on Credit Portfolio Loss in 1 Quarter $50 \mathrm{~K}$ replications

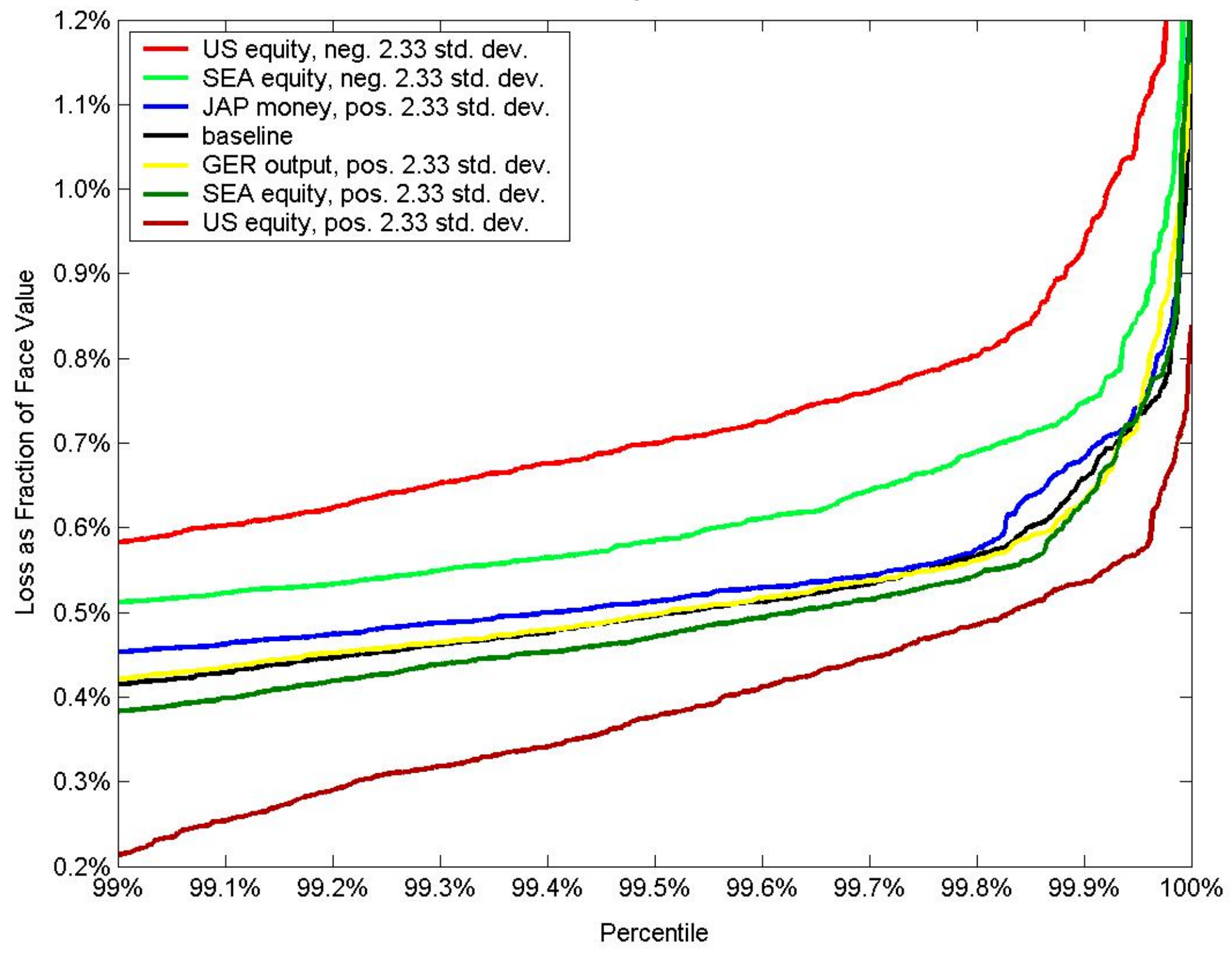


Figure 3

Shock Impacts on Credit Portfolio Loss in 4 Quarters

$50 \mathrm{~K}$ replications

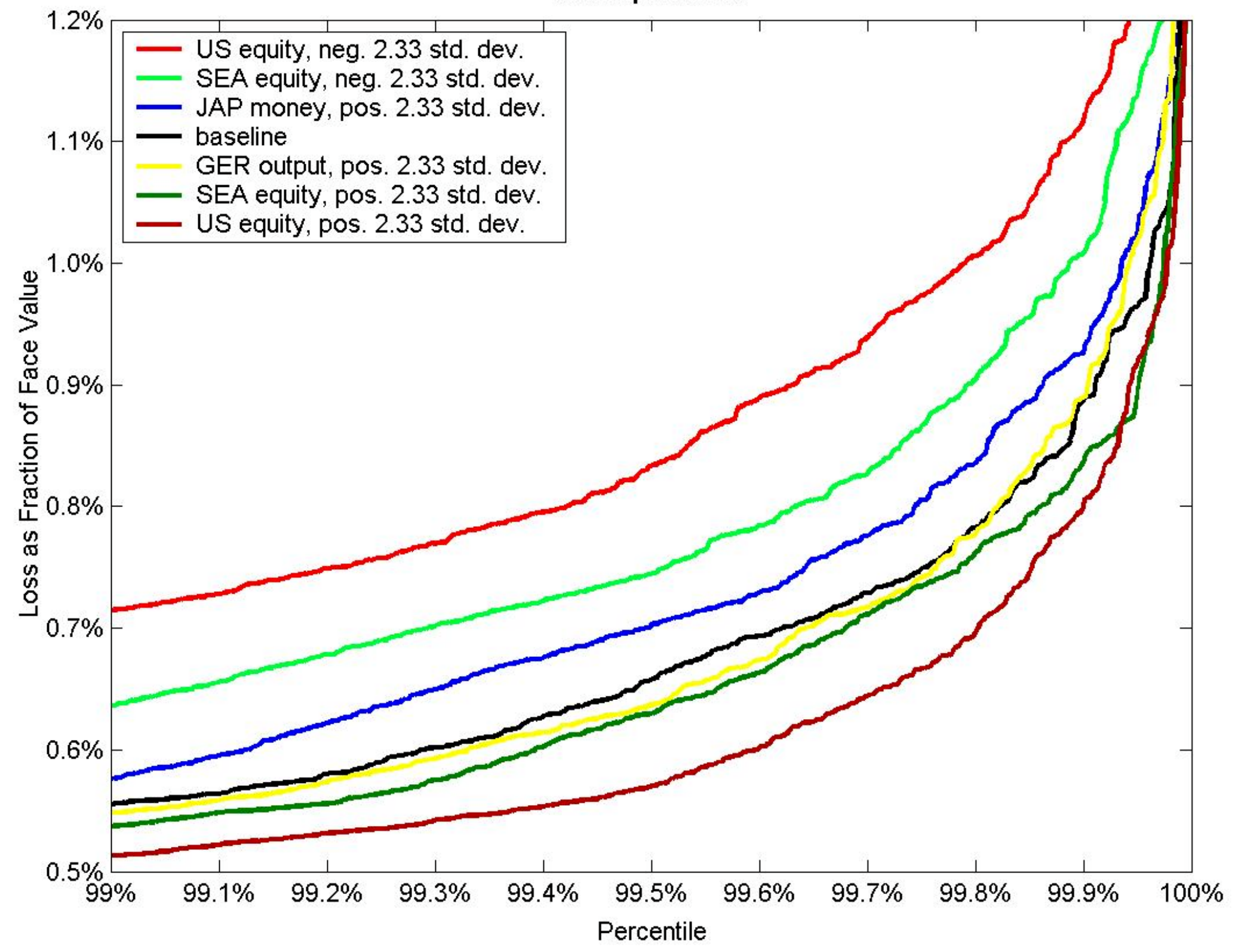


Figure 4

Shock Impacts on Credit Portfolio Loss in 8 Quarters $50 \mathrm{~K}$ replications

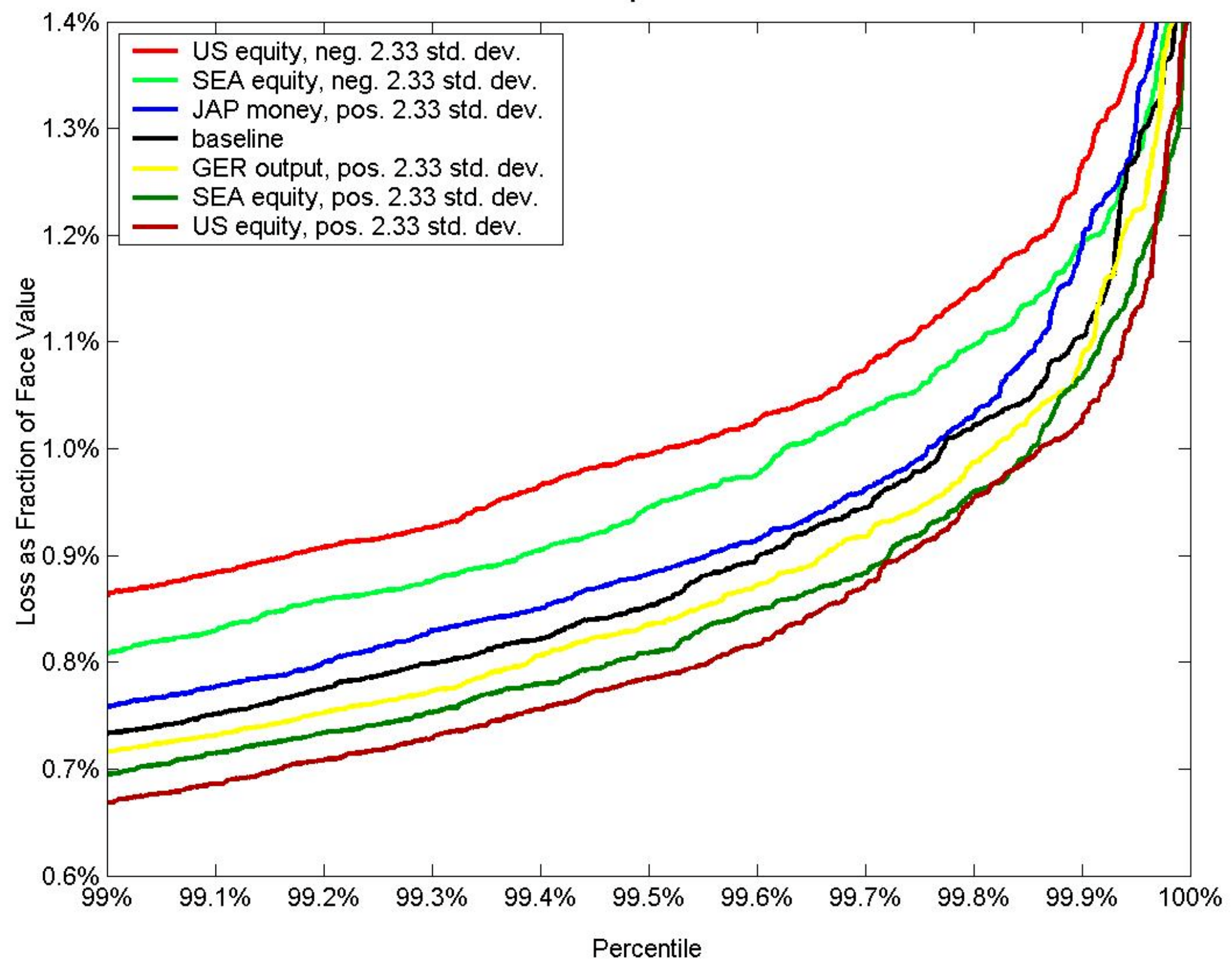


Figure 5a

Impacts of Oil Shocks on Credit Portfolio Loss in 4 Quarters

$50 \mathrm{~K}$ replications

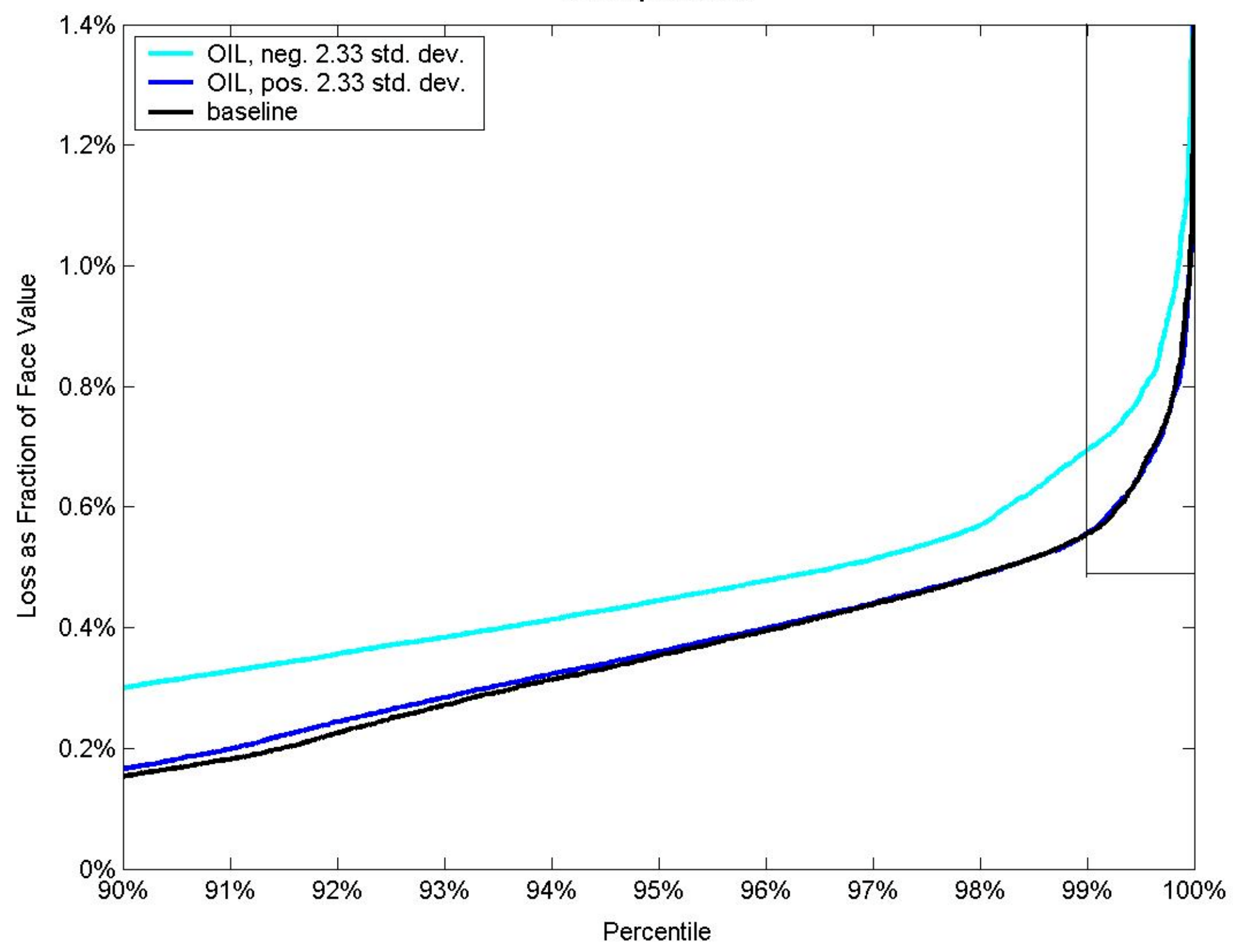


Figure $5 b$

Impacts of Oil Shocks on Credit Portfolio Loss in 4 Quarters $50 \mathrm{~K}$ replications

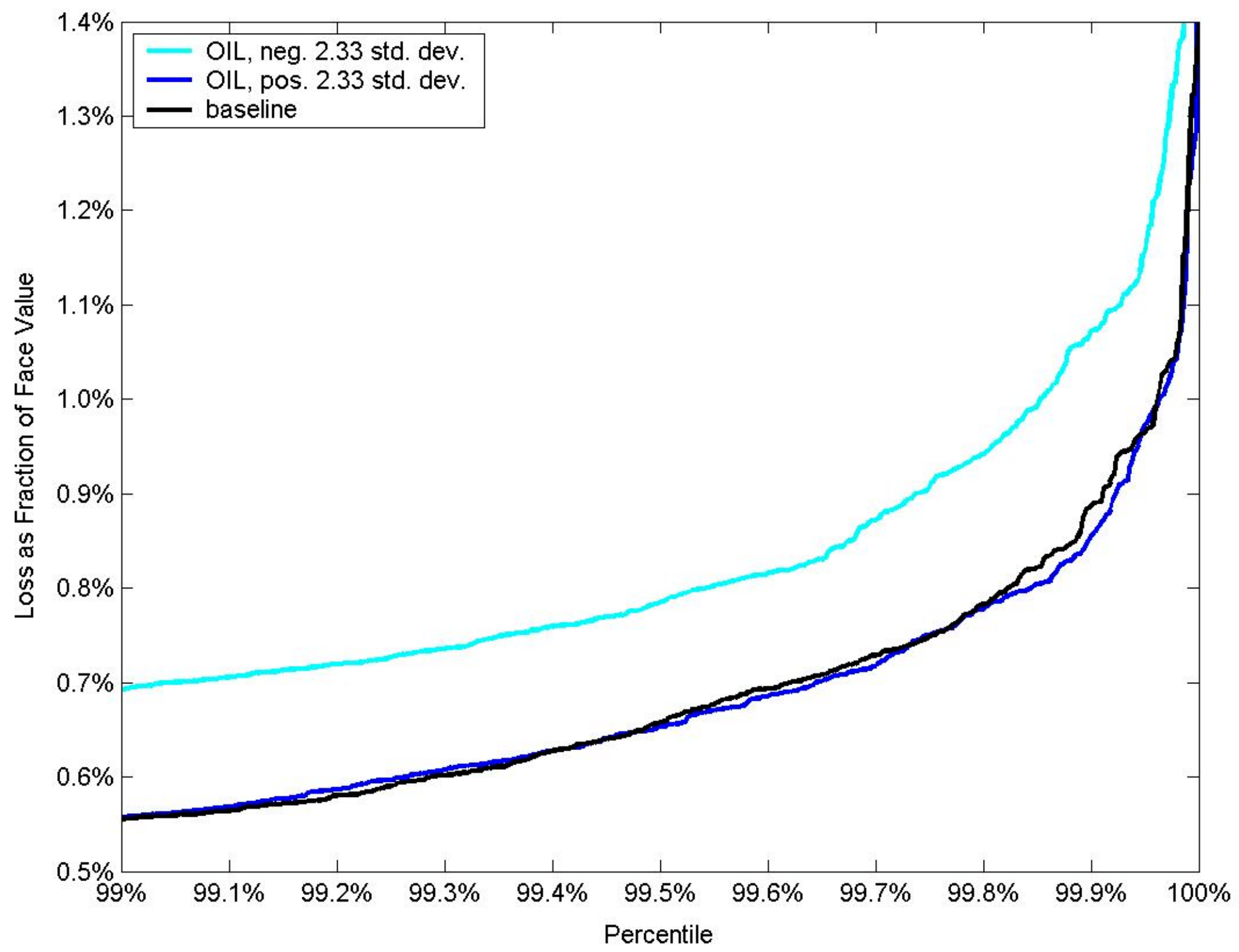


Figure 6

\section{Marginal Expected Loss per Quarter: Gaussian and $t[5,10]$} $50 \mathrm{~K}$ replications

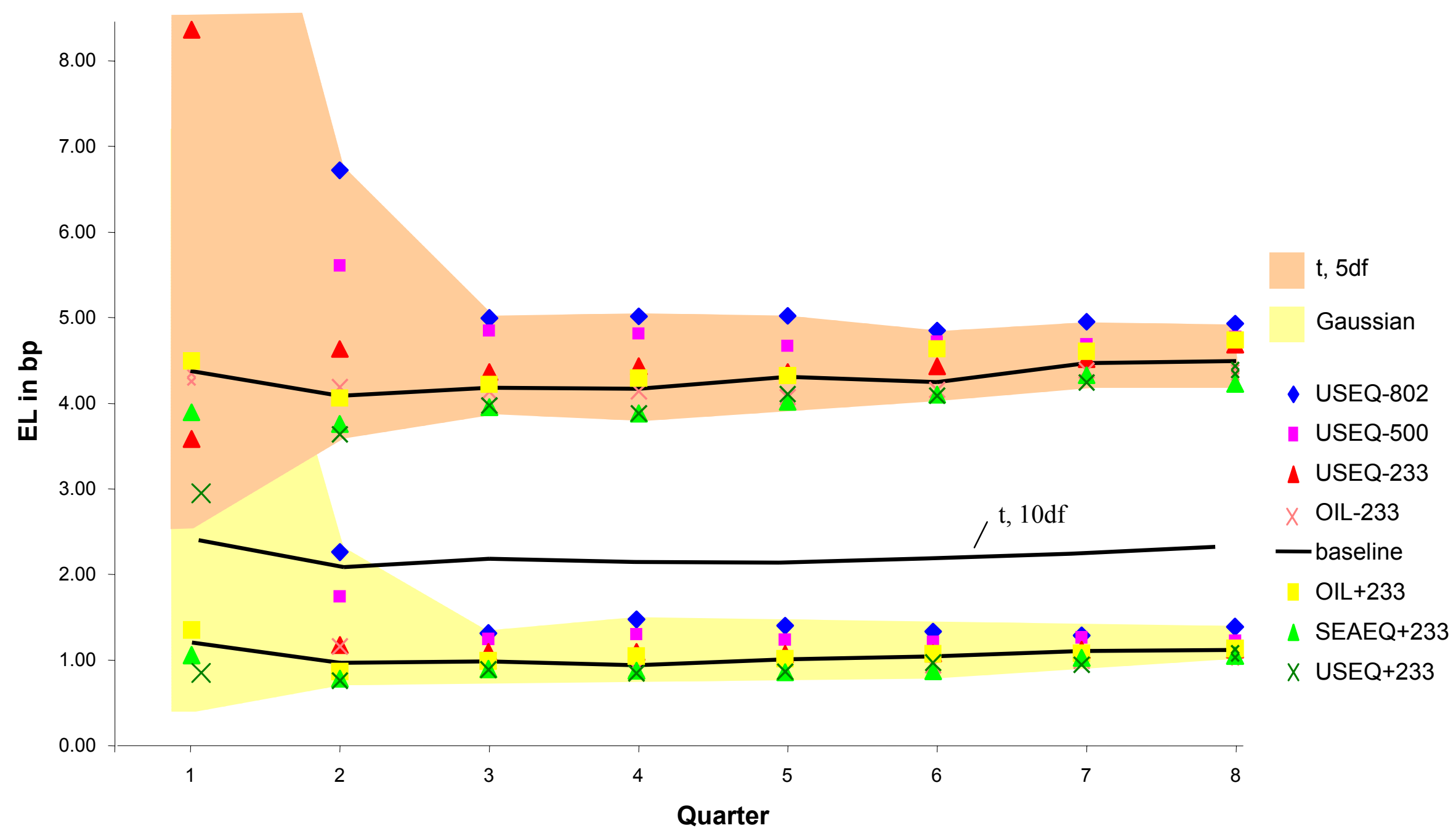


Figure 7

Credit Portfolio Loss in 4 Quarters for Gaussian and t-distributed Shocks $50 \mathrm{~K}$ replications

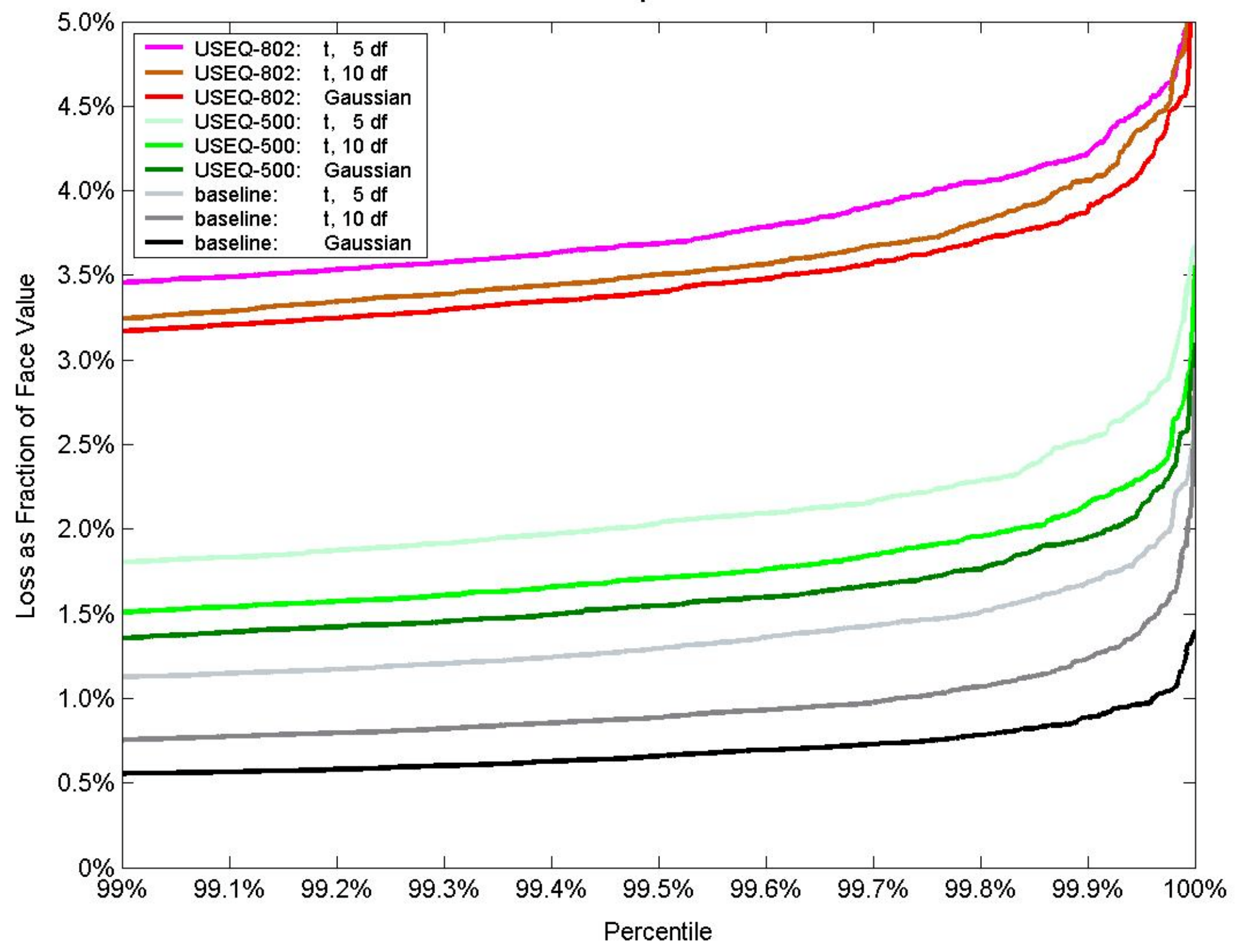

